\title{
Review of Dissimilar Metal Welding for the NGNP Helical-Coil Steam Generator
}

John N. DuPont

Ronald E. Mizia

March 2010

The INL is a

U.S. Department of Energy

National Laboratory

operated by

Battelle Energy Alliance

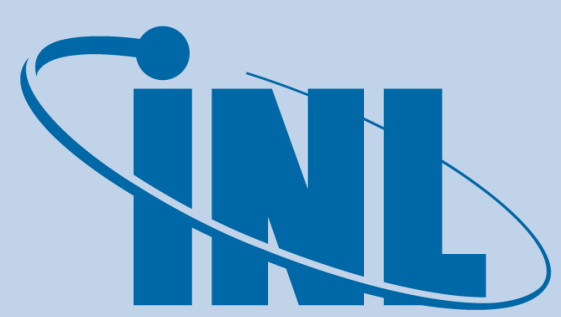

Idaho National Laboratory

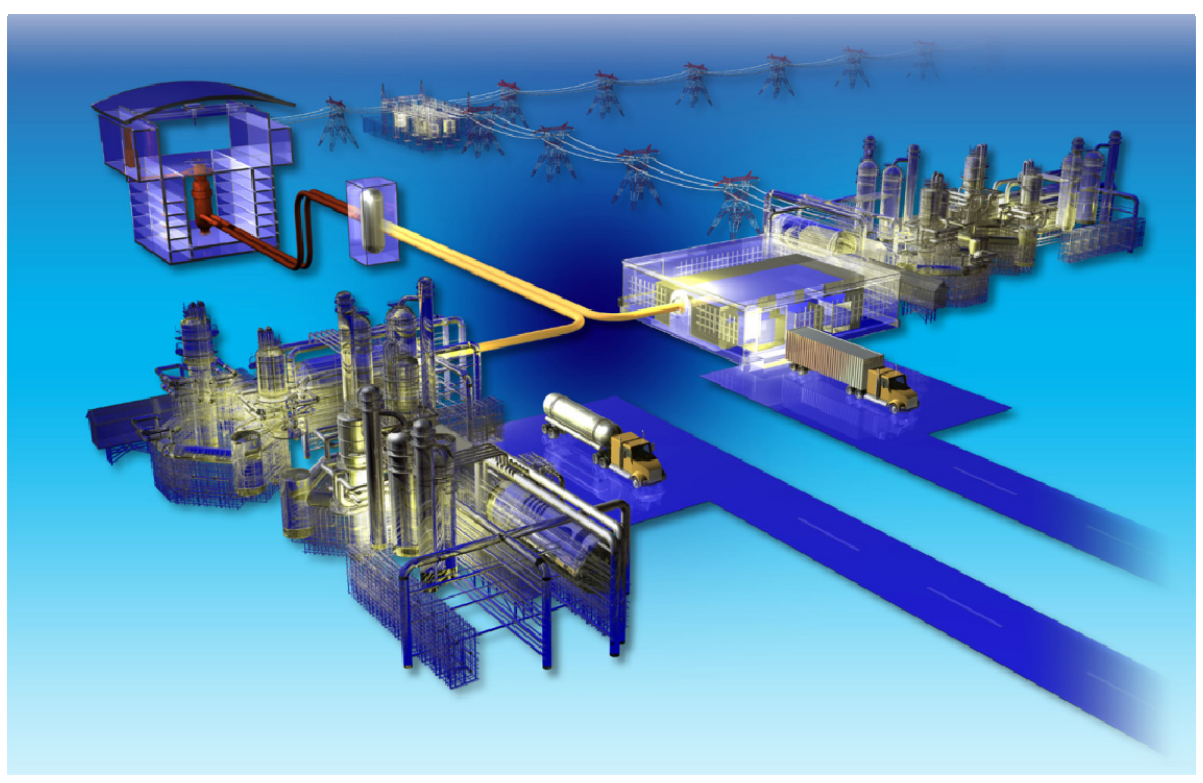




\section{DISCLAIMER}

This information was prepared as an account of work sponsored by an agency of the U.S. Government. Neither the U.S. Government nor any agency thereof, nor any of their employees, makes any warranty, expressed or implied, or assumes any legal liability or responsibility for the accuracy, completeness, or usefulness, of any information, apparatus, product, or process disclosed, or represents that its use would not infringe privately owned rights. References herein to any specific commercial product, process, or service by trade name, trade mark, manufacturer, or otherwise, does not necessarily constitute or imply its endorsement, recommendation, or favoring by the U.S. Government or any agency thereof. The views and opinions of authors expressed herein do not necessarily state or reflect those of the U.S. Government or any agency thereof. 



\title{
Review of Dissimilar Metal Welding for the NGNP Helical-Coil Steam Generator
}

\author{
John N. DuPont ${ }^{1}$ \\ Ronald E. Mizia \\ ${ }^{1}$ Lehigh University
}

March 2010

\begin{abstract}
Idaho National Laboratory
Next Generation Nuclear Plant Project

Idaho Falls, Idaho 83415
\end{abstract}

Prepared for the

U.S. Department of Energy

Office of Nuclear Energy

Under DOE Idaho Operations Office

Contract DE-AC07-05ID14517 

Next Generation Nuclear Plant Project

\section{Review of Dissimilar Metal Welding for the NGNP Helical-Coil Steam Generator}

INL/EXT-10-18459

March 2010

Approved by:

Date

Title [optional]

Name

Date

Title [optional]

Name

Date

Title [optional] 
Title [optional] 



\section{EXECUTIVE SUMMARY}

The U.S. Department of Energy (DOE) is currently funding research and development of a new high-temperature gas-cooled reactor (HTGR) that is capable of providing high-temperature process heat for industry. The steam generator of the HTGR will consist of an evaporator-economizer section in the lower portion and a finishing superheater section in the upper portion. Alloy $800 \mathrm{H}$ is expected to be used for the superheater section, and $2.25 \mathrm{Cr}$ - $1 \mathrm{Mo}$ steel is expected to be used for the evaporator-economizer section. Dissimilar metal welds (DMW) will be needed to join these two materials. It is well known that failure of DMWs can occur well below the expected creep life of either base metal and well below the design life of the plant. The failure time depends on a wide range of factors related to service conditions, welding parameters, and alloys involved in the DMW. The overall objective of this report is to review factors associated with premature failure of DMWs operating at elevated temperatures and identify methods for extending the life of the $2.25 \mathrm{Cr}-1 \mathrm{Mo}$ steel-to-alloy $800 \mathrm{H}$ welds required in the new HTGR. Information is provided on a variety of topics pertinent to DMW failures, including microstructural evolution, failure mechanisms, creep rupture properties, aging behavior, remaining-life estimation techniques, effect of environment on creep rupture properties, best practices, and research in progress to improve DMW performance.

The microstructure of DMWs in the as-welded condition consists of a sharp chemical concentration gradient across the fusion line that separates the ferritic and austenitic alloys. Upon cooling from the weld thermal cycle, a band of martensite forms within this concentration gradient due to high hardenability and the relatively rapid cooling rates associated with welding. Upon aging, during post-weld heat treatment (PWHT), and/or during high-temperature service, $\mathrm{C}$ diffuses down the chemical potential gradient from the ferritic $2.25 \mathrm{Cr}-1 \mathrm{Mo}$ steel toward the austenitic alloy. This can lead to formation of a soft $\mathrm{C}$ denuded zone near the interface on the ferritic steel, and nucleation and growth of carbides on the austenitic side that are associated with very high hardness. These large differences in microstructure and hardness occur over very short distances across the fusion line $(\sim 50-100 \mu \mathrm{m})$. A band of carbides also forms along the fusion line in the ferritic side of the joint. The difference in hardness across the fusion line increases with increasing aging time due to nucleation and growth of the interfacial carbides.

Premature failure of DMWs is generally attributed to several primary factors, including: the sharp change in microstructure and mechanical properties across the fusion line, the large difference in coefficient of thermal expansion (CTE) between the ferritic and austenitic alloys, formation of interfacial carbides that lead to creep cavity formation, and preferential oxidation of the ferritic steel near the fusion line. In general, the large gradient in mechanical properties and CTE serve to significantly concentrate the stress along the fusion where a creep-susceptible microstructure has evolved during aging. Presence of an oxide notch can concentrate the stress even further. Details of the failure mechanism and the relative importance of each factor varies. For DMWs made with Ni base filler metals, creep cavitation occurs in the ferritic steel along the row of carbides that form near the fusion line. For welds made with stainless steel filler metals, creep cavitation occurs along the prior austenite grain boundaries (PAGBs) at a distance of about one to two grains from the fusion line. In thin-walled tubing, the oxide notch can penetrate a relatively large fraction of the tube wall and play a major role in the failure. These mechanisms are not mutually exclusive, and mixed modes of failure can be observed.

A review of available creep-rupture data for DMWs indicates that a substantial reduction in creep life can be expected relative to the minimum creep-rupture life of $2.25 \mathrm{Cr}-1 \mathrm{Mo}$ base metal and welds. In addition, the difference in creep life between the DMWs and 2.25Cr-1Mo steel is expected to increase with increasing time at high temperature. Aging in service can also lead to moderate reductions in toughness and ductility within the fusion zone in welds made with Ni base filler metals. Several remaining life estimation techniques have been proposed specifically for DMWs and are reviewed. Impurities in the hot primary helium coolant of the HTGR can lead to reduced creep life in both the $2.25 \mathrm{Cr}-1 \mathrm{Mo}$ steel and alloy $800 \mathrm{H}$ from degradation due to accelerated oxidation in addition to 
carburization and/or decarburization. No information was available in the open literature on the influence of gaseous impurities on the corrosion and creep-rupture properties of DMWs, and this area warrants further attention.

The most effective practices for fabricating DMWs include the use of Ni base filler metals (to reduce $\mathrm{C}$ migration and CTE mismatch) and placement of welds in low-temperature/low-stress locations to the fullest extent permitted by design. Avoiding locations of aggressive environments that may accelerate the corrosion component of failure can also be effective. A variety of stress sources need to be considered, such as those from tube weight and pressure in addition to stresses from through-wall thermal gradients, temperature fluctuations, residual stresses from welding, and mechanical restraint. Additional steps to prolong the life include the use of wide groove angles, reduction in geometrical changes across the weld joint, and added weld reinforcement. The use of a PWHT was originally thought to be detrimental due to accelerated formation of the $\mathrm{C}$ denuded zone and interfacial carbides. However, more recent work has shown that PWHT does not significantly affect the creep life of DMWs, and the heat treatment should be advantageous for reducing residual stress. Research is currently in progress to develop a new Ni base filler metal and develop graded transition joints for extending the life of DMWs. Progress in each of these areas is described.

Several areas are identified that warrant further research to provide a better understanding of the behavior of DMWs in the HTGR environment and for potentially improving performance. Creep specimens fabricated for future testing should be prepared with Inconel 82 and 182 filler metals and include application of a PWHT. A review of the creep data available to date demonstrates that the applied stress during the tests must be carefully selected in order to properly simulate the failure mechanism observed in the field. In general, stress levels used for creep testing that are above $80 \mathrm{MPa}$ do not properly simulate the failure mechanism observed in the field. Thus, the applied stress levels used for future creep tests should be below approximately $80 \mathrm{MPa}$ in order to properly simulate field failures and provide data representative of service. The effect of gaseous impurities on the corrosion behavior of DMWs should be established prior to creep testing in order to guide selection of the environment used for the creep tests. The effect of sample diameter, gaseous environment, and weld-groove angle should be investigated within the matrix of creep tests, and finite-element analysis should be conducted to help elucidate the role of weld-groove angle. Creep samples should also be prepared and tested with the newer Ni based filler metal recently made available. Lastly, the use of transition alloys and graded transition joints between the $2.25 \mathrm{Cr}-1 \mathrm{Mo}$ steel and alloy $800 \mathrm{H}$ should be tested to verify the expected level of improvement. 


\section{CONTENTS}

EXECUTIVE SUMMARY

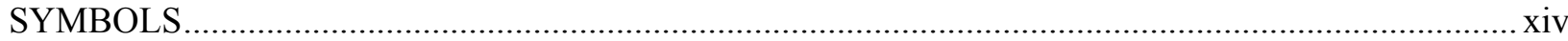

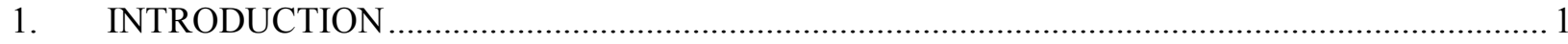

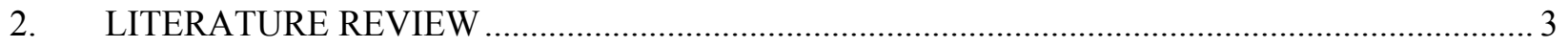

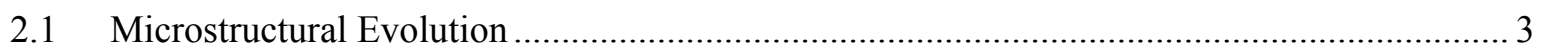

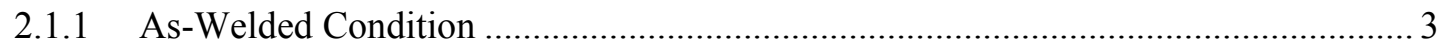

2.1.2 Microstructural Evolution During Aging and PWHT ........................................... 9

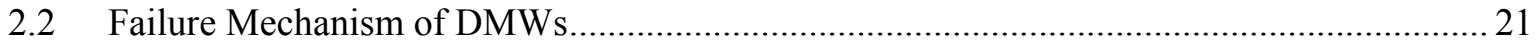

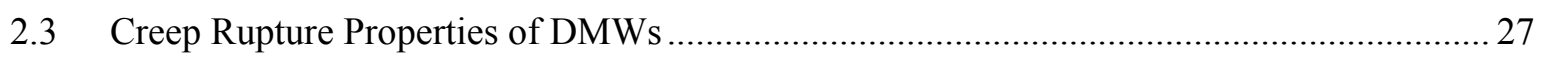

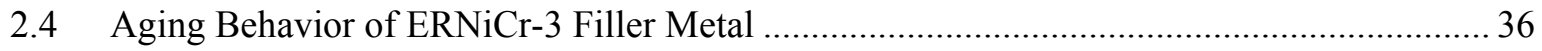

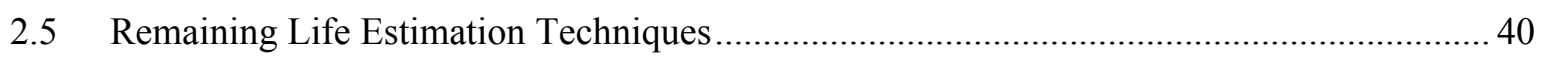

2.6 Effect of Environment on Creep Rupture Properties ..................................................... 43

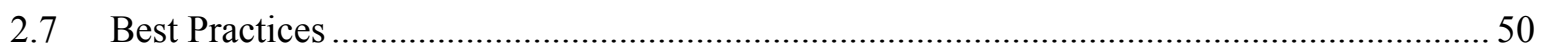

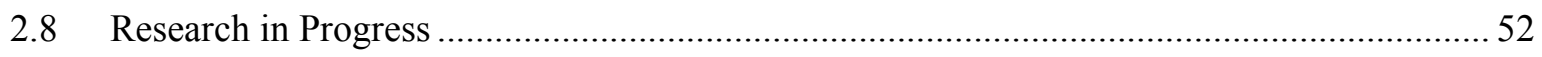

3. SUMMARY AND RECOMMENDATIONS FOR FUTURE RESEARCH …...........................63

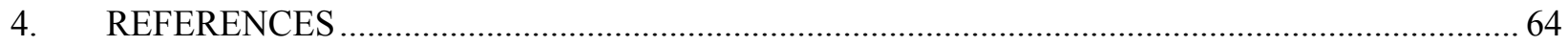

\section{FIGURES}

Figure 1. Schematic illustration of steam generator for the high-temperature gas reactor. ${ }^{2} \ldots \ldots \ldots \ldots \ldots \ldots \ldots . . . . . . . . .2$

Figure 2. Schematic illustration of four distinct microstructural zones that exist in dissimilar

welds.

Figure 3. Distribution of major alloying elements in the partially mixed zone of a dissimilar weld between $2.25 \mathrm{Cr}-1 \mathrm{Mo}$ and alloy $800 \mathrm{H} .{ }^{8}$

Figure 4. Schaeffler diagram used for prediction of microstructure in ferritic, austenitic, and dissimilar welds. ${ }^{7}$ 5

Figure 5. Examples of the martensite layers that form within the partially mixed zone in dissimilar welds between ferritic steel and (a) 309L stainless steel filler metal and (b) alloy 625 filler metal. ${ }^{9}$.

Figure 6. Variation in major alloying elements $(\mathrm{Fe}, \mathrm{Ni}$, and $\mathrm{Cr}$ ) across the fusion lines of the welds shown in Figure 5. (a) weld between ferritic steel and 309L stainless steel filler metal and (b) weld between ferritic steel and alloy 625 filler metal. $^{9}$ 7 
Figure 7. Variation in martensite start (Ms) temperature across the partially mixed zone for (a) weld between ferritic steel and 309L stainless steel filler metal and (b) weld between ferritic steel and alloy 625 filler metal. ${ }^{9}$

Figure 8. Differences in hardness that develop in the as-welded condition near the interface for a weld between $2.25 \mathrm{Cr}-1 \mathrm{Mo}$ steel and a $309 \mathrm{~L}$ stainless steel. ${ }^{12}$ 9

Figure 9. Microstructure and hardness variations that exist in a weld involving $2.25 \mathrm{Cr}$-1Mo steel with 309 stainless steel after a PWHT of $720^{\circ} \mathrm{C}$ for 10 hours. ${ }^{12}$ 10

Figure 10. Microstructure and hardness variations that exist in a weld involving $2.25 \mathrm{Cr}-1 \mathrm{Mo}$ steel with ERNiCr-3 filler metal after a PWHT of $690^{\circ} \mathrm{C}$ for 30 hours. ${ }^{12}$ 11

Figure 11. Carbon concentration profile across the fusion line of a service-exposed weld. ${ }^{20}$ 12

Figure 12. Transmission electron micrographs of carbon replicas showing carbides that form in a weld between $2.25 \mathrm{Cr}-1 \mathrm{Mo}$ steel and 309 stainless steel after a PWHT of $690^{\circ} \mathrm{C}$ for 30 hours. ${ }^{12}$

Figure 13. Variations in microhardness across the interfacial region of a weld made between $2.25 \mathrm{Cr}-1 \mathrm{Mo}$ steel and alloy $800 \mathrm{H}$ in the as-welded condition, after application of a PWHT at $700^{\circ} \mathrm{C}$ for one hour, and after creep testing at $150 \mathrm{MPa} / 550^{\circ} \mathrm{C}$ (with a corresponding failure time of approximately 1,000 hours) ${ }^{8}$ 13

Figure 14. Hardness differences in welds involving 2.25Cr-1Mo steel with (a) Inconel 182 filler metal and (b) 316 stainless steel filler metal after PWHT at $700^{\circ} \mathrm{C}$ for 3 hours and after aging at $580^{\circ} \mathrm{C}^{32}$ 14

Figure 15. Schematic illustration of variation in composition in the as-welded and PWHT condition for a weld between $2.25 \mathrm{Cr}$-1Mo steel and $309 \mathrm{~L}$ stainless steel. ${ }^{12}$

Figure 16. Carbide morphologies observed in dissimilar welds during aging. (a) and (b) Type I carbides that form very close to the fusion line in the HAZ of the ferritic steel, ${ }^{16} \mathrm{c}$ ) Type II carbides that form as a wide band associated with the martensite region. ${ }^{17}$

Figure 17. Variation in major and minor axes of the Type I carbides with aging time at $625^{\circ} \mathrm{C}$ for weld between $2.25 \mathrm{Cr}$-1Mo steel and Inconel 182 filler metal. ${ }^{17}$

Figure 18. Variation in carbide density as measured by number of carbides per unit length for welds between $2.25 \mathrm{Cr}$-1Mo steel and Inconel 182 filler metal. ${ }^{17}$

Figure 19. Schematic illustration showing the evolution of microstructure in dissimilar welds for the as-welded condition.

Figure 20. Schematic illustration showing the evolution of microstructure in dissimilar welds for the aged condition. 
Figure 21. Features of dissimilar weld failures. a) photograph showing failure along the fusion line of the ferritic steel, b) example of oxide notching on the ferritic side of the weld, c) creep cavitation along the row of Type I carbides for welds made with Ni base filler metals, ${ }^{35}$ d) creep cavitation associated with prior austenite grain boundaries in welds made with stainless steel filler metals.

Figure 22. Variation in coefficient of thermal expansion for a variety of materials pertinent to dissimilar welds. ${ }^{56}$

Figure 23. Results from instrumented creep test on a weld involving $2.25 \mathrm{Cr}$-1Mo steel and Inconel 82 filler metal where the extension was measured globally (i.e., within the entire gage length) and locally along the interface. ${ }^{34}$

Figure 24. Results of creep tests on a weld involving $2.25 \mathrm{Cr}$-1Mo steel and Inconel 82 filler metal showing the influence of environment on the creep behavior. ${ }^{35}$

Figure 25. Schematic illustration of commonly used transition joint design for welding ferritic steels to austenitic stainless steels (the Alloy 800 to 316 weld is now typically made with Inconel 82 or 182 filler metal). ${ }^{56}$

Figure 26. Finite element stress analysis results for welds made between ferritic steels and (a) 316 stainless steel with ERNiCr-3 filler metal and (b) alloy 800 with ERNiCr-3 filler metal. ${ }^{56}$

Figure 27. Results from an industrial survey showing the effect of filler metal on the service life of dissimilar welds (relative to 309 filler metal). ${ }^{58}$

Figure 28. Creep life (a) and ductility (b) of welds between $2.25 \mathrm{Cr}$-1Mo steel and alloy $800 \mathrm{H}$ at $550^{\circ} \mathrm{C}$ over stresses from 90 to $250 \mathrm{MPa} .^{8}$

Figure 29. Influence of PWHT condition and aging treatments on the creep properties of $2.25 \mathrm{Cr}$-1Mo steel/alloy $800 \mathrm{H}$ joints at $510^{\circ} \mathrm{C}$ (prepared with ERNiCr-3 filler metal). ${ }^{42}$

Figure 30. Results from creep tests at temperatures of 590,605 , and $625^{\circ} \mathrm{C}$ for welds between $2.25 \mathrm{Cr}$-1Mo steel and 316 stainless steel made with Inconel 82/182 filler metal. a) "new" condition, b) "aged" condition. ${ }^{35}$

Figure 31. Photographs showing a) sample that exhibited ductile failure in the $2.25 \mathrm{Cr}-1 \mathrm{Mo}$ at elevated stress, and b) sample that failed along the interface with very low ductility via creep cavitation at low stress. ${ }^{35}$

Figure 32. Creep rupture data for dissimilar welds involving ferritic steel and Inconel type filler metals. ${ }^{16}$

Figure 33. Larson-Miller plot of creep rupture data for a wide range of dissimilar welds involving ferritic steel and Inconel-type filler metals. ${ }^{16}$ 
Figure 34 . Creep rupture data for $2.25 \mathrm{Cr}-1 \mathrm{Mo}$ base metal and welds at $593^{\circ} \mathrm{C}\left(1100^{\circ} \mathrm{F}\right)$. Also shown is the minimum stress rupture curve for the base metal according to data from Code Case N-47 of the American Society of Mechanical Engineers (now replaced by Subsection $\mathrm{NH}$ ) along with the reduction-factored values of the minimum stress rupture curve for the weld metal. Trend lines for dissimilar welds from Figure 32 are also shown for comparison. ${ }^{64}$

Figure 35 . Creep rupture data for $2.25 \mathrm{Cr}-1 \mathrm{Mo}$ base metal and welds at $621^{\circ} \mathrm{C}\left(1150^{\circ} \mathrm{F}\right)$. Also shown is the minimum stress rupture curve for the base metal according to data from Code Case N-47 of the American Society of Mechanical Engineers (now replaced by Subsection $\mathrm{NH}$ ) along with the reduction-factored values of the minimum stress-rupture curve for the weld metal. Trend line for dissimilar welds from Figure 32 is also shown for comparison. ${ }^{64}$

Figure 36. Creep rupture data for $2.25 \mathrm{Cr}$-1Mo base metal and weldments plotted according to the Larson Miller parameter. The ASTM/ASME minimum curve provided is the same curve as the minimum stress-rupture curve for the base metal shown in Figures 34 and 35 , and is also the same curve for the $2.25 \mathrm{Cr}$-1Mo steel shown in Figure 33 . The minimum trend line for dissimilar welds shown in Figure 33 is also shown for comparison. ${ }^{64}$

Figure 37. Influence of aging time and temperature on the yield strength and ductility of ERNiCr-3 weld metal. ${ }^{65}$

Figure 38. Variation in hardness and impact toughness of the fusion zone for welds between $9 \mathrm{Cr}--1 \mathrm{Mo}$ steel and alloy $800 \mathrm{H}$ (made using ERNiCr-3 filler) that were aged at $625^{\circ} \mathrm{C} .{ }^{67}$ 38

Figure 39. SEM photomicrographs of the charpy impact specimens in the (a) as-welded condition and (b) aged for 5,000 hours at $625^{\circ} \mathrm{C}^{67}$

Figure 40. Qualitative relation between damage morphology and remaining life for homogenous wrought materials. ${ }^{68}$ 40

Figure 41. a) Maximum amount of cavities (measured in number of cavities per unit length along the interface) as a function of life fraction for DMWs between $2.25 \mathrm{Cr}$-1Mo steel and 316 stainless steel welded with Inconel 82 and 182 filler metals, b) experimental data along with a plot of equation (3) using a value of $\lambda=2.5$. $^{35}$

Figure 42. Comparison of calculated damage to that observed experimentally using the PODIS method, where the dotted lines are for a 95\% confidence interval. ${ }^{69}$

Figure 43. Creep rupture data for $9.5 \mathrm{~mm}$ diameter samples of (a) $2.25 \mathrm{Cr}-1 \mathrm{Mo}$ steel and (b) alloy $800 \mathrm{H}$ in the simulated HTGR helium gas with $1500 \mu$ atm $\mathrm{H}_{2}, 450 \mu$ atm $\mathrm{CO}, 50 \mu$ atm $\mathrm{CH}_{4}, 50$ ratm $\mathrm{H}_{2} \mathrm{O}$, and $5 \mu \mathrm{atm} \mathrm{CO}_{2}$. Minimum and scatter-band lines are taken from data within ASME Code Case N-47 (now replaced by Subsection NH). ${ }^{59}$ 
Figure 44. Creep strain as a function of time for (a) $2.25 \mathrm{Cr}$-1Mo steel and (b) alloy $800 \mathrm{H}$ tested in

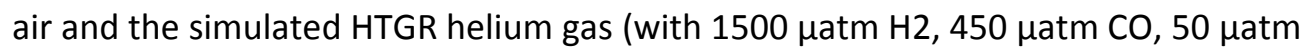

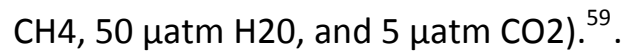

Figure 45. Creep strain as a function of time for $4.8 \mathrm{~mm}$ and $9.5 \mathrm{~mm}$ diameter samples of (a)

2.25 Cr-1Mo steel and (b) alloy $800 \mathrm{H}$ tested in simulated HTGR helium gas (with 1500

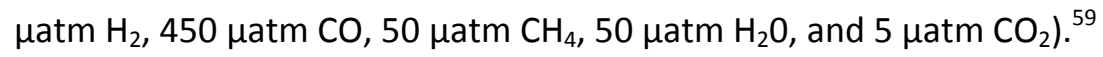

Figure 46. Percentage of affected cross section as a function of reaction depth (i.e., depth of corrosion) for sample diameters of $4.8 \mathrm{~mm}$ and $9.5 \mathrm{~mm}^{59}$

Figure 47. Residual axial stress distribution of welds between $2.25 \mathrm{Cr}-1 \mathrm{Mo}$ steel and 316 stainless made with Inconel 82 filler metal. a) as-welded condition, b) Weld prepared with a 6 $\mathrm{mm}$ "butter" layer of Inconel 82 on the $2.25 \mathrm{Cr}$-1Mo steel, exposed to a PWHT at $725^{\circ} \mathrm{C}$ for one hour, and then welded to the 316 stainless steel using the same filler metal. ${ }^{84}$

Figure 48. Short-term/high-temperature strength data of all-weld-metal and cross-weld samples for dissimilar welds between Grade 91 and 347H made with P87 filler metal. a) yield strength, b) tensile strength. ${ }^{27}$

Figure 49. Creep-rupture results in the form of a Larson-Miller parameter for welds made with P87 filler metal using various welding processes. The Grade 91 average and minimum values are also shown for reference. ${ }^{27}$

Figure 50. Schematic illustration of Laser Engineered Net Shaping process. ${ }^{86}$ .54

Figure 51. Schematic illustration of graded transition-joint concept. ${ }^{86}$ .55

Figure 52. Transition joint between 1080 steel and 316 stainless steel produced with the Laser Engineered Net Shaping process. ${ }^{86}$ 56

Figure 53. Comparison of $\mathrm{Ni}$ and $\mathrm{Cr}$ concentration gradients along a) dissimilar weld and $\mathrm{b}$ ) transition joint between 1080 steel and 316 stainless steel produced with the Laser Engineered Net Shaping process. ${ }^{86}$

Figure 54. Comparison of hardness gradient along a) dissimilar weld and b) transition joint between 1080 steel and 316 stainless steel produced with the Laser Engineered Net Shaping Process. ${ }^{86}$

Figure 55. Examples of the finite-element calculations showing Von Mises stress for a) $5 \mathrm{~mm}$ graded transition between the $2.25 \mathrm{Cr}-1 \mathrm{Mo}$ steel and Alloy $800 \mathrm{H}$ where the maximimum stress is $200 \mathrm{MPa}$, b) $25 \mathrm{~mm}$ graded transition between the $2.25 \mathrm{Cr}-1 \mathrm{Mo}$ steel and Alloy $800 \mathrm{H}$ where the maximimum stress is $168 \mathrm{MPa}^{87}$. 60

Figure 56. Calculated chemical potential of $\mathrm{C}$ as a function of position for a graded transition joint between $2.25 \mathrm{Cr}$-1Mo steel, alloy $800 \mathrm{H}$, and 347 stainless steel. ${ }^{87}$................. 
Figure 57. Calculated change in C concentration between $2.25 \mathrm{Cr}-1 \mathrm{Mo}$ steel and alloy $800 \mathrm{H}$ as a function of time at $650^{\circ} \mathrm{C}$ for transition lengths of a) $5 \mathrm{~mm}$ and b) $100 \mathrm{~mm} .{ }^{87}$

\section{TABLES}

Table 1. Chemical compositions of typical high-temperature materials (wt\%). ...................................... 4 


\section{SYMBOLS}

D Carbide diameter after some exposure time

$\mathrm{D}_{\mathrm{o}} \quad$ Original carbide diameter

B Temperature-dependent material constant

$\mathrm{t}$ time or life fraction

$t_{f} \quad$ Fracture life

k Material constant

Q Activation energy for precipitate growth

M Major carbide axis

$\mathrm{m} \quad$ Minor carbide axis

$\mathrm{N} \quad$ Instantaneous cavity density

$\mathrm{N}_{\mathrm{f}} \quad$ Cavity density at fracture

$\lambda \quad$ Monkman-Grant constant

$\mathrm{D}_{\text {TOT }}$ Total damage in service

$\mathrm{D}_{\mathrm{I}} \quad$ Intrinsic damage associated with temperature cycling

$\mathrm{D}_{\mathrm{P}} \quad$ Damage associated with primary loads during steady state operation

$\mathrm{D}_{\mathrm{S}} \quad$ Damage from secondary bending loads

$\mathrm{A}_{\mathrm{o}} \quad$ Original interfacial area of the weld prior to service

$\mathrm{A}_{\mathrm{i}} \quad$ Remaining interfacial area not been damaged after some service time

$\mathrm{m} \quad$ Number of loading conditions

$\sigma_{\mathrm{P}} \quad$ Primary axial stress

$\sigma_{\mathrm{S}} \quad$ Secondary axial stress

$t_{m} \quad$ Incremental time for a constant $\sigma_{P}$

$t_{n} \quad$ Cumulative time from $t=0$ up to $t_{m}$

$\mathrm{T}_{\mathrm{o}} \quad$ Average operating temperature at steady state loading conditions, $\mathrm{m}$

$\mathrm{f}\left(\mathrm{T}_{\mathrm{o}}\right) \quad$ Functions of $\mathrm{T}_{\mathrm{o}}$ in equation (6)

$\mathrm{g}\left(\mathrm{T}_{\mathrm{O}}\right) \quad$ Functions of $\mathrm{T}_{\mathrm{o}}$ in equation (6)

$\varepsilon_{\mathrm{S}} \quad$ Strain range

$\mathrm{k}^{\mathrm{i}}, \gamma, \beta \quad$ Material constants in equation (6) 


\section{Review of Dissimilar Metal Welding for the NGNP Helical-Coil Steam Generator}

\section{INTRODUCTION}

The U.S. Department of Energy (DOE) is currently funding research and development of a new high-temperature gas-cooled reactor (HTGR) that is capable of providing high-temperature process heat for industry ${ }^{1,2,3,4,5}$. The HTGR operates at higher temperatures than reactors currently operating in the United States. Reactors that operate at higher temperatures can generate higher temperature steam and other high-temperature process heat that can be integrated into conventional industrial processes. In the proposed system, steam is generated by passing the hot primary helium coolant over a system of helically-coiled tubes contained in a vertically--oriented enclosure vessel. The steam generator is shown schematically in Figure 1. The assembly is approximately 4.1 meters in diameter and 10.3 meters in length. The heat-transfer surfaces consist of an evaporator-economizer section in the lower portion of the enclosure vessel, and a finishing superheater section in the upper portion. The helium outlet temperature is currently designed for a temperature of $750^{\circ} \mathrm{C}^{6}$. The main steam pressure is $17.3 \mathrm{MPa}$, and the main steam temperature is $541^{\circ} \mathrm{C}$. The feedwater temperature is set at $193^{\circ} \mathrm{C}$. The steam tubes are oriented vertically in the space between the evaporator-economizer section and the finishing superheater section. Alloy $800 \mathrm{H}$ is expected to be used for the superheater section, and $2.25 \mathrm{Cr}-1 \mathrm{Mo}$ steel is expected to be used for the evaporator-economizer section. Dissimilar metal welds (DMW) will be needed to join these two materials. Materials selection considerations ${ }^{1}$ indicate that the lower temperature steam generator tube temperature will be approximately $400^{\circ} \mathrm{C}$ during normal operation. Thus, the DMW between the $2.25 \mathrm{Cr}-1 \mathrm{Mo}$ steel and alloy $800 \mathrm{H}$ is expected to operate near this temperature. Experience in fossil and nuclear power plants has demonstrated that failures of DMWs can occur prematurely at service times below the expected creep life of either base metal and well below the design life of the plant. The failure time depends on a wide range of factors related to service conditions, welding parameters, and alloys involved in the DMW.

The overall objective of this report is to review factors associated with premature failure of DMWs operating at elevated temperatures and identify methods for extending weld life. The review begins with a description of microstructural evolution that occurs around the interface between ferritic and austenitic materials in both the as-welded and aged conditions. The failure mechanism of DMWs operating at high temperatures is then reviewed, followed by an assessment of the creep-rupture behavior of DMWs relative to $2.25 \mathrm{Cr}-1 \mathrm{Mo}$ steel base metal and welds. The effect of aging on the mechanical properties of the filler metal that is most commonly used to join $2.25 \mathrm{Cr}-1 \mathrm{Mo}$ steel is also considered. Techniques for remaining life assessment are then discussed. The potential influence of gaseous impurities on the creep-rupture properties is considered, and a description of best welding practices for improving the performance of DMWs is provided. The review concludes with sections on research currently in progress for improving the performance of DMWs and recommendations for future research to consider, associated specifically with the HTGR design. The DMW between $2.25 \mathrm{Cr}-1 \mathrm{Mo}$ and Alloy $800 \mathrm{H}$ is the primary focus of the review. However, pertinent information from DMWs between other ferritic steels and stainless steels are also included as this information can shed light on the expected performance of the $2.25 \mathrm{Cr}-1 \mathrm{Mo} /$ Alloy $800 \mathrm{H}$ weld. 


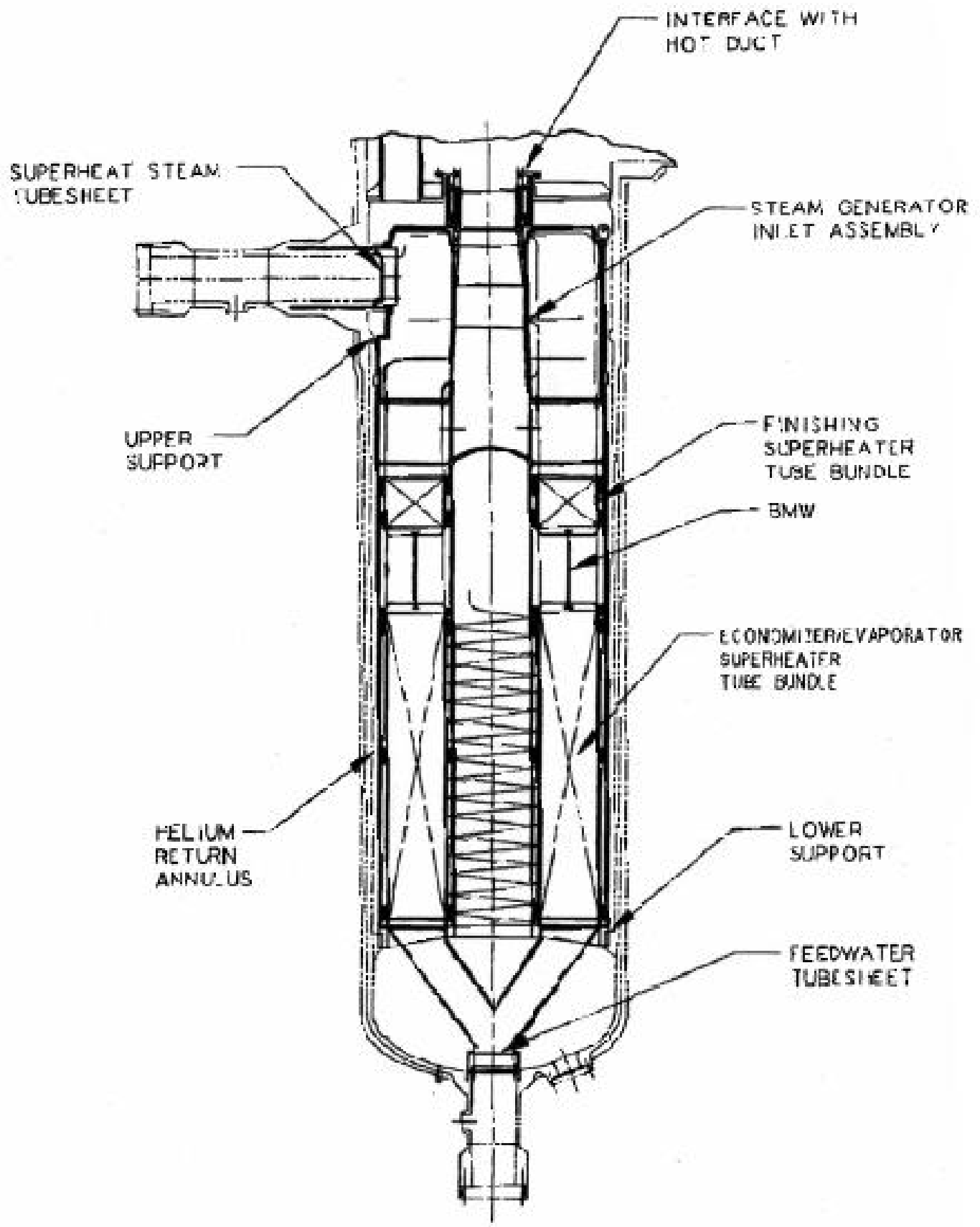

Figure 1. Schematic illustration of steam generator for the high-temperature gas reactor. ${ }^{2}$

It is recognized that stress corrosion cracking has been observed in various welds in the reactor coolant systems of some pressurized water reactors. These welds often involve joining of alloy 600 to dissimilar alloys. This issue is generally associated with the inadequate stress corrosion cracking resistance of alloy 600, and not directly related to the DMW. Current efforts to mitigate this problem involve eventual replacement of alloy 600 with alloy 690, which provides better resistance to stress corrosion cracking, and use of structural weld overlays. Other mitigation steps are also being implemented. This issue of stress corrosion cracking in these particular welds is beyond the scope of this review. 


\section{LITERATURE REVIEW}

\subsection{Microstructural Evolution}

\subsubsection{As-Welded Condition}

Welds made between two dissimilar alloys will generally consist of four distinct microstructural zones, as shown schematically in Figure 2. The fusion zone is the region where complete mixing occurs between the two base metals and (if used) the filler metal. There is considerable fluid flow that occurs in the weld metal while in the liquid state; this is driven by a variety of sources, including differences in density and surface tension along with impingement from the high-temperature plasma ${ }^{7}$. Thus, it is well known that the composition within the fusion zone is macroscopically uniform due to this rather aggressive mixing that occurs prior to solidification. However, within the fusion zone there is a stagnant boundary layer adjacent to the partially melted base metal where mixing between the base metal and filler metal is incomplete. A partially mixed zone (PMZ) forms in this small region in which the composition gradually changes from that of the fusion zone to that of the base metal. The composition gradients associated with the PMZs of dissimilar welds are particularly important in terms of microstructural evolution and resultant service performance. They are discussed in more detail below. Adjacent to the PMZ will be a region where the actual temperature was between the liquidus and solidus of the base metal during welding. This region will therefore exhibit various degrees of liquation that can often be observed microstructurally (e.g., localized melting of secondary phases), but the composition in this region is identical to the base metal since no mixing occurred with the filler metal. The heat affected zone (HAZ) consists of the region within the base metal where the actual temperature is below the terminal solidus temperature of the alloy, but above the temperature at which solid state transformations will occur.

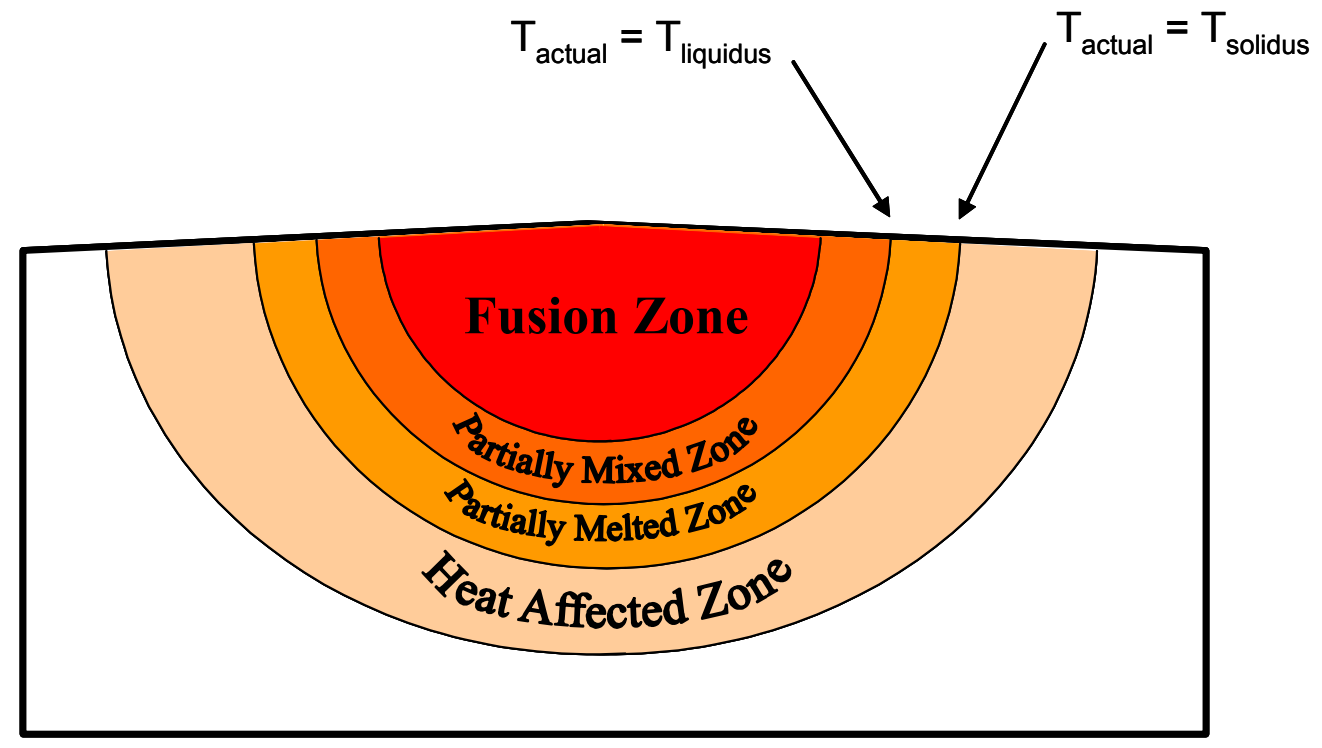

Figure 2. Schematic illustration of four distinct microstructural zones that exist in dissimilar welds.

The distribution of major alloying elements in the PMZ of a dissimilar weld between $2.25 \mathrm{Cr}-1 \mathrm{Mo}$ and alloy $800 \mathrm{H}$ is shown in Figure $3^{8}$. This weld was fabricated using the shielded metal arc welding process with Inconel 182 electrode. Inconel 82 solid wire is used for gas tungsten arc welding of $2.25 \mathrm{Cr}-1 \mathrm{Mo}$ steel to alloy $800 \mathrm{H}$, and Inconel 182 coated electrode is used for the shielded metal arc welding process. The chemical compositions of typical high-temperature materials discussed in this review are provided in Table 1. The region of partial mixing that occurred prior to solidification is clearly observed as a transition in composition between the $2.25 \mathrm{Cr}-1 \mathrm{Mo}$ base metal and the fusion zone. Similar composition profiles are available in the literature for a wide range of dissimilar alloy combinations ${ }^{9},{ }^{10},{ }^{11}$ and 
demonstrate that a PMZ of finite width always forms, regardless of the alloys involved and welding parameters utilized. The actual width of the PMZ depends on welding variables such as heat input and filler metal feed rate ${ }^{10}$. Under most welding conditions, the size of the PMZ is very small (approximately $20-100 \mu \mathrm{m}$ ) in relation to the width of the fusion zone. However, PMZs as large as 2-3 mm have been observed under very high filler metal feed rate conditions ${ }^{10}$.

Table 1. Chemical compositions of typical high-temperature materials (wt\%).

\begin{tabular}{|l|c|c|c|c|c|c|c|c|c|c|c|}
\hline Material & $\mathrm{Al}$ & $\mathrm{C}$ & $\mathrm{Cr}$ & $\mathrm{Cu}$ & $\mathrm{Fe}$ & $\mathrm{Mn}$ & $\mathrm{Mo}$ & $\mathrm{Nb}+\mathrm{Ta}$ & $\mathrm{Ni}$ & $\mathrm{Si}$ & $\mathrm{Ti}$ \\
\hline \hline 2.25Cr-1Mo steel & --- & $.05-.15$ & $2-2.5$ & --- & $95.1-96.75$ & $.3-.6$ & $.9-1.1$ & --- & .045 & .5 & --- \\
\hline 9Cr-1Mo steel & --- & 0.15 & $8-10$ & --- & $87.1-90.55$ & $.3-.6$ & $.9-1.1$ & --- & --- & $.25-1.0$ & --- \\
\hline Alloy 800H & $.15-.6$ & $.06-.1$ & $19-23$ & 0.75 & $\min 39.5$ & 1.5 & --- & --- & $30-35$ & 1 & $.15-.6$ \\
\hline 309 stainless & --- & .1 & 23.4 & --- & 61 & 1.8 & --- & --- & 13.1 & .6 & --- \\
\hline 316 stainless & --- & .07 & $16-18$ & --- & $61.9-72$ & 2 & $2-3$ & --- & $10-14$ & 1 & --- \\
\hline 347H stainless & --- & $.04-.1$ & $17-20$ & --- & $62.8-73.6$ & 2 & --- & $.3-1$ & $9-13$ & 1 & --- \\
\hline Inconel 82* & --- & 0.1 & $18-22$ & 0.5 & 3 & $2.5-3.5$ & --- & $2.0-3.0$ & $67(\min )$ & 0.5 & 0.75 \\
\hline Inconel 182* & --- & 0.1 & $13-17$ & 0.5 & 10 & $5.0-9.0$ & --- & 1 & $59(\min )$ & 1 & 1 \\
\hline EPRI P87* & $.1-.2$ & $.09-.14$ & $8.5-9.5$ & --- & $38-42$ & $1.2-1.8$ & $1.8-2.2$ & --- & $54(\max )$ & $.05-.25$ & 0.05 \\
\hline
\end{tabular}

$*=$ filler metals

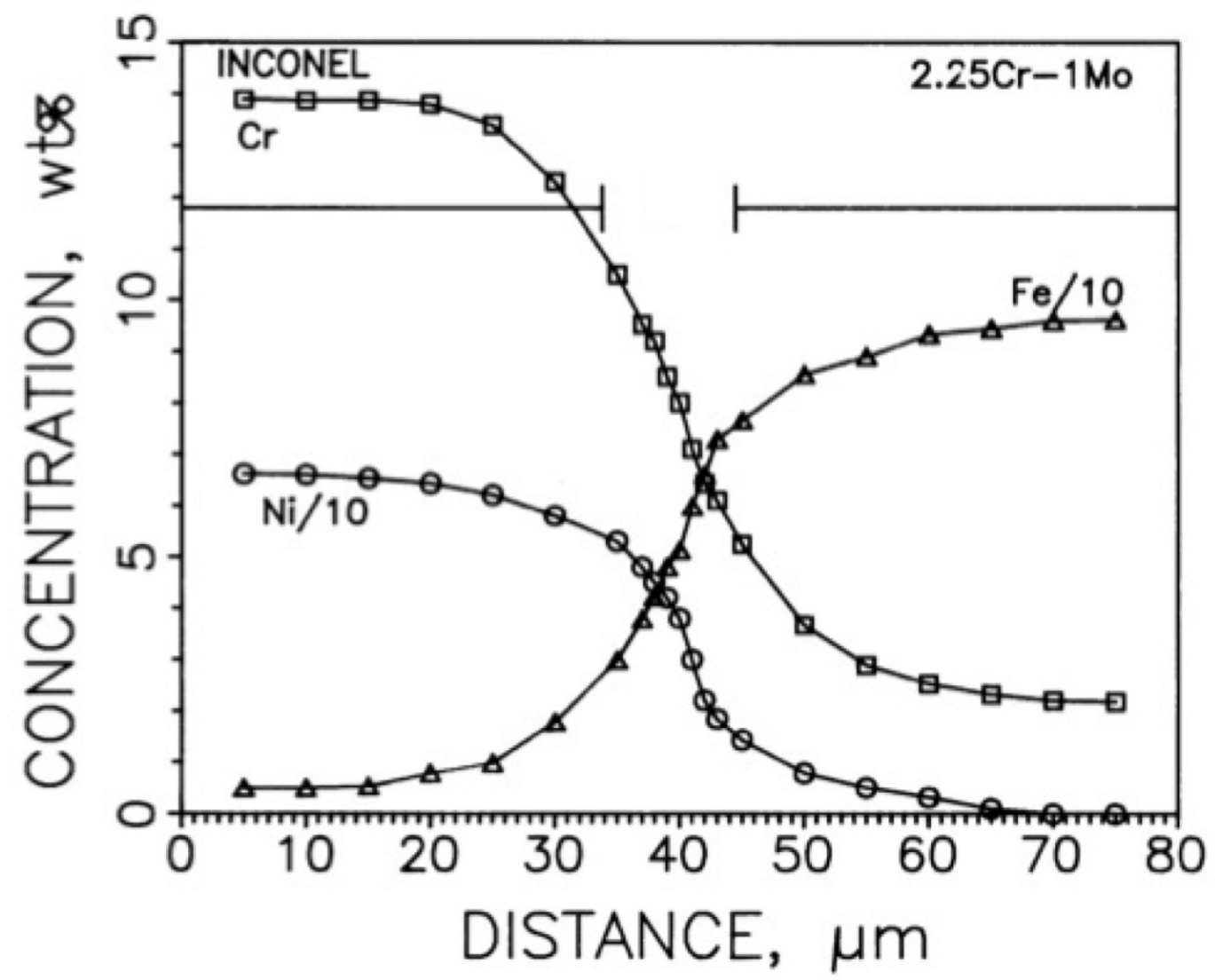

Figure 3. Distribution of major alloying elements in the partially mixed zone of a dissimilar weld between $2.25 \mathrm{Cr}-1 \mathrm{Mo}$ and alloy $800 \mathrm{H}^{8}$

As shown by Figure 3, the Ni content in the PMZ will decrease from the fusion zone toward the $2.25 \mathrm{Cr}-1 \mathrm{Mo}$ base metal. A point will eventually be reached where the Ni content is too low to stabilize the austenite during cooling to room temperature. In addition, the relatively high alloy content within this zone promotes high hardenability so that martensite will form under even the slowest cooling rate 
conditions associated with fusion welding. This can be understood with reference to the Schaeffler diagram shown in Figure 4 . This diagram reveals the microstructural constituents that form in welds of alloy steels and stainless steels under cooling rate conditions typical of arc welding. Use of the diagram is appropriate for interpreting microstructural formation in the PMZ of dissimilar welds since the PMZ composition falls within the experimentally verified regions of the diagram. This is shown in Figure 4 by plotting the $\mathrm{Ni}$ and $\mathrm{Cr}$ equivalents for alloy $800 \mathrm{H}$ and $2.25 \mathrm{Cr}-1 \mathrm{Mo}$ steel directly on the Schaeffler diagram. Since the PMZ will consist of all compositions that connect these two points, the PMZ has to traverse through a martensitic region.

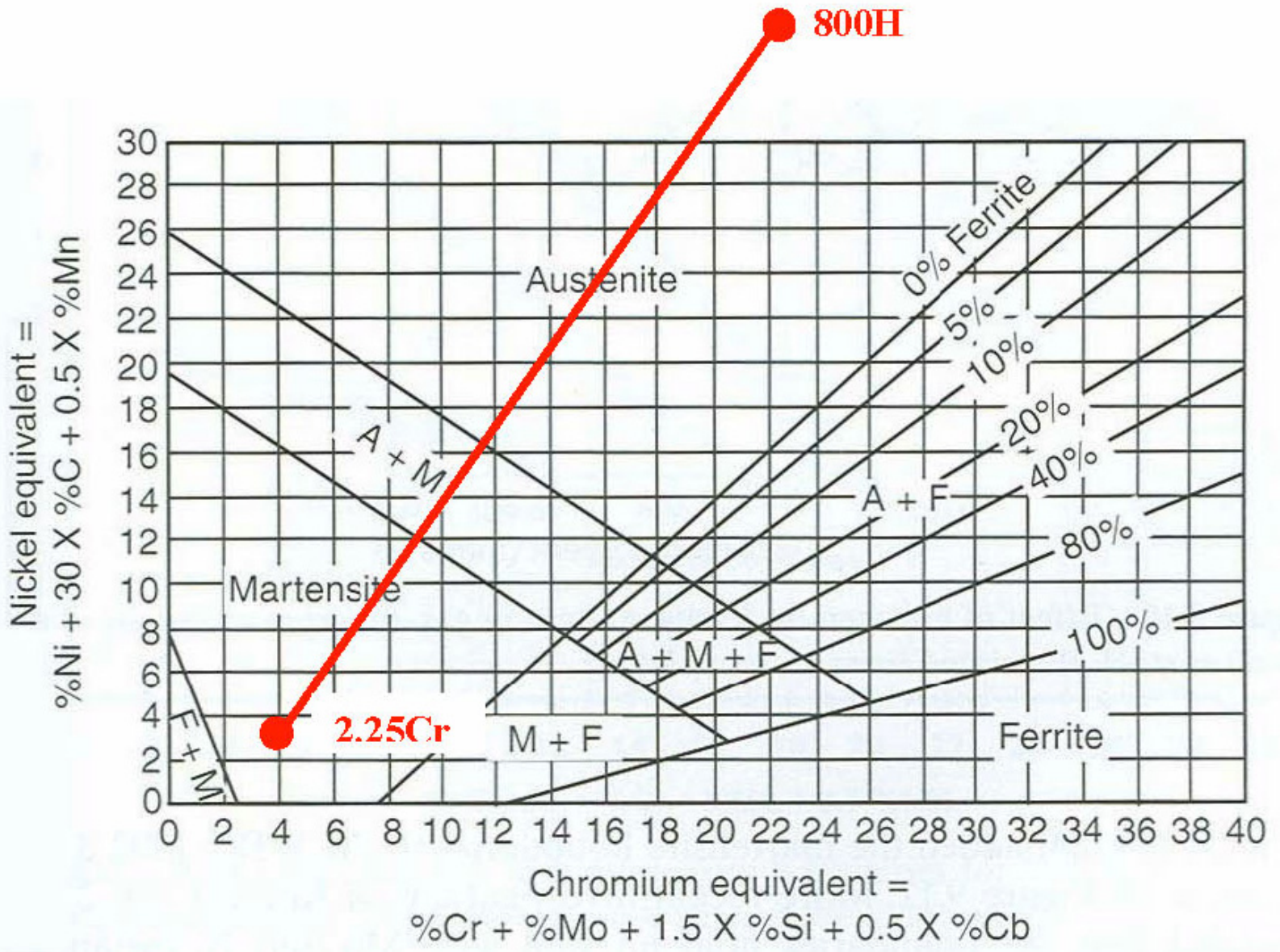

Figure 4. Schaeffler diagram used for prediction of microstructure in ferritic, austenitic, and dissimilar welds. ${ }^{7}$

Examples of the martensite layers that form within the PMZ of welds in dissimilar welds between ferritic steels and stainless steels, as well as ferritic steels and Ni base alloys, are shown in Figure $5^{9}$. As shown by the photomicrographs in Figure 5, the use of Ni base filler metals will result in the formation of a thin martensite layer at the fusion line, while the martensite layer that results from the use of stainless steel filler metals is relatively thick. Recent work ${ }^{9}$ has shown that this difference is attributed to the variations in concentration gradients that exist in the PMZ between the two types of filler metal. The black vertical line in each photomicrograph of Figure 5 represents the locations of composition traces acquired with electron probe microanalysis. The variation in martensite-layer widths is readily evident from these figures. The martensite layer in the 309L weld was 30-37 $\mu \mathrm{m}$ in thickness while that in the IN625 weld was only 1-3 $\mu \mathrm{m}$ in thickness. The variation in major alloying elements $(\mathrm{Fe}, \mathrm{Ni}$, and $\mathrm{Cr})$ across the fusion lines of the welds is shown in Figure 6. The composition gradient is steeper for the weld 
prepared with IN625 filler metal because of the increase in nominal Ni content and decrease in nominal Fe content compared to the weld prepared with 309L stainless steel. The composition gradients produce a variation in the martensite start (Ms) temperature across the fusion line, and the differences in composition gradients and resultant Ms gradients between the two welds can be used to explain the observed variation in martensite widths. Using the measured values for $\mathrm{Ni}, \mathrm{Cr}$, and $\mathrm{Mo}$ along with estimated values of $\mathrm{C}$ and $\mathrm{Mn}$, the variation in Ms temperature across the partially mixed zone was determined. Figure 7 shows the results. The two curves on each plot represent the highest and lowest possible Ms temperature based on the range in dilution that was experimentally determined within the PMZ. The martensite layer within the partially mixed zone should begin near the start of the composition gradient adjacent to the carbon steel base metal and end at a location where the Ms temperature intersects room temperature. The exact start and end locations cannot be known with a high degree of certainty since this will depend on the local hardenability (as determined by local composition) and local cooling rate. However, comparison of the Ms gradient plots in Figure 7 clearly shows that a thinner martensite layer is expected in welds prepared with Ni base filler metals. This can be attributed to the higher concentration gradient within the partially mixed zone (due to higher Ni concentration) which, in turn, stabilizes the austenite at a shorter location within the partially mixed zone. According to Figure 7, the martensite layer should be approximately 35-39 $\mu \mathrm{m}$ for the weld prepared with 309L filler metal and approximately $2-3 \mu \mathrm{m}$ in the weld prepared with the IN625 filler metal. These values compare reasonably well with those measured at the location of the microprobe trace for each weld in Figure $5, \sim 34 \mu \mathrm{m}$ for 309L and $\sim 3 \mu \mathrm{m}$ for IN625. It should be noted that the exact width of the martensite layer can vary within a given weld due to local variations in the composition gradient (due to local variations in fluid flow behavior) and local differences in cooling rate. In addition, variations in fluid flow behavior are expected when changes are made to processing parameters. The objective of the results presented here was not to predict the size of the martensite layer within a given weld or with variations in processing parameters, but to demonstrate why significant differences exist between the widths of martensite layers in welds prepared with $\mathrm{Ni}$ base and $\mathrm{Fe}$ base alloys. These results demonstrate that the reduced width of the martensite layer in Ni base alloys can be attributed to the steeper gradient in composition and concomitant Ms temperature within the partially mixed zone.
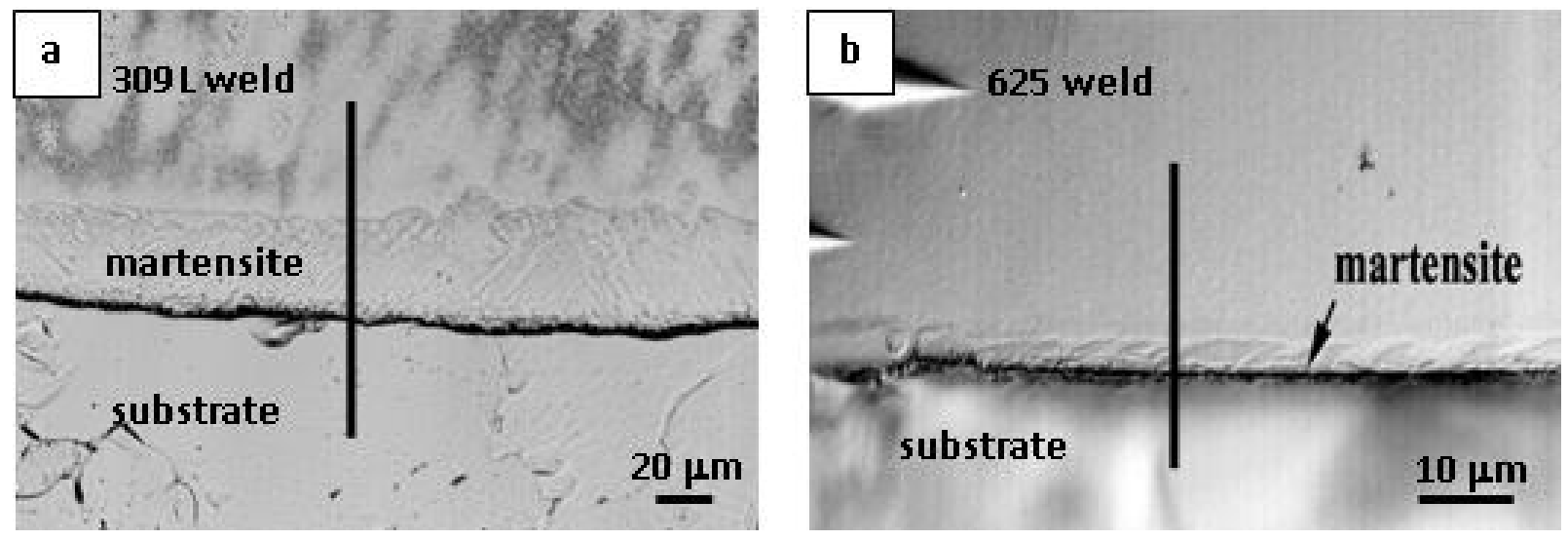

Figure 5. Examples of the martensite layers that form within the partially mixed zone in dissimilar welds between ferritic steel and (a) 309L stainless steel filler metal and (b) alloy 625 filler metal. ${ }^{9}$ 

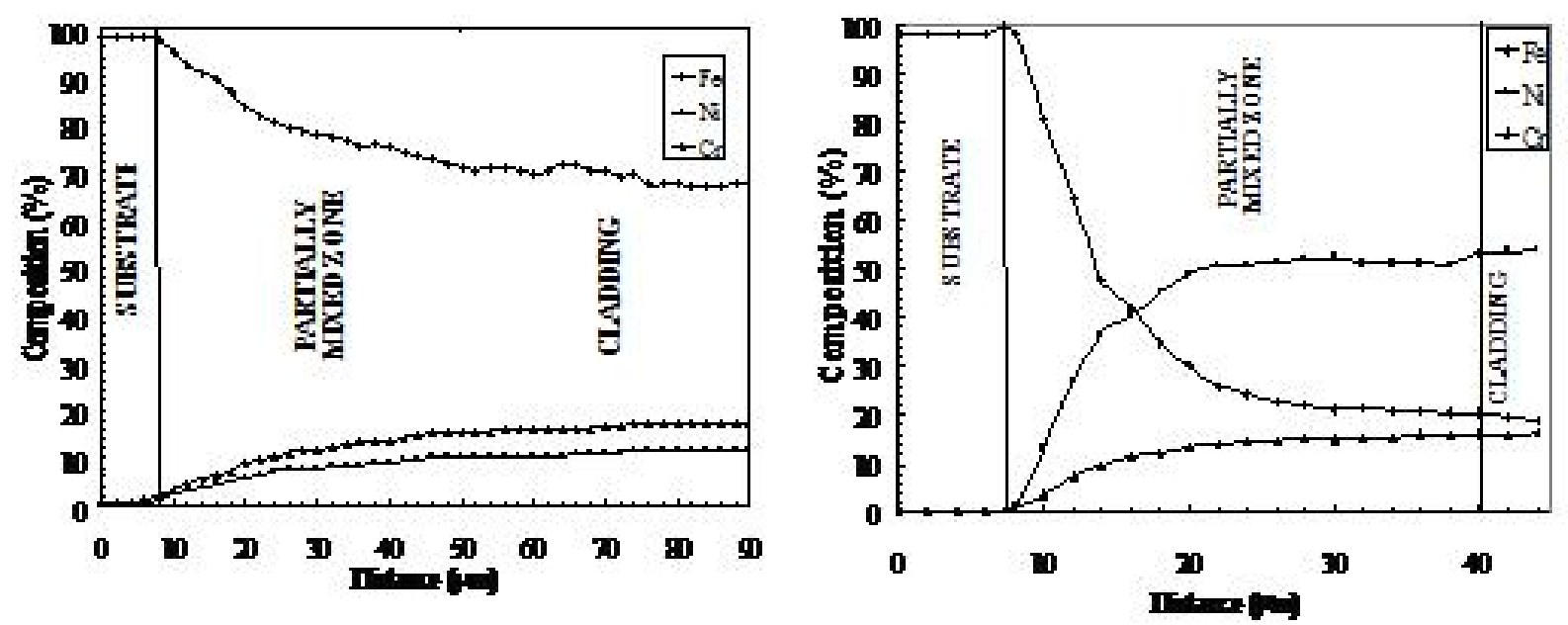

Figure 6. Variation in major alloying elements ( $\mathrm{Fe}, \mathrm{Ni}$, and $\mathrm{Cr}$ ) across the fusion lines of the welds shown in Figure 5. (a) weld between ferritic steel and 309L stainless steel filler metal and (b) weld between ferritic steel and alloy 625 filler metal. ${ }^{9}$

Figure 8 illustrates the large differences in hardness that develop near the interface in DMWs ${ }^{12}$. The example shown is for a DMW between 2.25Cr-1Mo steel and a 309L stainless steel, but similar trends have been observed for welds made between $2.25 \mathrm{Cr}-1 \mathrm{Mo}$ and alloy $800 \mathrm{H}$ (shown in more detail in the next section). Note that the hardness in the 2.25Cr-1Mo steel decreases from $\sim 300$ Vickers hardness (HV) to $280 \mathrm{HV}$ at the fusion line. The slight reduction in hardness is attributed to carbon diffusion from the high $\mathrm{C}$ ferritic steel to the low $\mathrm{C}$ stainless steel and is discussed in more detail in the next section. This effect can be observed microstructurally in Figure 8 since there is less carbide (dark etching constituent) near the interface where the $\mathrm{C}$ content and associated hardness are low. There is then a large increase in hardness to $435 \mathrm{HV}$ over a very short distance, and the high hardness is associated with formation of the martensite layer. Thus, in the as-welded condition, DMWs between ferritic steels and austenitic alloys will consist of a concentration gradient and hard martensite layer within the PMZ that is adjacent to a relatively soft layer in the ferritic steel. The formation and extent of the softened region in the ferritic steel depends on the composition of the filler metal and is discussed in more detail below. It has recently been suggested $^{13}$ that martensite formation can be avoided in DMWs by careful control over the welding parameters so that the cooling rate is low enough to avoid martensite formation within the concentration gradient of the PMZ. Unfortunately, no detailed microstructural information was provided to support this claim, and this is not consistent with the large body of experimental evidence $e^{8,9,12,14,15,16,17,18,19}$ that clearly shows martensite will always form under the combination of composition and cooling rate associated with practical welding conditions. 

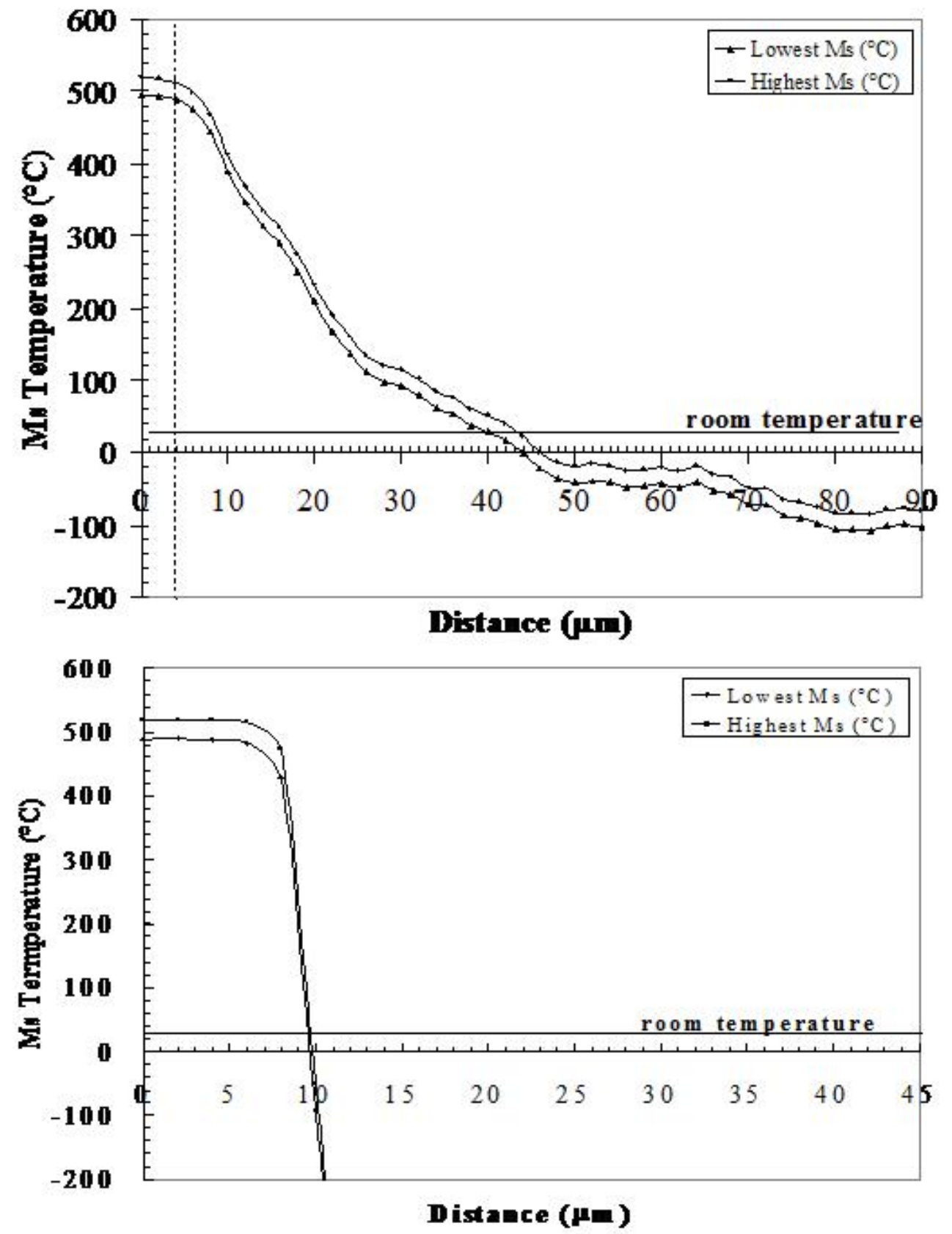

Figure 7. Variation in martensite start (Ms) temperature across the partially mixed zone for (a) weld between ferritic steel and 309L stainless steel filler metal and (b) weld between ferritic steel and alloy 625 filler metal. ${ }^{9}$ 


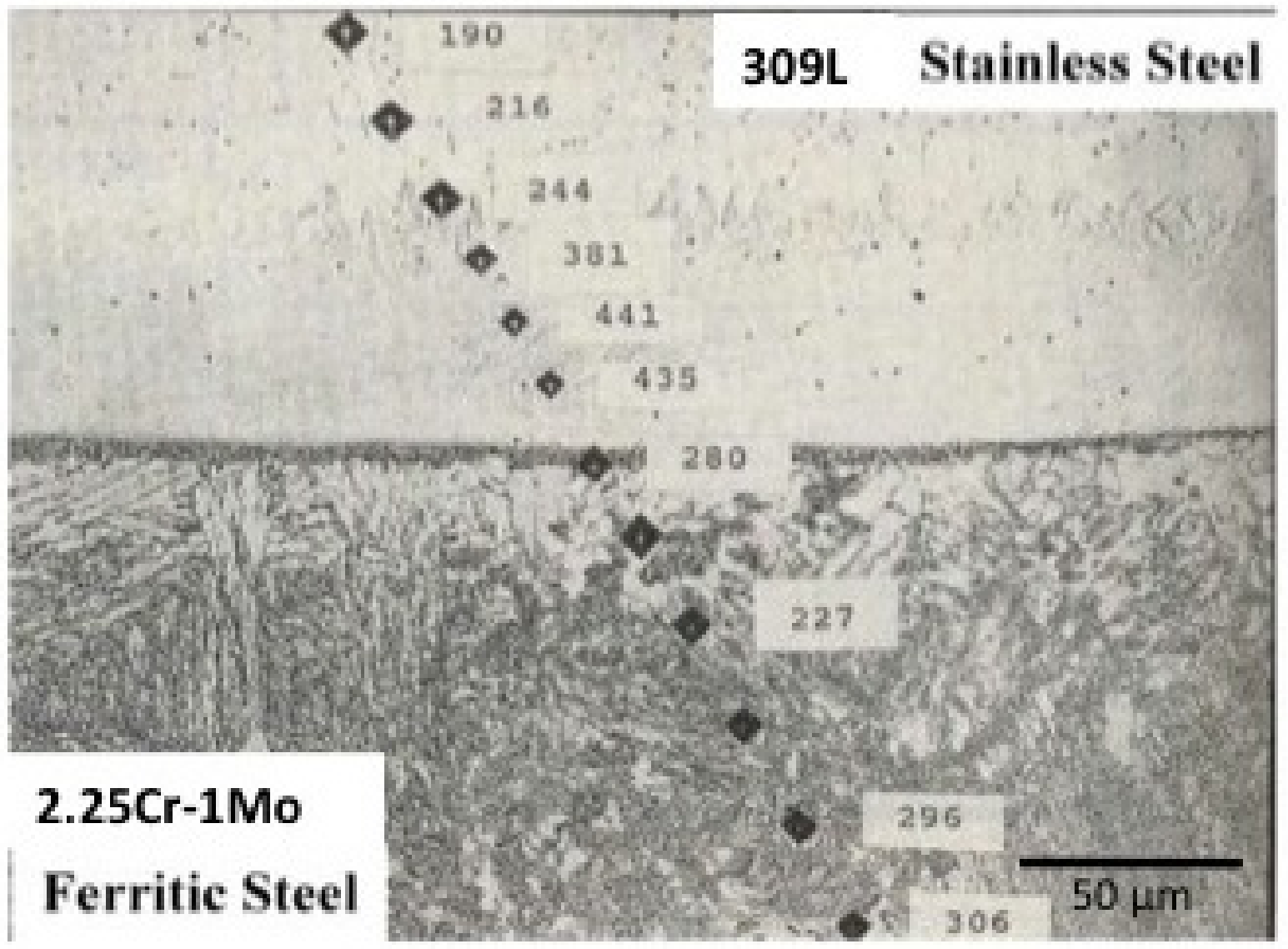

Figure 8. Differences in hardness that develop in the as-welded condition near the interface for a weld between $2.25 \mathrm{Cr}-1 \mathrm{Mo}$ steel and a 309L stainless steel. ${ }^{12}$

\subsubsection{Microstructural Evolution During Aging and PWHT}

The concentration gradient within the PMZ, together with large differences in C solubility and diffusivity between the ferritic and austenitic alloys, leads to significant microstructural changes during PWHT and aging in service. Figure 9 and Figure 10 show the microstructure and hardness variations that exist in DMWs involving 2.25Cr-1Mo steel with stainless steel (Figure 9) and Ni base filler metals (Figure 10) after a PWHT is applied ${ }^{12}$. Figure 8 (as welded condition) can be compared directly with Figure 9 (PWHT condition) since these figures are from the same study. Note that the hardness differences are now even further pronounced, with the minimum hardness of the $2.25 \mathrm{Cr}$-1Mo steel decreased to $134 \mathrm{HV}$ (compared to $280 \mathrm{HV}$ in the as-welded condition) and the maximum hardness in the PMZ increased to 487 (compared to $441 \mathrm{HV}$ in the as-welded condition). Although there is also a significant hardness gradient in the weld made with the Ni base filler metal, the difference in hardness is not quite as large as that observed for the stainless steel filler metal. This trend has been observed by several investigators and represents one of the advantages of Ni base filler metals ${ }^{14,15,16,20}$. Note that a dark etching band also appears at the end of the PMZ after application of a PWHT. 


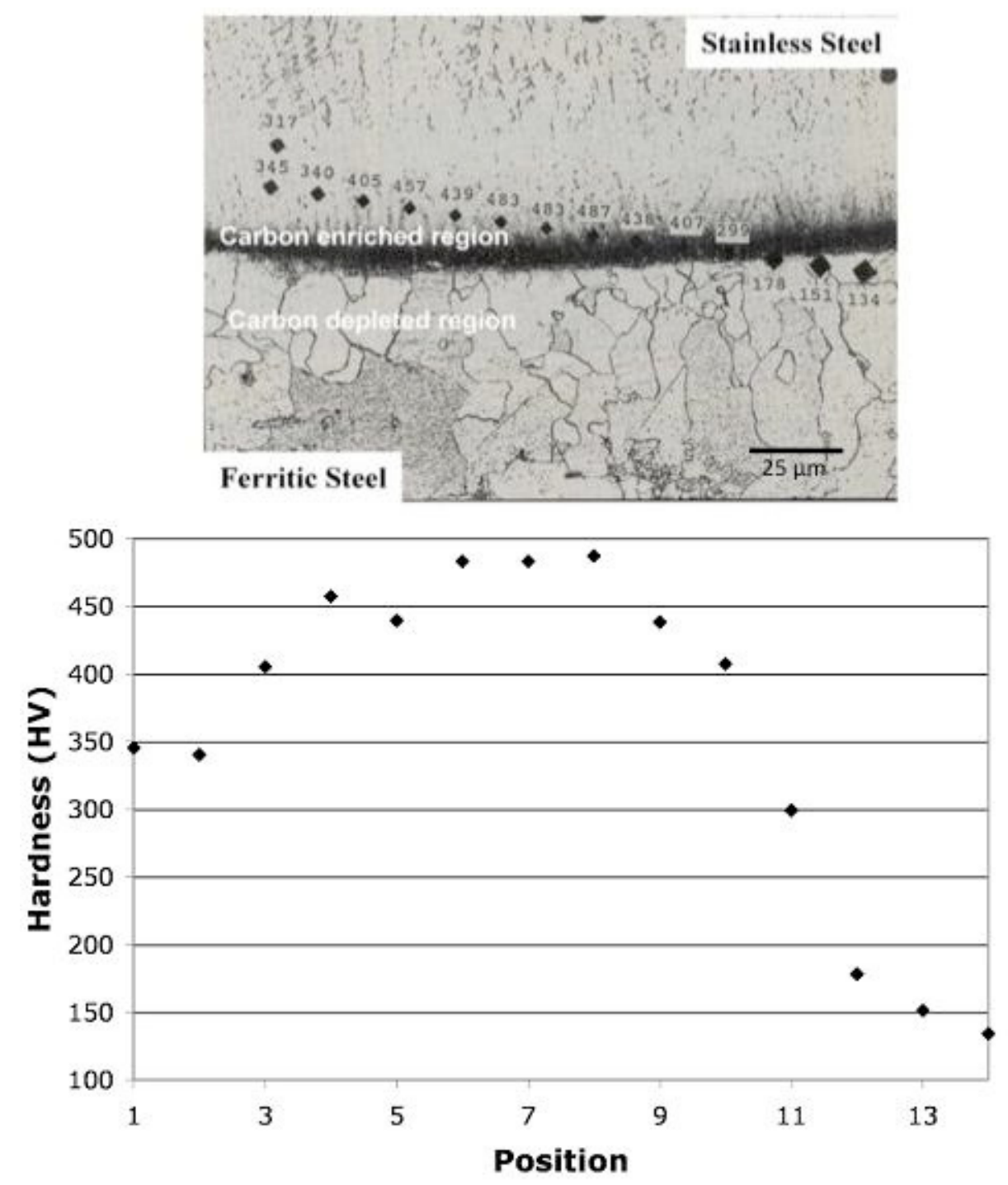

Figure 9. Microstructure and hardness variations that exist in a weld involving 2.25Cr-1Mo steel with 309 stainless steel after a PWHT of $720^{\circ} \mathrm{C}$ for 10 hours. ${ }^{12}$ 


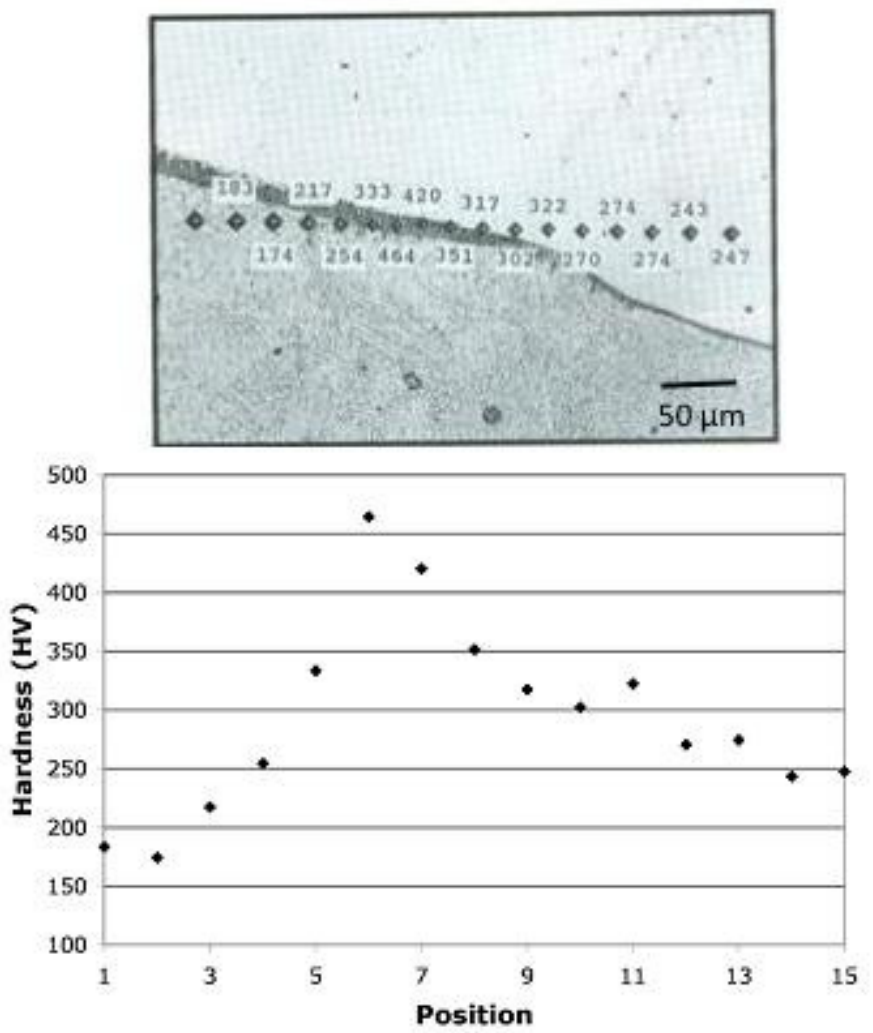

Figure 10. Microstructure and hardness variations that exist in a weld involving 2.25Cr-1Mo steel with ERNiCr-3 filler metal after a PWHT of $690^{\circ} \mathrm{C}$ for 30 hours. ${ }^{12}$

Measurements of $\mathrm{C}$ concentration profiles within the $\mathrm{PMZ}$ are difficult due to its low atomic number and low concentration. However, it is readily evident that the $\mathrm{C}$ concentration profile in the as-welded condition will look similar to that of Fe shown in Figure 3 since the $\mathrm{C}$ content of the ferritic steel is typically higher than that of the austenitic alloy. Thus, there is a $\mathrm{C}$ concentration gradient that is high in the ferritic alloy and decreases toward the austenitic alloy. At elevated temperatures, $\mathrm{C}$ will diffuse down the chemical potential gradient. In view of this, it is important to note that $\mathrm{Cr}$ lowers the chemical potential of $\mathrm{C}^{8,21}$, and the $\mathrm{Cr}$ level increases from the ferritic side to the austenitic side of the interface. Thus, the $\mathrm{C}$ and $\mathrm{Cr}$ concentration gradients produce a rather sharp $\mathrm{C}$ chemical potential gradient across the interface. Furthermore, the diffusivity of $\mathrm{C}$ in ferrite is significantly higher than in austenite, and the solubility is significantly lower. As a result of these factors, there is a strong driving force for $\mathrm{C}$ to diffuse from the ferritic alloy to the austenitic alloy. This produces a decarburized layer in the ferritic side that accounts for the significant reduction in hardness. Carbon migration has been shown to be an important component of DMW failures and has received much attention in the literature ${ }^{21,22,23,24,25,26}$.

Note from Figure 8 that some decarburization can also occur during the welding operation. Although $\mathrm{C}$ diffusion also occurs in welds made with Ni base alloys, the problem is substantially reduced to the point where a decarburized layer is very small or not observed at all on the ferritic side of the joint (Figure 10) $)^{12,14,16,27,28}$. Although the reasons for this have not been discussed in detail, the large Ni concentration of the filler metal must be responsible for a reduction in the $\mathrm{C}$ chemical potential gradient across the fusion line. Carbon diffusion towards the austenitic alloy side of the joint also leads to a $\mathrm{C}$-enriched region just inside the fusion line. An example of this is shown from examination of a service-exposed weld in Figure $11^{20}$. Just beyond the interface, on the austenitic side of the fusion line, the $\mathrm{C}$ concentration is significantly enriched to the point where the solubility limit of $\mathrm{C}$ in austenite is exceeded. This leads to formation of carbides within this region, and this accounts for the dark etching 
area often observed after PWHT or aging in service (see, for example, the darkly etched region in Figure 9). Transmission electron micrographs of carbon replicas showing an example of this are provided in Figure $12^{12}$. Detailed microstructural characterization studies ${ }^{12,29,30,31}$ have shown that these are $\mathrm{M}_{23} \mathrm{C}_{6}$ and $\mathrm{M}_{6} \mathrm{C}$ carbides.

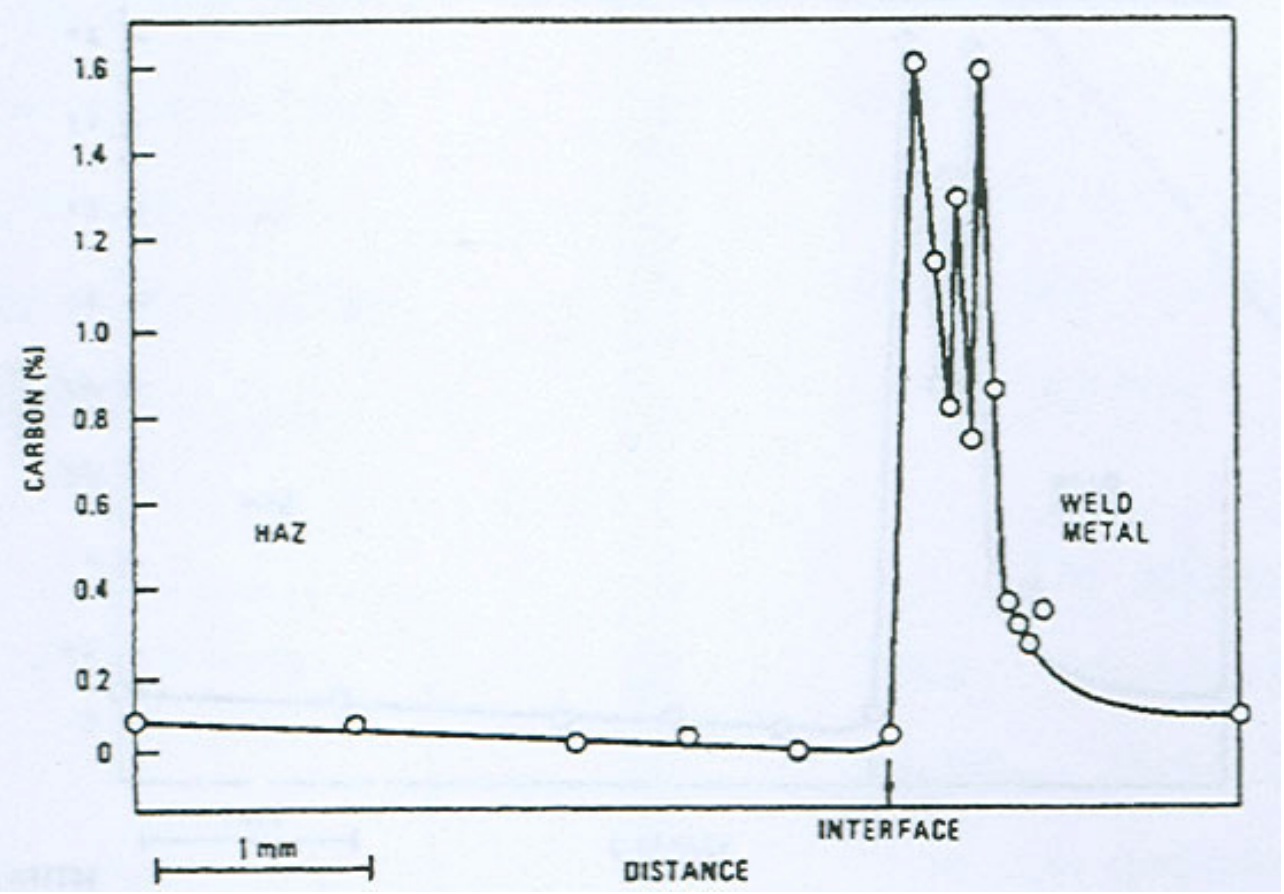

Figure 11. Carbon concentration profile across the fusion line of a service-exposed weld. ${ }^{20}$
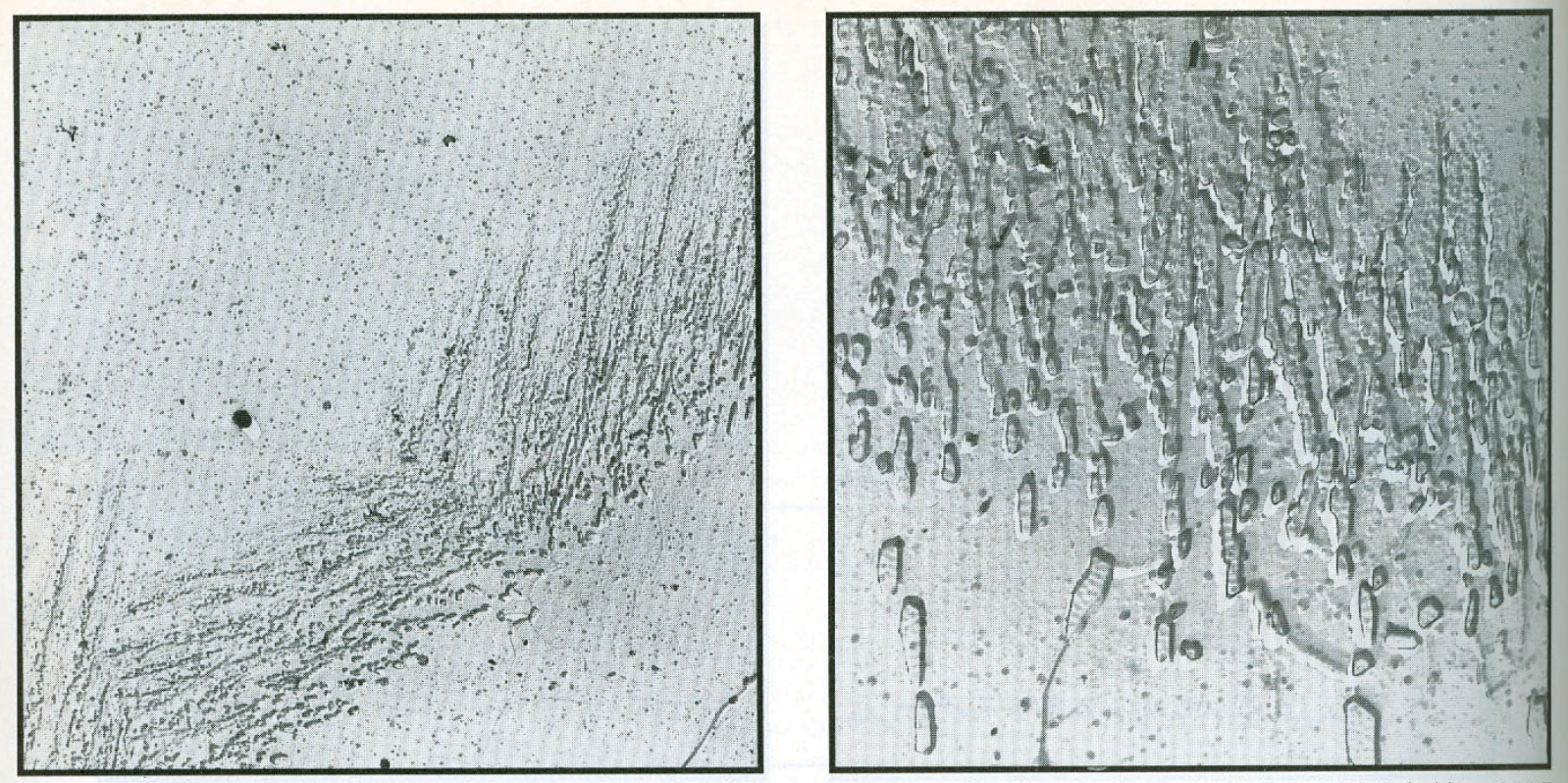

Figure 12. Transmission electron micrographs of carbon replicas showing carbides that form in a weld between $2.25 \mathrm{Cr}-1 \mathrm{Mo}$ steel and 309 stainless steel after a PWHT of $690^{\circ} \mathrm{C}$ for 30 hours. $^{12}$ 
Figure $13^{8}$ shows the variations in microhardness across the interfacial region of a weld made between $2.25 \mathrm{Cr}-1 \mathrm{Mo}$ steel and alloy $800 \mathrm{H}$ in the as-welded condition after application of a PWHT at $700^{\circ} \mathrm{C}$ for one hour, and after creep testing at $150 \mathrm{MPa} / 550^{\circ} \mathrm{C}$ (with a corresponding failure time of approximately 1,000 hours). This weld was made with Inconel 182 filler metal. The interface position is noted in the figure. The high hardness in the $2.25 \mathrm{Cr}-1 \mathrm{Mo}$ steel HAZ directly after welding is attributed to formation of martensite in this region. Note that the HAZ hardness is decreased considerably after PWHT. However, a highly localized hardness peak evolves just inside the interface on the fusion-zone side of the weld, and this peak hardness increases after creep testing. The localized increase in hardness that occurs with increased aging time is associated with nucleation and growth of the carbides in the PMZ that occurs due to $\mathrm{C}$ diffusion. Figure 14 compares hardness differences in welds involving $2.25 \mathrm{Cr}-1 \mathrm{Mo}$ steel with Inconel 182 filler metal (Figure 14a) and 316 stainless steel filler metal (Figure 14b) ${ }^{32}$. Results are shown for the PWHT condition $\left(700^{\circ} \mathrm{C} / 3\right.$ hours) and after aging at $580^{\circ} \mathrm{C}$. The expected hardness peaks just inside the interface are observed. However, note that the weld made with the 316 stainless steel filler metal also shows a significant decrease in hardness on the $2.25 \mathrm{Cr}-1 \mathrm{Mo}$ side of the weld. Such a hardness trough is not observed in the weld made with the Inconel 182 filler metal. As described above, the hardness trough in the weld made with the 316 filler metal is associated with relatively intense $\mathrm{C}$ migration from the ferritic side to the austenitic side of the joint. This leads to softening in the ferritic side due to decarburization and hardening on the austenitic side due to nucleation and growth of carbides. The decarburized layer in the weld made with Inconel 182 filler metal is significantly minimized because the $\mathrm{C}$ migration problem is reduced.

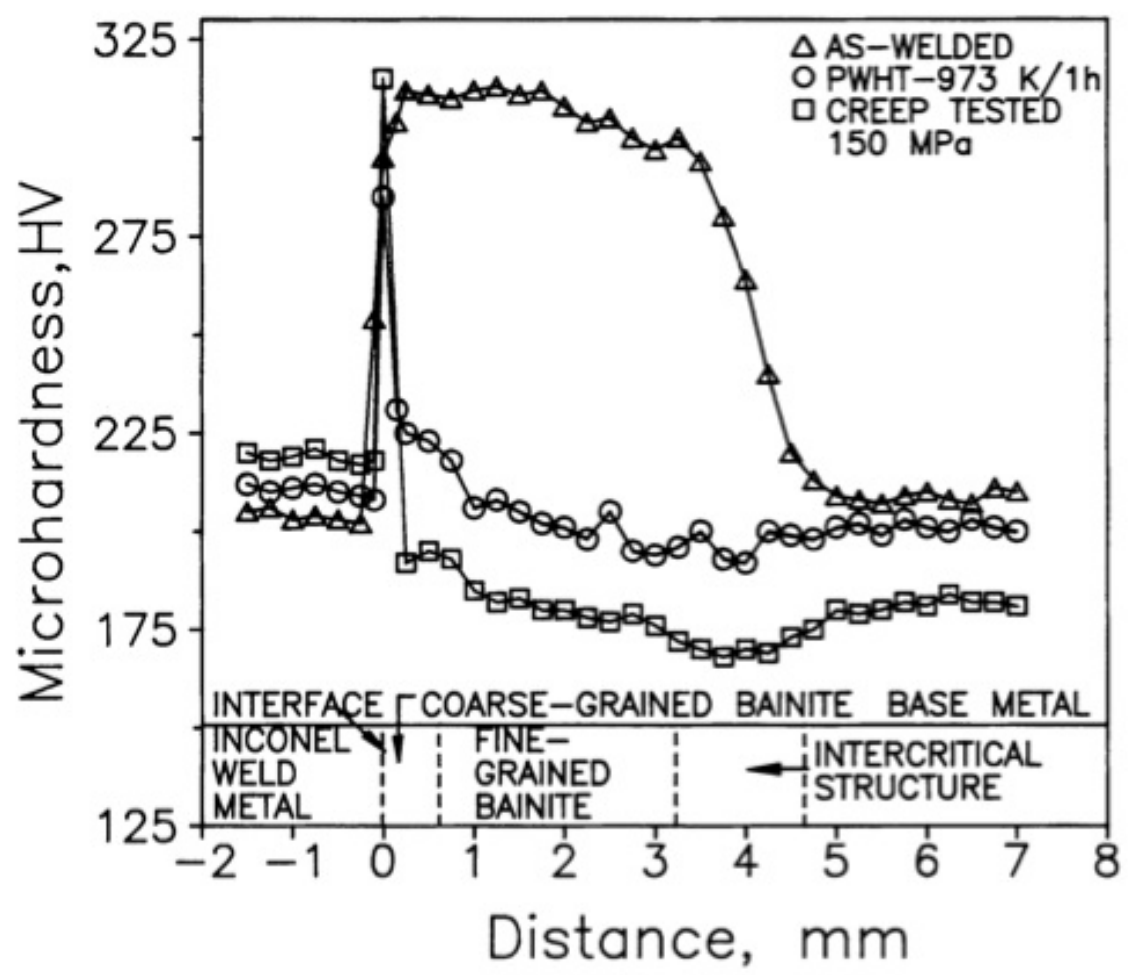

Figure 13. Variations in microhardness across the interfacial region of a weld made between $2.25 \mathrm{Cr}-1 \mathrm{Mo}$ steel and alloy $800 \mathrm{H}$ in the as-welded condition, after application of a PWHT at $700^{\circ} \mathrm{C}$ for one hour, and after creep testing at $150 \mathrm{MPa} / 550^{\circ} \mathrm{C}$ (with a corresponding failure time of approximately 1,000 hours). ${ }^{8}$ 


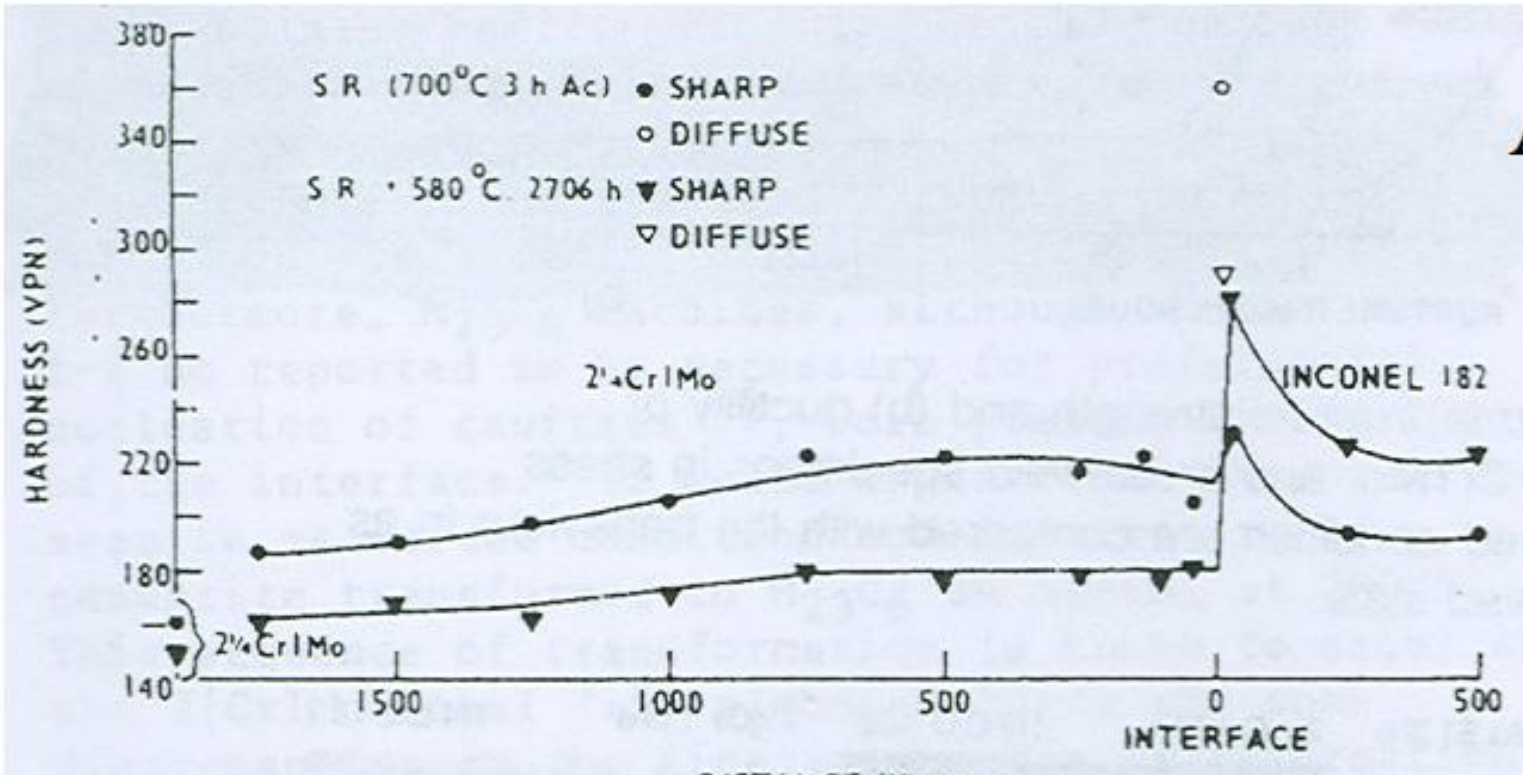

DISTANCE IN $\mu \mathrm{m}$

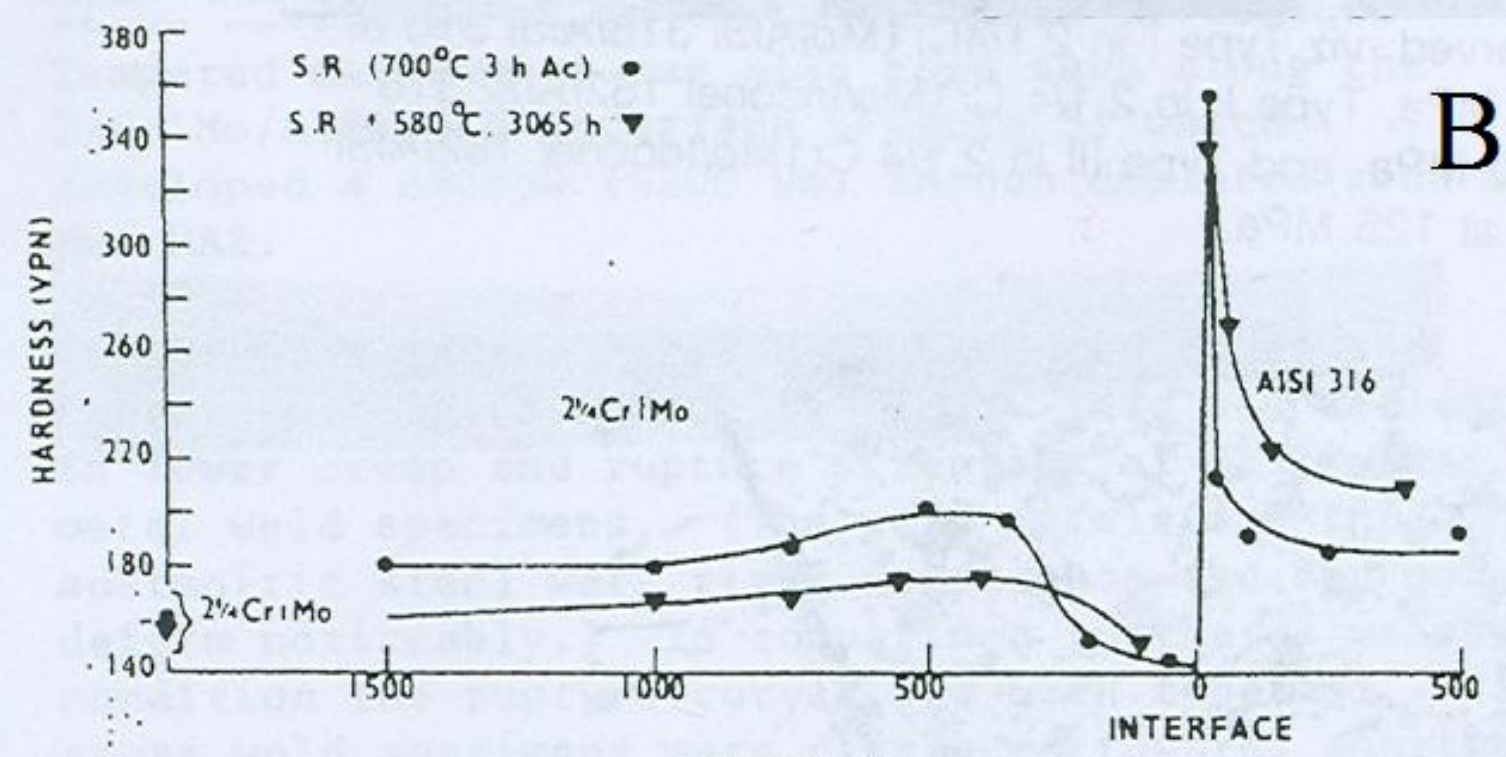

DISTANCE IN $\mu \mathrm{m}$

Figure 14. Hardness differences in welds involving 2.25Cr-1Mo steel with (a) Inconel 182 filler metal and (b) 316 stainless steel filler metal after PWHT at $700^{\circ} \mathrm{C}$ for 3 hours and after aging at $580^{\circ} \mathrm{C} .^{32}$

Gittos and Gooch have demonstrated that the application of a PWHT can also cause increases in hardness due to formation of virgin martensite on cooling from the PWHT temperature ${ }^{12}$. This can be understood with reference to Figure 15, which shows the variation in composition in the as-welded and PWHT condition. The diffusion rates of substitutional alloying elements are too low to promote composition changes during PWHT and aging ${ }^{33}$. Thus, the C content is the only one which will change near the interface after exposure to high temperatures. The Ms temperature is also shown at several locations within the transition region for the as-welded (AW) and PWHT condition. These values were estimated from the measured composition gradient. Also noted is the approximate position at which the $\mathrm{Ac}_{1}$ (i.e., temperature at which ferrite transforms to austenite on heating) is $550^{\circ} \mathrm{C}$. This Figure is not meant to be exact, but to provide a general description of how the concentration gradient and $\mathrm{C}$ migration 
affect the transformation temperatures. The $\mathrm{Ac}_{1}$ temperature generally decreases with increasing alloying additions. Thus, as shown in Figure 15, for most PWHT temperatures (which are approximately 600 $700^{\circ} \mathrm{C}$ ) a portion of the $\mathrm{PMZ}$ will be re-austenitized during the PWHT because the $\mathrm{Ac}_{1}$ is lower than the PWHT temperature. Furthermore, C migration will lead to extensive formation of $\mathrm{Cr}$-rich carbides, which reduce the amount of $\mathrm{Cr}$ in solution. This raises the $\mathrm{Ms}$ temperature within this region and also causes virgin martensite to form on cooling from the PWHT.

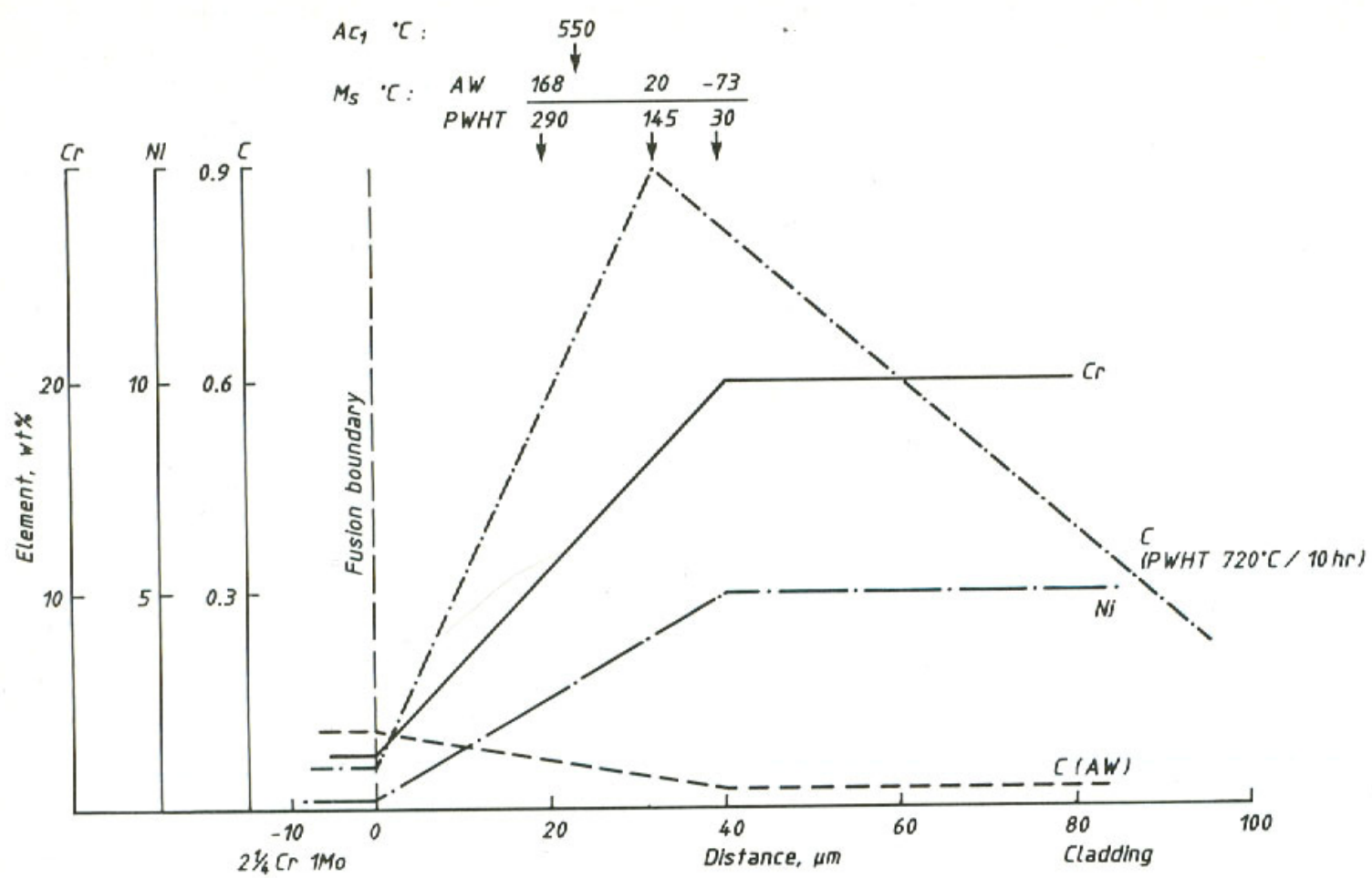

Figure 15. Schematic illustration of variation in composition in the as-welded and PWHT condition for a weld between $2.25 \mathrm{Cr}-1 \mathrm{Mo}$ steel and 309L stainless steel. ${ }^{12}$

It is now recognized ${ }^{15,16,20,34,35,36}$ that two distinct carbide morphologies will evolve in DMWs during aging. Examples of these are shown in Figure 16. Type I carbides (Figure 16a and Error! Reference source not found.b) are the ones most frequently observed. These actually form very close to the fusion line $(\sim 1 \mu \mathrm{m})$ in the HAZ of the ferritic steel. These carbides initially form with a spherical shape, but gradually acquire a lenticular morphology and can eventually form regions of continuous or semi-continuous carbides as they grow and coalesce. Examples of this morphological change are shown by the photomicrographs in Figure $16 \mathrm{a}$ (aged at $625^{\circ} \mathrm{C}$ for 2,000 hours) and Figure $16 \mathrm{~b}$ (aged at $625^{\circ} \mathrm{C}$ for 6,000 hours). The Type II carbides (Figure 16c) generally form as a wide band and are associated with the martensite region that forms within the PMZ. 


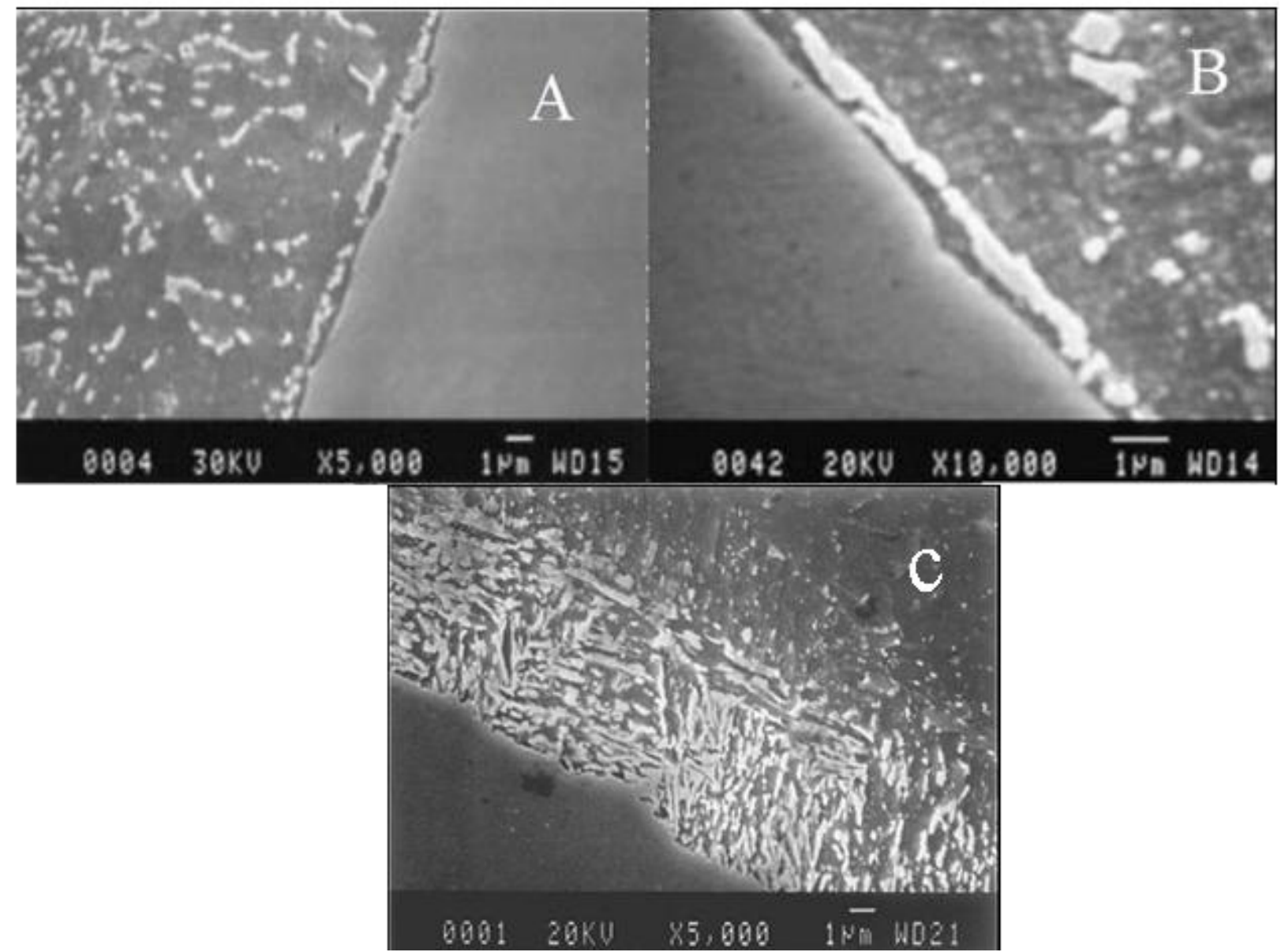

Figure 16. Carbide morphologies observed in dissimilar welds during aging. (a) and (b) Type I carbides that form very close to the fusion line in the HAZ of the ferritic steel, ${ }^{16}$ c) Type II carbides that form as a wide band associated with the martensite region. ${ }^{17}$

As discussed in more detail in the next section, examinations of service and laboratory induced failures ${ }^{15,16,20,34,35,36,37}$ have shown that premature failure of DMWs made with Ni base filler metals is associated with formation of creep cavities around the Type I carbides. Thus, the nucleation, growth and morphological changes that occur in Type I carbides have received considerable attention, and several kinetic studies have been reported ${ }^{17,38,39}$. Most recently, Parker and Stratford provided a detailed study of the growth rate and change in morphology of Type I carbides that occur in the transition region between $2.25 \mathrm{Cr}-1 \mathrm{Mo}$ steel and Inconel 182 filler metal ${ }^{17}$. The carbide sizes and number densities were determined on samples aged at $625^{\circ} \mathrm{C}$ for times up to 6,000 hours. Samples that were creep tested at temperatures of $590^{\circ} \mathrm{C}, 605^{\circ} \mathrm{C}$, and $625^{\circ} \mathrm{C}$ for times between 350 and 8,600 hours were also included in the study.

Figure 17 demonstrates how the major and minor axes of the carbides change with aging time at $625^{\circ} \mathrm{C}$. Note that the growth rate of the major axis is higher than that of the minor axis, which supports the view that the carbides become elongated during aging and align themselves along the interface direction (see Figure 16a and Figure 16b). Figure 18 shows the variation in carbide density as measured by number of carbides per unit length. Note that the carbide density increases up to about 2,000 hours. After this point, the carbides begin to coalesce due to continued growth, often resulting in a continuous or semi-continuous carbide network along the interface. It was also noted that the Type II carbides generally dissolved with increased aging time. The data in Figure 17 for aged (i.e., stress-free) and creep-tested samples are 
essentially indistinguishable. Thus, the application of a stress does not appear to affect the growth rate of the carbides.

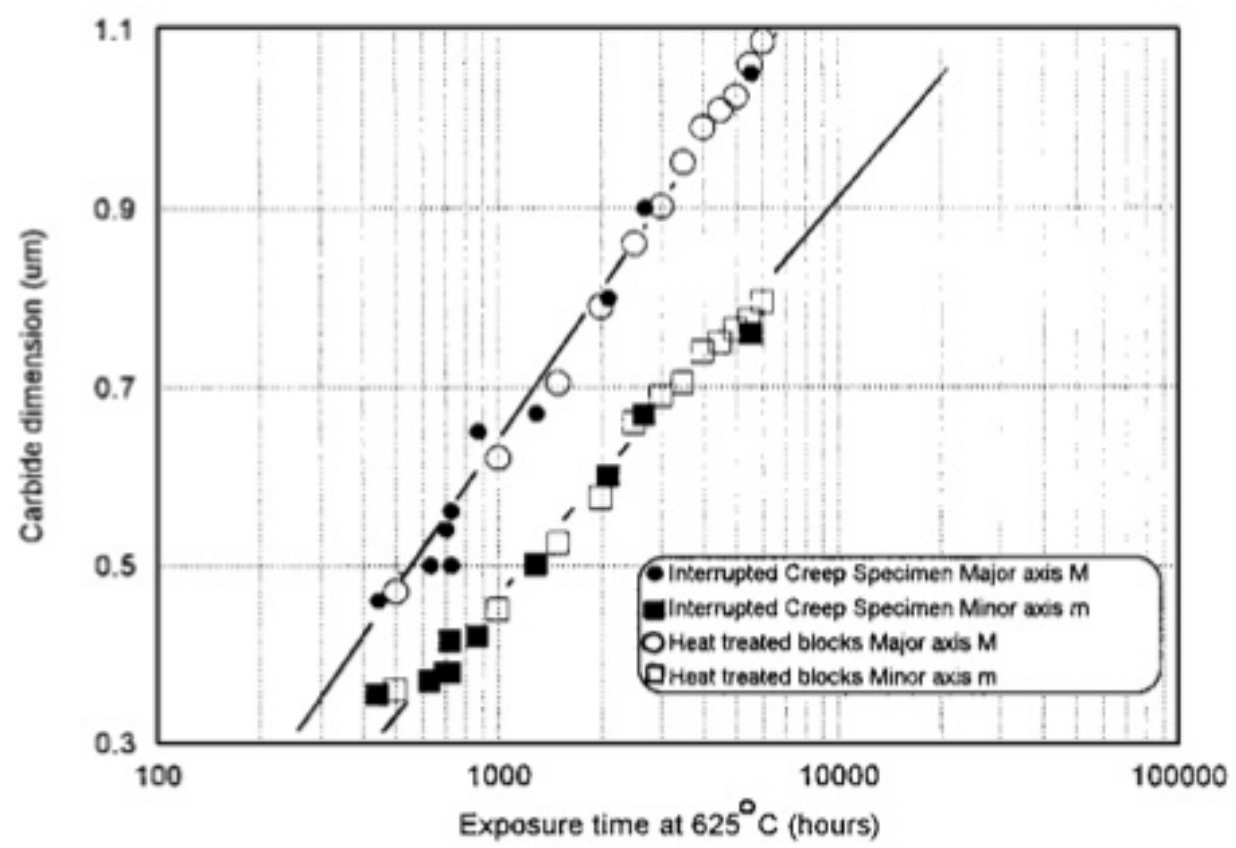

Figure 17. Variation in major and minor axes of the Type I carbides with aging time at $625^{\circ} \mathrm{C}$ for weld between $2.25 \mathrm{Cr}-1 \mathrm{Mo}$ steel and Inconel 182 filler metal. ${ }^{17}$

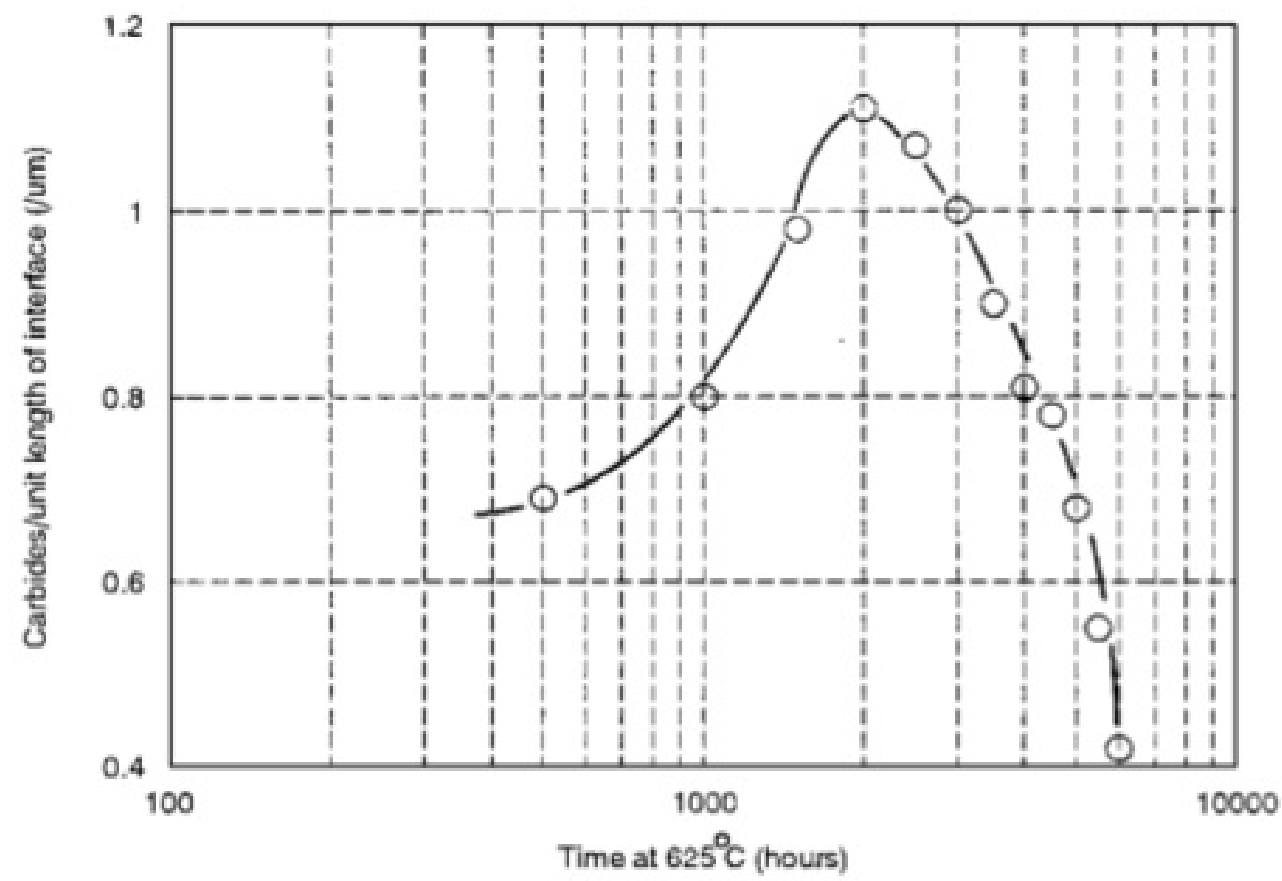

Figure 18. Variation in carbide density as measured by number of carbides per unit length for welds between $2.25 \mathrm{Cr}-1 \mathrm{Mo}$ steel and Inconel 182 filler metal. ${ }^{17}$ 
The change in carbide growth dimensions with time and temperature can be described using the well-known Wagner-Lifshitz expression ${ }^{40,41}$

$$
D^{3}=D_{o}^{3}+B t
$$

where $\mathrm{D}$ is the carbide diameter after some exposure time, $\mathrm{D}_{\mathrm{o}}$ is the original carbide diameter, $\mathrm{B}$ is a temperature-dependent material constant, and $t$ is time. Since the initial carbide size is small, and taking the temperature dependence of $\mathrm{B}$ into account, the carbide diameter can be expressed as

$D^{3}=k t \exp \left(\frac{-Q}{R T}\right)$

where $\mathrm{k}$ is a material constant, and $\mathrm{Q}$ is the activation energy for growth. Experimentally determined values for $\mathrm{k}$ and $\mathrm{Q}$ were developed for both the major $(\mathrm{M})$ and minor $(\mathrm{m})$ carbide axes $^{17}$ (for $\mathrm{M}: \mathrm{k}=$ $1.199 \times 10^{9} \mu \mathrm{m} \cdot \mathrm{mol} \cdot \mathrm{K} \cdot \mathrm{t}^{-1}$ and $\mathrm{Q}=279 \mathrm{~kJ} / \mathrm{mol}$, for $\mathrm{m}: \mathrm{k}=1.162 \times 10^{12} \mu \mathrm{m} \cdot \mathrm{mol} \cdot \mathrm{K} \cdot \mathrm{t}^{-1}$ and $\mathrm{Q}=257 \mathrm{~kJ} / \mathrm{mol}$ ). These values compare well with similar results, obtained by Viswanathan $e t$ al. ${ }^{39}$, that were acquired on service-exposed samples. Nicholson proposed a somewhat similar approach ${ }^{38}$, except he assumed that the carbide particles remained spherical during growth. As a result, his analysis generally underestimates the particle sizes when compared to data obtained from service exposed samples.

The evolution of microstructure in DMWs is summarized in Figure 19 and Figure 20 for the as-welded and aged condition. In the as-welded condition (Figure 19), there is a sharp concentration gradient within the PMZ that creates a zone of high alloy content (relative to $2.25 \mathrm{Cr}$-1Mo steel) and high hardenability. As a result, as-quenched martensite forms within the PMZ during cooling from the weld thermal cycle. As-quenched martensite also forms in the HAZ of the $2.25 \mathrm{Cr}$ - $1 \mathrm{Mo}$ steel. The regions of as-quenched martensite produce high hardness, but this hardness decreases sharply near the interface between the as-quenched martensite in the PMZ and the austenite region in the fusion zone. As shown in Figure 20, upon PWHT and/or aging in service, the concentration gradient for the major alloying elements will not change significantly because the diffusion rates of these elements are too low. However, the large change in $\mathrm{C}$ concentration, combined with the $\mathrm{Cr}$ concentration gradient, produces a $\mathrm{C}$ chemical potential gradient that is high in the ferritic steel and low in the austenitic steel. This leads to $\mathrm{C}$ migration from the $2.25 \mathrm{Cr}-1 \mathrm{Mo}$ steel toward the fusion zone. The $\mathrm{C}$ migration problem is more intense for welds made with stainless steel filler metals, and this can lead to a decarburized region in the ferritic steel that has reduced carbide content and low hardness. Such a zone is not always observed with nickel base filler metals (and is not shown in Figure 20). The PWHT and/or aging will temper the martensite and reduce the high hardness associated with regions that were originally as-quenched martensite. However, migration and concomitant enrichment of $\mathrm{C}$ leads to the formation of Type I and Type II carbides in the interface region that produce a very localized increase in hardness. As described above by the work of Gittos and Gooch ${ }^{12}$, it is also possible for as-quenched martensite to form upon cooling from the PWHT temperature. 


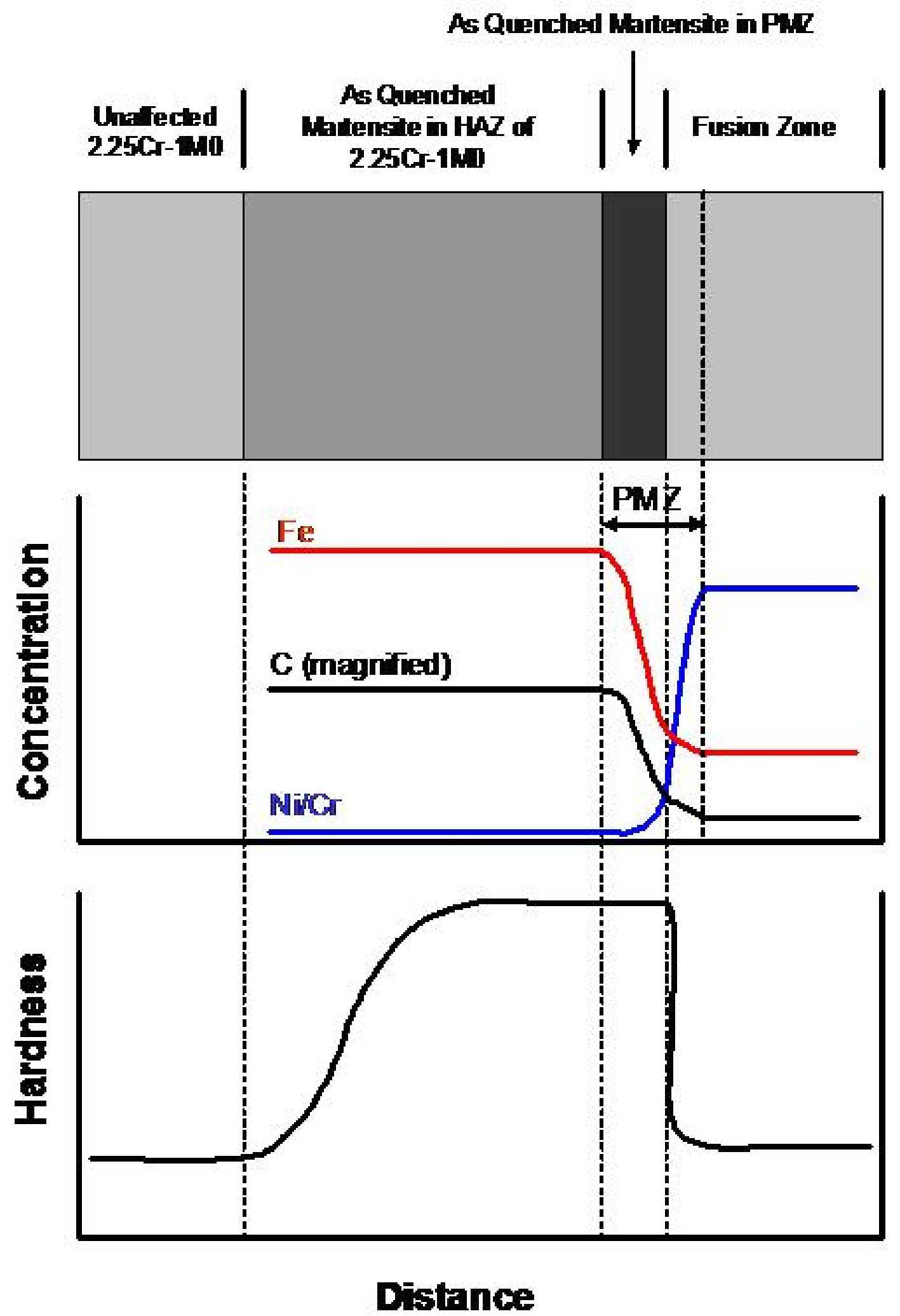

Figure 19. Schematic illustration showing the evolution of microstructure in dissimilar welds for the as-welded condition. 
Tempered Matensite wih Type 1 Cariles in FMR

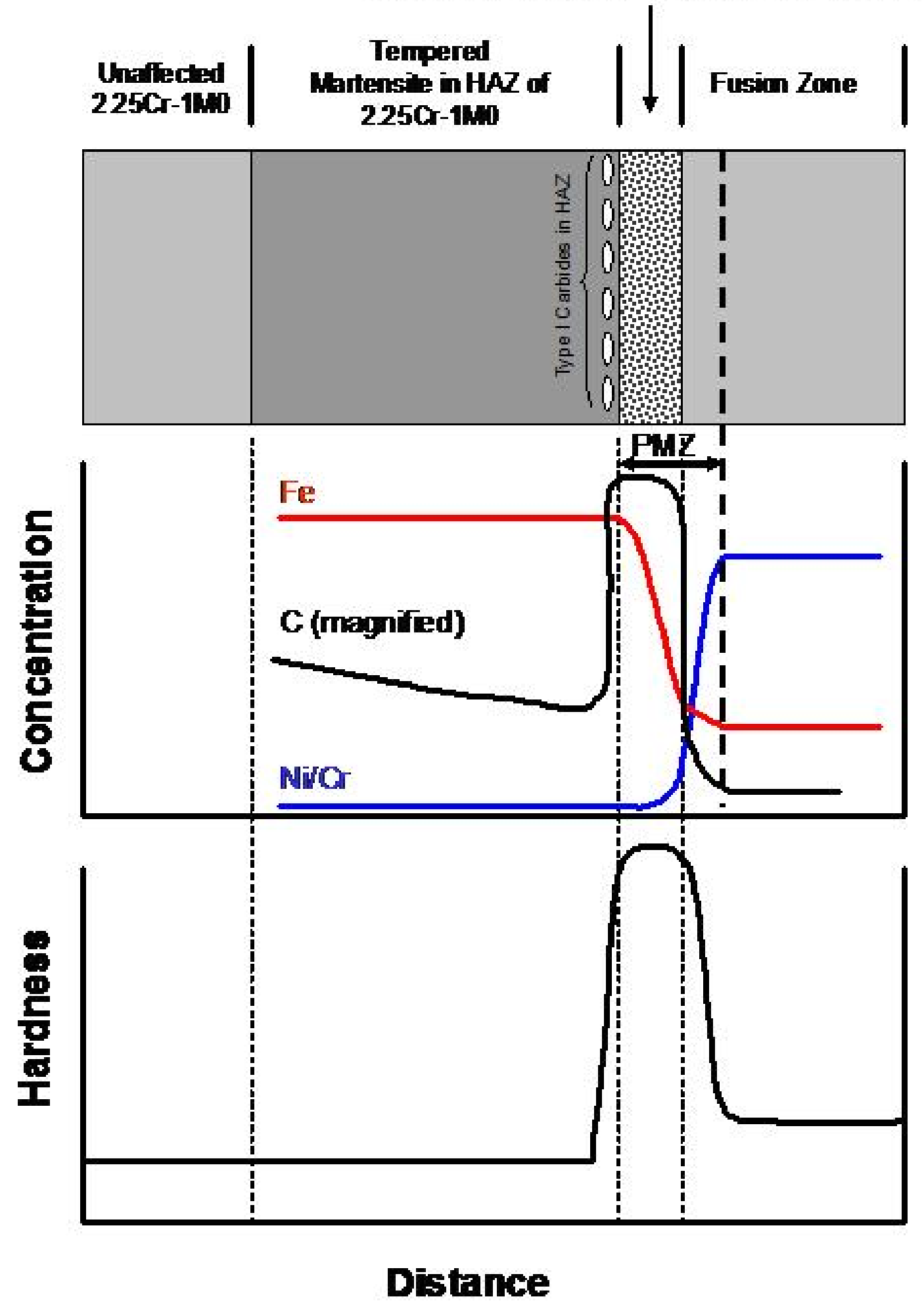

Figure 20. Schematic illustration showing the evolution of microstructure in dissimilar welds for the aged condition. 


\subsection{Failure Mechanism of DMWs}

Numerous investigations have been conducted of both service and laboratory-induced failures of DMWs $1,14,15,16,18,20,32,33,34,35,36,37,42,43,44,45,46,47,48,49,50,51,52,53,54$ and the failure mechanism is now largely understood. There are generally four factors that contribute to premature failure of DMWs during high temperature service:

1. The large difference in coefficient of thermal expansion (CTE) between the ferritic and austenitic alloys causes a significant stress concentration along the interface.

2. An oxide notch often forms on the ferritic side of the weld that can concentrate the stress even further. The oxide notch represents an area of localized oxidation that occurs near the fusion line of the ferritic steel that is driven by localized strain.

3. The highly localized change in composition and microstructure lead to large differences in creep strength near the interfacial region.

4. For DMWs prepared with nickel base filler metals, the Type I carbides that form along the interface provide a site for nucleation and growth of creep cavities that eventually lead to premature cracking. For DMWs made with stainless steel filler metals, cracking typically occurs along the prior austenite grain boundaries (PAGBs) in the ferritic HAZ at a location of about one or two grains away from the fusion line.

Figure 21 shows examples that highlight various features of DMW failures ${ }^{15,35,55}$. From a macroscopic view, failures occur at the fusion line on the ferritic side of the joint (Figure 21a). An example of oxide notching that can occur on the ferritic side, which leads to additional stress concentration, is shown in Figure 21b. The microstructural aspects of the failure are shown in Figure 21c and Figure 21d. Figure 21c shows the typical morphology observed for welds made with Ni base filler metals in which failure is initiated by nucleation and growth of creep cavities along the row of Type I carbides that form along the interface. Figure $21 \mathrm{~d}$ shows creep cavitation associated with PAGBs that occurs in welds made with stainless steel filler metals ${ }^{15,16}$. It is important to note that these failure mechanisms are not mutually exclusive. Failures of DMWs made with stainless steel filler metals can often exhibit oxide notches and cracking along both the PAGBs and Type I carbides. In addition, oxide notching can often be the major contributing factor, particularly in thin-walled tubing where the oxide notch can penetrate a significant thickness of the tube and lead to a considerable increase in the local stress.

Figure 22 shows the differences in CTE for a variety of materials pertinent to DMWs. Note that rather larger differences in CTE exist between the ferritic and austenitic alloys. This large difference in CTE, combined with the large differences in creep strength across the interface, lead to highly localized shear stresses along the fusion line ${ }^{56,57}$. These stresses can be exacerbated even further due to formation of the oxide notch that can develop in the ferritic side of the weld. The oxide notch has been attributed to the relatively poor oxidation resistance of the $2.25 \mathrm{Cr}-1 \mathrm{Mo}$ steel and localized strain near the fusion zone that can lead to repetitive oxide spallation ${ }^{33,42}$. Thus, thermal cycling can intensify this factor. 


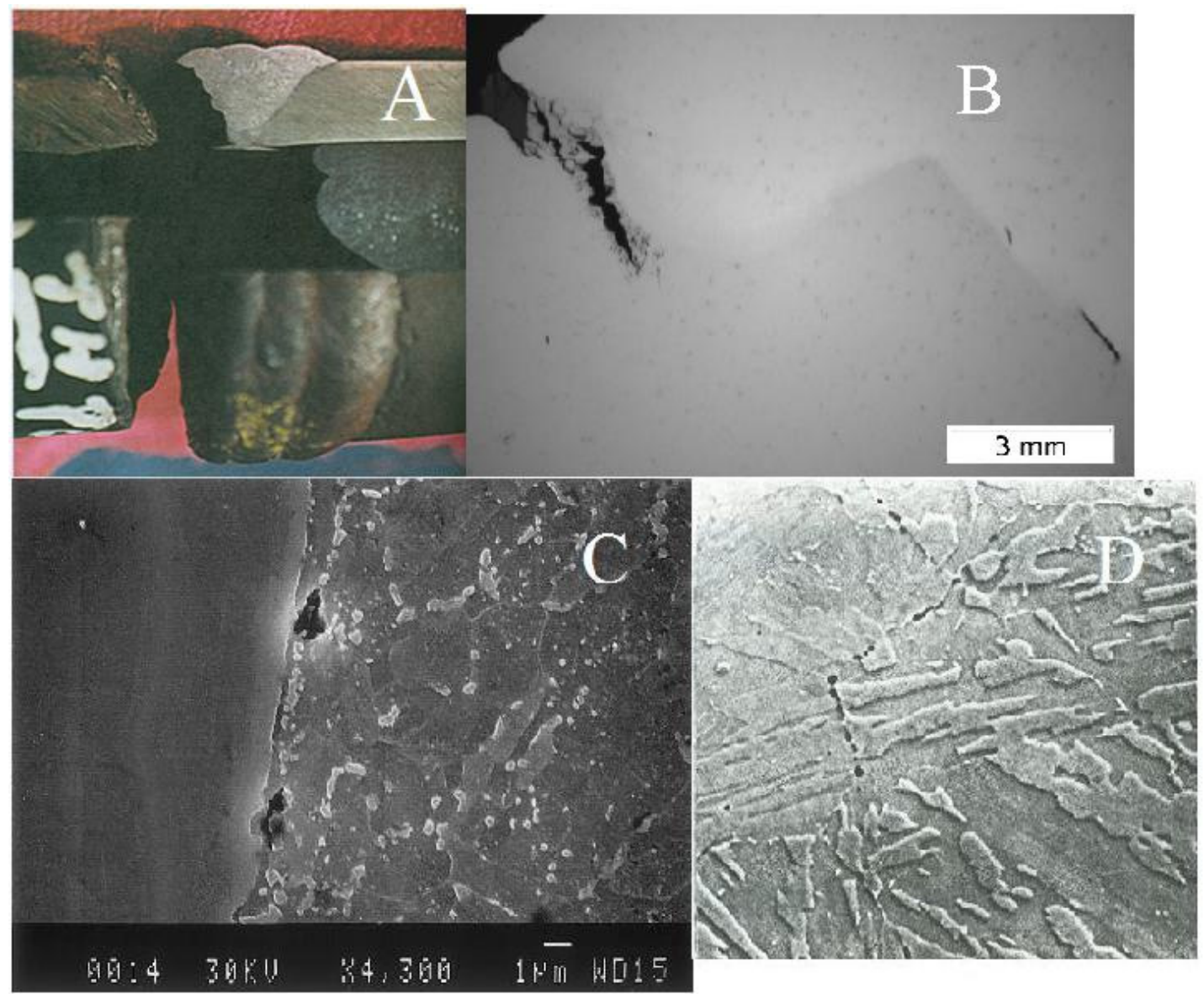

Figure 21. Features of dissimilar weld failures. a) photograph showing failure along the fusion line of the ferritic steel, b) example of oxide notching on the ferritic side of the weld, c) creep cavitation along the row of Type I carbides for welds made with Ni base filler metals, ${ }^{35} \mathrm{~d}$ ) creep cavitation associated with prior austenite grain boundaries in welds made with stainless steel filler metals.

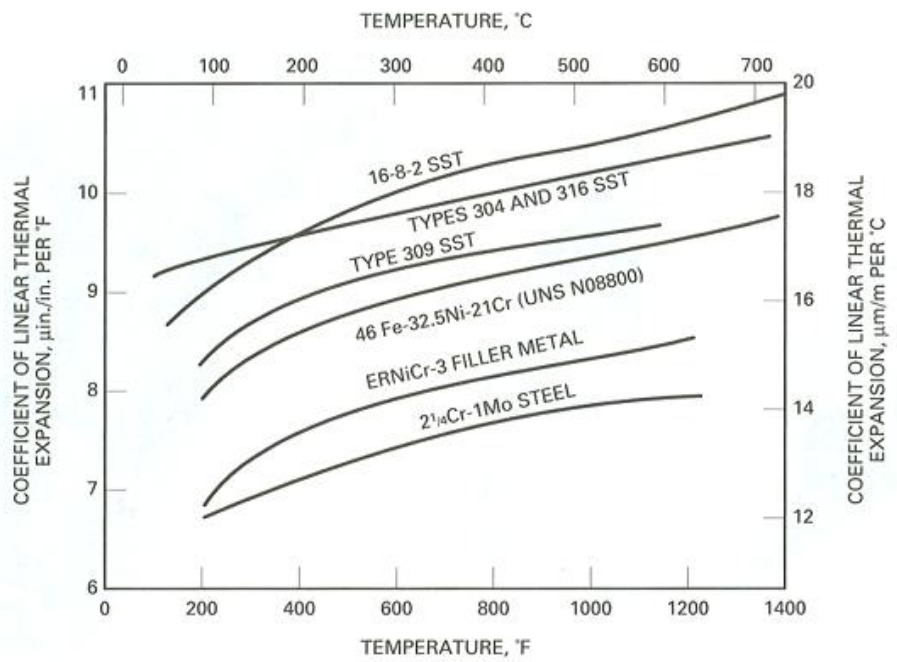

Figure 22. Variation in coefficient of thermal expansion for a variety of materials pertinent to dissimilar welds. ${ }^{56}$ 
Recent experimental studies ${ }^{8,34}$ have confirmed that most of the strain that occurs during creep deformation is associated with the localized strain near the interface. Figure 23 shows results from an instrumented creep test on a weld involving $2.25 \mathrm{Cr}-1 \mathrm{Mo}$ steel and Inconel 82 filler metal where the extension was measured globally (i.e., within the entire gage length) and locally along the interface. The extension near the interface was recorded at the top and side of the fusion line. Note that the amount of global and local extension during creep are very similar, which confirms that most of the strain is localized near the interface due to the large strength gradients at that location. The influence of environment on the creep behavior of DMWs is shown in Figure $24^{35}$. In these tests, welds involving $2.25 \mathrm{Cr}-1 \mathrm{Mo}$ steel and Inconel 82 filler metal were tested at $625^{\circ} \mathrm{C}$ and $60 \mathrm{MPa}$. Two samples were initially tested in air while one sample was coated (coating type not specified) to protect the surface from oxidation. Note the large differences in creep rate between the coated and exposed samples. After 356 hours of exposure, one of the originally uncoated samples was coated and reintroduced into the creep test. This led to a reduction of the creep rate. These results are significant in two aspects. First, they demonstrate that creep testing for purposes of acquiring design data need to be conducted in an environment that closely simulates that expected in service. Second, the results indicate that considerable improvements in creep resistance should be possible with the application of protective coatings. Unfortunately, this area has not received considerable attention.

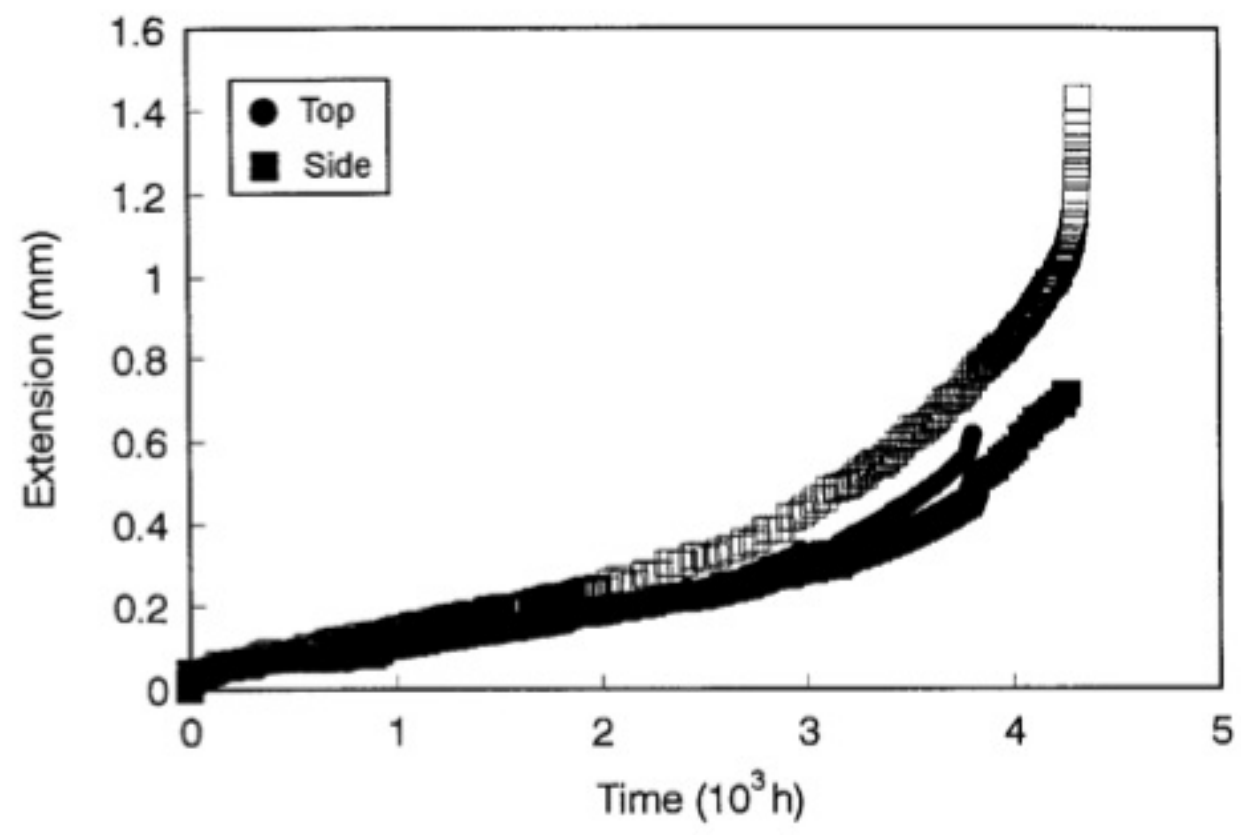

Figure 23. Results from instrumented creep test on a weld involving 2.25Cr-1Mo steel and Inconel 82 filler metal where the extension was measured globally (i.e., within the entire gage length) and locally along the interface. ${ }^{34}$ 

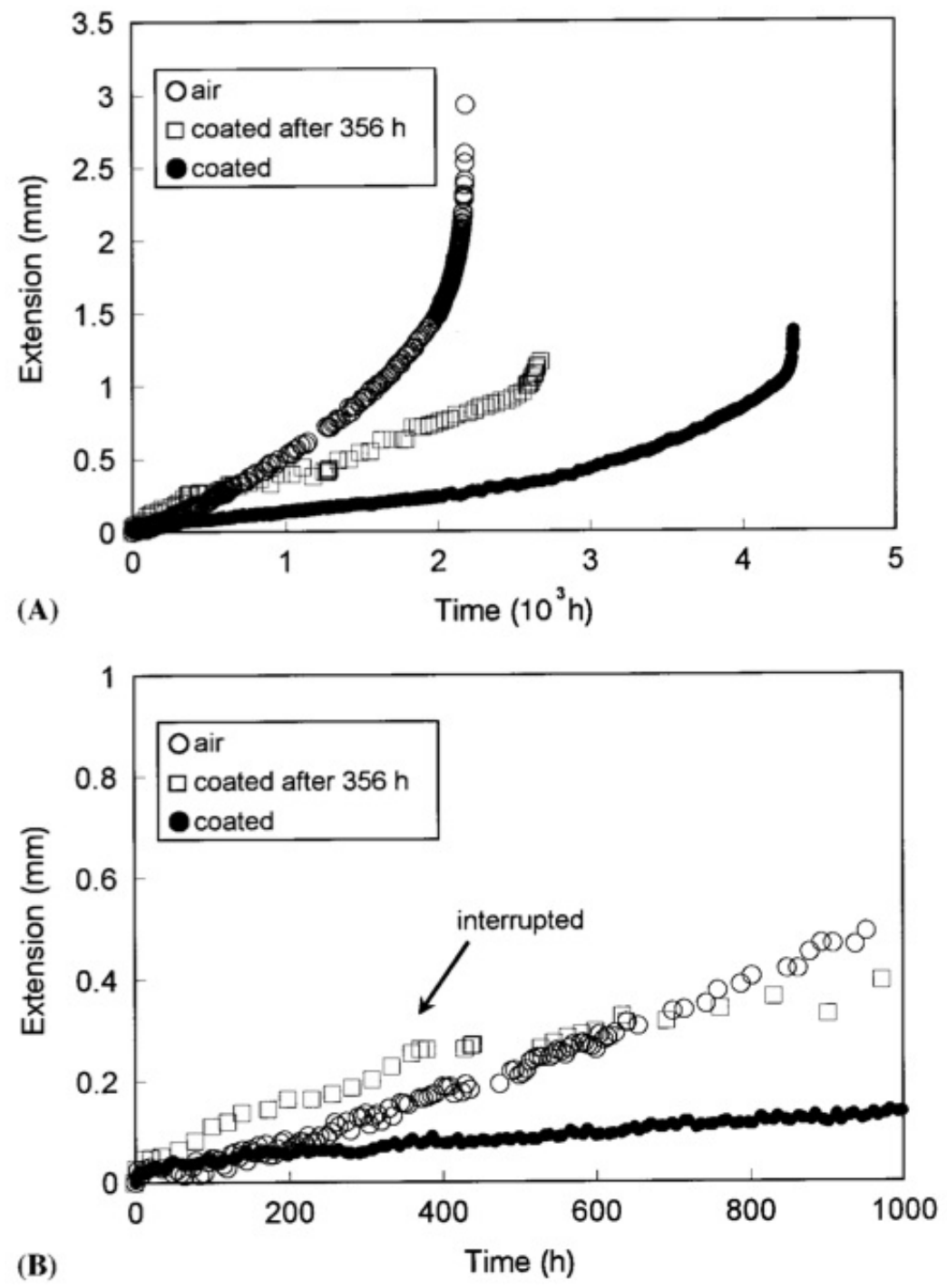

Figure 24. Results of creep tests on a weld involving 2.25Cr-1Mo steel and Inconel 82 filler metal showing the influence of environment on the creep behavior. ${ }^{35}$

It is important to note that there are various sources of stress beyond those due to normal operation that contribute to premature failures of DMWs and need to be considered from a design perspective ${ }^{16,36}$. The stress sources are typically divided into one of four categories:

1. Operating stresses that arise from pipe weight, internal pressure, and thermal gradients through the wall thickness

2. Self stresses that result from CTE mismatch and residual stresses from welding

3. System stresses that arise due to mechanical constraints of thermal expansion

4. Cyclic stresses due to thermal cycling that are induced due to CTE and strength mismatch

Most of the early premature failures of DMWs involved those in which ferritic steel was joined to stainless steel using a stainless steel filler metal. The service life of these welds can be reduced significantly due to the very large CTE mismatch coupled with rather intense C migration that produced 
both carbide formation (in the austenitic side of the interface) and decarburization (on the ferritic side of the interface). It was initially suspected that failure occurred within the decarburized region due to the relatively poor creep strength at that location. However, more detailed examinations acquired from service failures ${ }^{16,36}$ have demonstrated that failure is initiated along PAGBs in the ferritic steel HAZ (for welds made with stainless steel filler metals). Thus, although the presence of the $\mathrm{C}$ denuded zone may exacerbate the problem by producing steep gradients in strength mismatch along the interface, it is not a necessary condition for failure. The welding of ferritic to stainless steels is now done with the use of transition joints and Ni base filler metals. In this case, failure is initiated from the Type I carbides. One of the most commonly used joint designs is shown in Figure 25. An alloy $800 \mathrm{H}$ transition piece is inserted between the ferritic and stainless steel alloys. These alloys are joined with Ni base filler metal ERNiCr-3 (Inconel 82 solid filler metal for the gas tungsten arc welding and Inconel 182 coated electrode for shielded metal arc welding). Initially the alloy $800 \mathrm{H}$ to stainless steel weld was made using a stainless steel filler metal (as shown in the figure). However, this weld is now typically made with Inconel 82 or 182 filler metal.

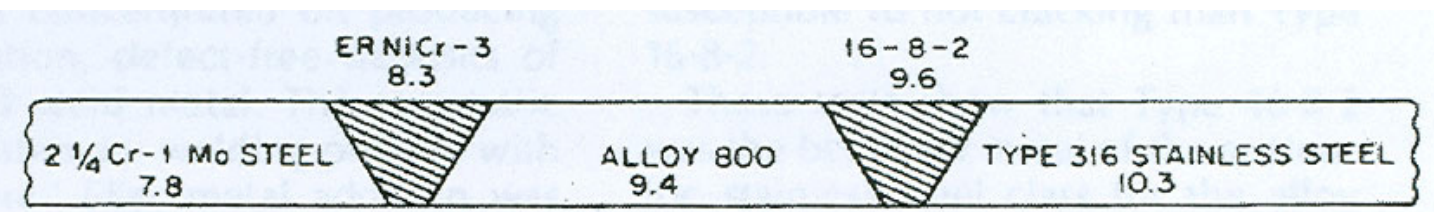

Figure 25. Schematic illustration of commonly used transition joint design for welding ferritic steels to austenitic stainless steels (the Alloy 800 to 316 weld is now typically made with Inconel 82 or 182 filler metal). ${ }^{56}$

There are two major advantages of this joint configuration. First, Figure 22 shows that alloy $800 \mathrm{H}$ provides an intermediate CTE to the $2.25 \mathrm{Cr}-1 \mathrm{Mo}$ steel and typical austenitic stainless steels, and the ERNiCr-3 filler metal provides an intermediate CTE to the $2.25 \mathrm{Cr}-1 \mathrm{Mo}$ and alloy $800 \mathrm{H}$ materials. Thus, the CTE mismatches are smoothed out to reduce the stress concentration along the interface. King et al. ${ }^{56}$ conducted finite-element analysis of the stresses that develop in these transition welds and compared the results to direct welds made between ferritic steels and stainless steels with ERNiCr-3 filler metal. The calculations were made for a pipe with a $600 \mathrm{~mm}$ outside diameter and $13 \mathrm{~mm}$ wall thickness operating at $512^{\circ} \mathrm{C}$ with an internal pressure of $1.38 \mathrm{MPa}$. An included angle of $75^{\circ}$ was considered for the joint design. A thermal gradient was simulated by a drop in temperature from $512^{\circ} \mathrm{C}$ to $343^{\circ} \mathrm{C}$ in 1000 seconds, with a maximum cooling rate of $1.1^{\circ} \mathrm{C} /$ second. Contributions to the stress from CTE mismatch, temperature gradients through the wall thickness, and internal pressure were considered. Only elastic deformation was included, and the joint was assumed to be stress-free at $732^{\circ} \mathrm{C}$, which is a typical PWHT temperature. The localized differences in creep strength across the interface due to decarburization and dilution were not considered. The results are shown in Figure 26 for the hoop stresses since they are the largest component of stress. The authors noted that the axial, radial, and shear stresses showed similar trends. 


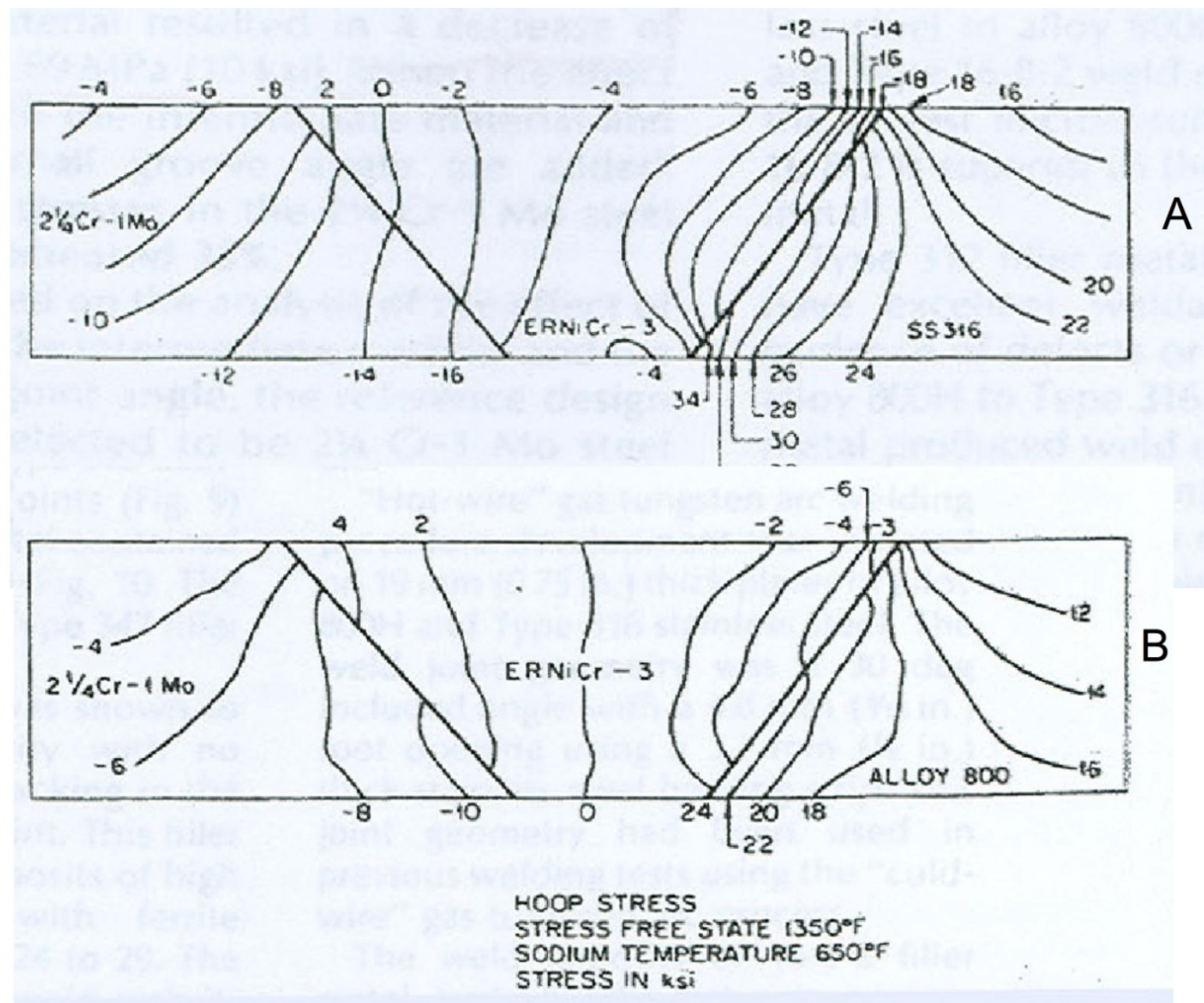

Figure 26. Finite element stress analysis results for welds made between ferritic steels and (a) 316 stainless steel with ERNiCr-3 filler metal and (b) alloy 800 with ERNiCr-3 filler metal. ${ }^{56}$

Note that the maximum tensile stresses are expected along the interface of the welds between the two austenitic materials, but failure is not observed along this interface in service. This demonstrates the importance of the complex microstructure in contributing to failure along the ferritic-to-austenitic fusion line. Although the overall stresses are lower along the interface between the ferritic-to-austenitic alloys, failure occurs there because of the susceptible microstructure that develops during welding and after aging. It is interesting to note that the stress state in the ferritic side of the joint is expected to be compressive based on these results. King et al. ${ }^{56}$ point out that, due to assumptions in the stress analysis, these values may not be highly accurate and should only be used for comparison purposes. In view of this, they note that about a $37 \%$ reduction in stress is possible with the alloy $800 \mathrm{H}$ transition piece. Also, note that the difference in stress across the interface is significantly reduced with the use of the alloy $800 \mathrm{H}$ transition piece. As shown in Figure 27, an industrial survey ${ }^{58}$ has shown that the use of the transition-joint design typically extends the service life of DMWs by a factor of approximately five compared to direct welds between ferritic and stainless steels made with stainless steel filler metals. A wide cap on the $2.25 \mathrm{Cr}-1 \mathrm{Mo}$ steel (in which the bevel angle of the joint is increased near the surface of the weld) has also been shown to provide further improvement, presumably due to a reduction in stress concentration along the interface. The wide cap is accomplished by simply increasing the bevel angle of the joint near the surface of the weld. Thus, the joint design shown in Figure 25 is often used in coal and nuclear power plants for optimization of DMW service life. In view of this, the DMW between alloy 
$800 \mathrm{H}$ and 2.25Cr-1Mo steel proposed as part of the HTGR steam generator is expected to provide longer life compared to direct welds made between ferritic and stainless steel alloys. However, it should be noted that failures often still occur prematurely in these transition joints, and further improvements in service life should be possible (as discussed in Section 2.8).

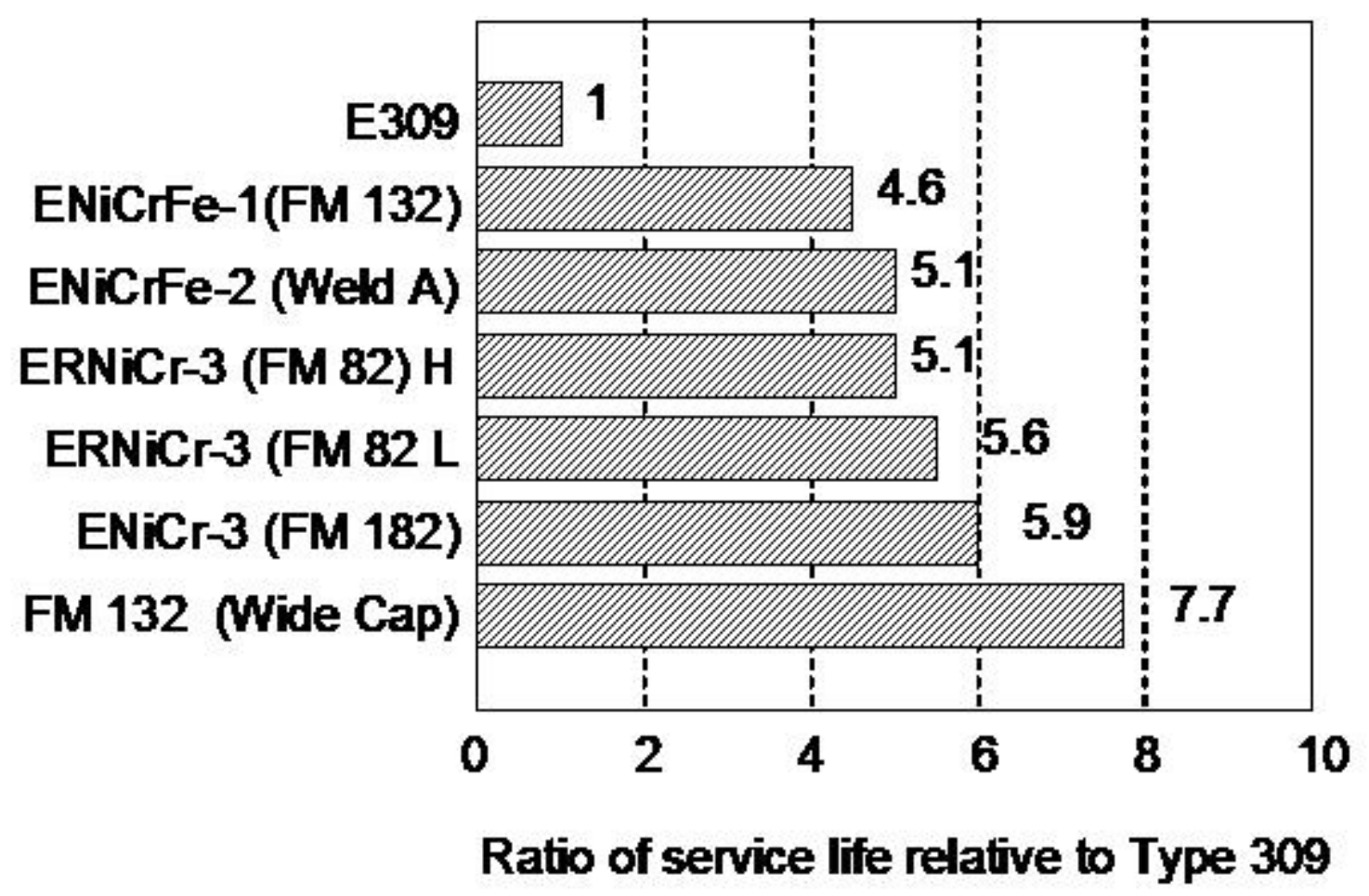

Figure 27. Results from an industrial survey showing the effect of filler metal on the service life of dissimilar welds (relative to 309 filler metal). ${ }^{58}$

\subsection{Creep Rupture Properties of DMWs}

Many investigators have attempted to develop creep-rupture data of DMWs in order to determine the effective service life for a given set of stress, temperature, and environmental conditions. A review of the data developed to date indicates this can be a difficult task due to the complex changes in microstructure that evolve during aging. Creep tests conducted at stresses significantly higher than those expected in service often produce short failure times in which the microstructure partially responsible for failure does not have enough time to properly develop. As a result, the failure mechanism observed in the field is not properly replicated in the laboratory and the usefulness of the data is therefore questionable. Similarly, the environment can play an important role in reducing the overall life due to preferential oxidation ${ }^{34,35}$ and other degradation mechanisms such as carburization and decarburization ${ }^{59}$. This effect can, in turn, be influenced by the test sample diameter when the size of the degraded zone becomes an appreciable fraction of the sample diameter. This raises the applied stress on the sample significantly beyond the nominal applied stress associated with the test. Creep tests conducted under parameters that more closely simulate the actual service conditions obviously provide data that are more accurate for life-time predictions, but these tests may be prohibitively long and expensive. In view of these factors, creep testing of DMWs requires careful consideration in order to utilize tests that provide meaningful data within reasonable test times. The data available are reviewed in this section for the purposes of: 1) comparing available creep rupture data of DMWs to that of existing data on 2.25Cr-1Mo base metal and welds that are used for design purposes; 2) identifying important factors that need to be considered in future testing; and 3) identifying methods that may provide improved performance. 
Laha et al. ${ }^{8}$ recently investigated the creep strength of welds between $2.25 \mathrm{Cr}-1 \mathrm{Mo}$ steel and alloy $800 \mathrm{H}$ at $550^{\circ} \mathrm{C}$ over stresses from 90 to $250 \mathrm{MPa}$. Comparison was made between $2.25 \mathrm{Cr}-1 \mathrm{Mo}$ similar welds and base metal. The welds were given a typical PWHT of $700^{\circ} \mathrm{C}$ for one hour prior to testing. Results of the rupture life and reduction in area are shown in Figure 28. Similar welds of 2.25Cr-1Mo steel typically exhibit reduced failure times compared to the base metal. This has been attributed to the inferior creep resistance of recrystalized grains in the intercritical portion of the HAZ. The dissolution of $\mathrm{Mo}_{2} \mathrm{C}$ carbides within this region during the weld thermal cycle has also been cited as a contributing factor to early fracture $e^{60}, 6162,63$. The DMW appears to provide better creep life than the similar weld at high stresses and short rupture times. However, at stresses below about $130 \mathrm{MPa}$, the life of the DMW is below that of the similar 2.25Cr-1Mo weld. A difference in failure mode of the DMW was also observed with changes in applied stress level. At stresses above $150 \mathrm{MPa}$, extensive necking of the ferritic steel was observed, and failure occurred in the intercritical region of the 2.25Cr-1Mo steel HAZ. As shown in Figure 28b, this produced failures with rather high ductility. At stresses below $150 \mathrm{MPa}$, failure occurred by intergranular creep cavitation in the coarse PAGBs of the $2.25 \mathrm{Cr}-1 \mathrm{Mo}$ steel with relatively little ductility. The low ductility occurs because most of the deformation is localized along the weld interface, which is typically observed in field failures.
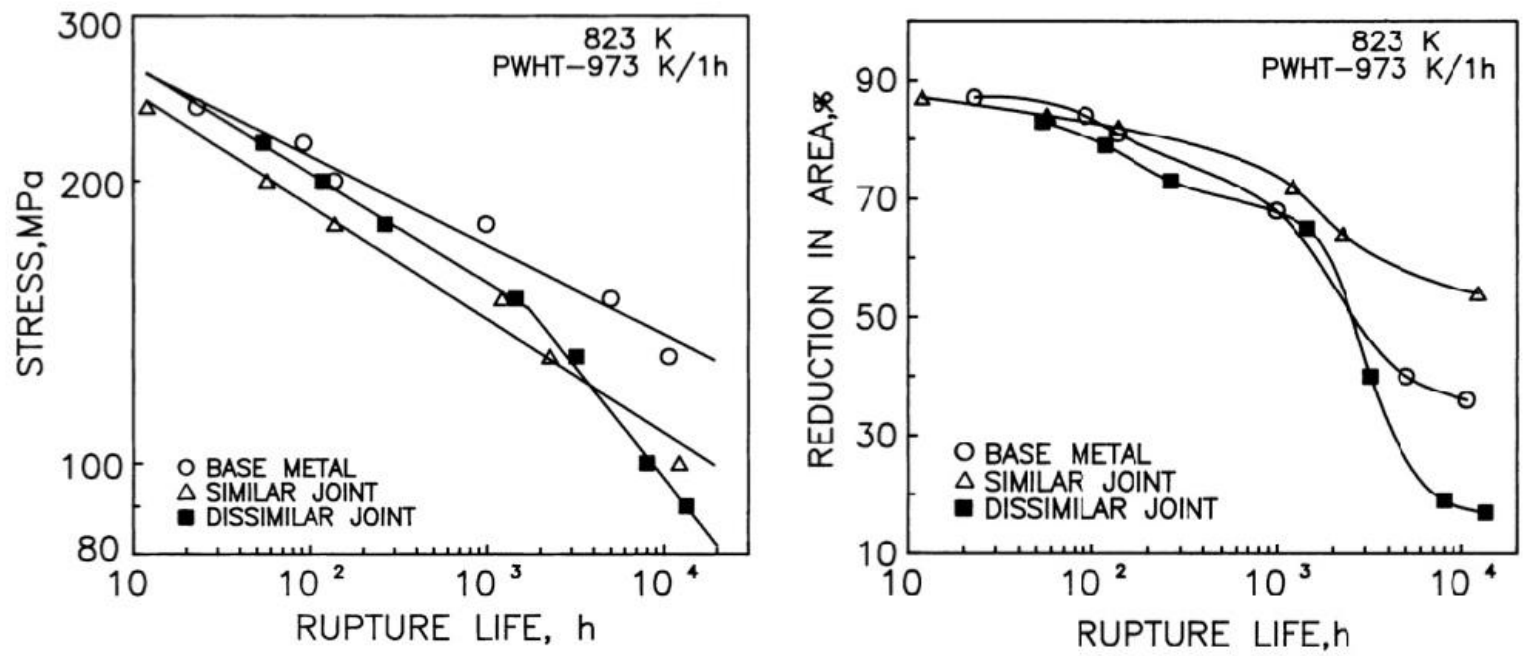

Figure 28. Creep life (a) and ductility (b) of welds between $2.25 \mathrm{Cr}-1 \mathrm{Mo}$ steel and alloy $800 \mathrm{H}$ at $550^{\circ} \mathrm{C}$ over stresses from 90 to $250 \mathrm{MPa}^{8}$

Fracture along the coarse PAGBs that occurred at the lower stress levels is similar to that which occurs in relatively short times in the field for welds made with stainless steel filler metals ${ }^{15,16,20}$ (see section 2.2 above). However, it is important to note that the observed failure modes associated with the data in Figure 28 at both low and high stresses does not properly simulate that observed in service for welds made with $\mathrm{Ni}$ base filler metals. (i.e., creep cavitation at Type I carbides). The authors noted that some creep cavities started to develop around the interfacial carbides, but these were not associated with the final fracture. This indicates that the stresses were too high, and the corresponding test times too low to permit development of the interfacial microstructure and stress state responsible for failures observed in the field.

Klueh and King ${ }^{42}$ conducted tests on the same DMW combination as part of a program associated with fabrication of the heat exchanger for the Clinch River Breeder Reactor Plant. The influence of various PWHT conditions and aging treatments on the creep properties of the joints at $510^{\circ} \mathrm{C}$ were evaluated. A summary of these test results is shown in Figure 29. Note that most of the applied stresses are well above $100 \mathrm{MPa}$. It is important to note that all but three samples exhibited high ductility failures (greater than $65 \%$ reduction in area) that occurred in the $2.25 \mathrm{Cr}-1 \mathrm{Mo}$ steel. Thus, these failures are not 
typical of those in service. Also, note that the effect of aging, either in the form of PWHT or artificial aging, is to reduce the rupture life. This occurs because the aging reduces the creep strength of the 2.25Cr-1Mo steel (where the failure occurs). The three samples that failed at longer times exhibited fractures near the fusion line in a fashion similar to that described above by Laha $e t a l .{ }^{8}$. Klueh and King suggested that the failure of DMWs under both test and plant conditions is dominated by oxide notch formation that is driven by a chromium-depleted region in the $2.25 \mathrm{Cr}-1 \mathrm{Mo}$ adjacent to the interface. As discussed above (section 2.2), the oxide notch can be an important factor in many DMWs, but it is not the primary cause of failure.

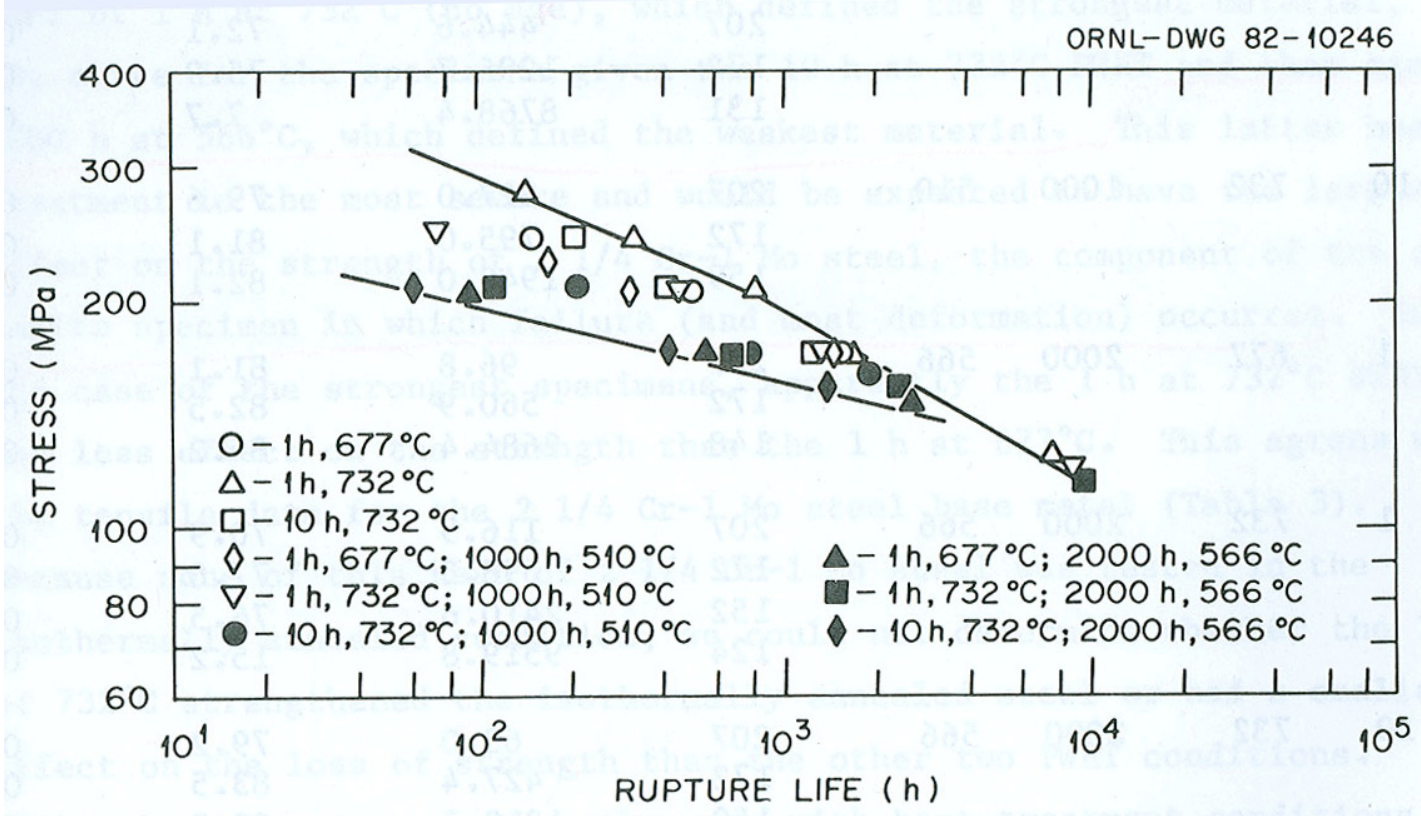

Figure 29. Influence of PWHT condition and aging treatments on the creep properties of $2.25 \mathrm{Cr}-1 \mathrm{Mo}$ steel/alloy $800 \mathrm{H}$ joints at $510^{\circ} \mathrm{C}$ (prepared with ERNiCr-3 filler metal). ${ }^{42}$

Parker and Stratford ${ }^{34,35}$ recently recognized the importance of test conditions for accurately simulating the failure mode observed in the field. They conducted tests at temperatures of 590,605, and $625^{\circ} \mathrm{C}$ and reduced stresses of 30-80 MPa. The reduced stresses were used in an attempt to provide increased failure lives and, thereby, more closely simulate the field-failure mode. The influence of aging was also considered. Samples were tested in the "new" condition, which only received a typical PWHT of $700^{\circ} \mathrm{C}$ for 3 hours. "Aged" samples were given the identical PWHT treatment in addition to a thermal treatment of $625^{\circ} \mathrm{C}$ for 3,500 hours. This treatment was done in order to nucleate and grow the Type I interfacial carbides that are known to induce nucleation and growth of the creep cavities that eventually lead to failure. Their data are provided in Figure 30. The new weld samples exhibited failure at the interface with very low ductility via creep cavitation along the Type I carbides for all stress and temperature combinations considered. The aged samples exhibited ductile failure (typically greater than $90 \%$ reduction in area) in the $2.25 \mathrm{Cr}-1 \mathrm{Mo}$ steel away from the weld area at stresses of $60 \mathrm{MPa}$ and above. At applied stresses of $50 \mathrm{MPa}$ and below, failure of the aged welds occurred by creep cavitation around the Type I carbides. Thus, the conditions of this test (below $50 \mathrm{MPa}$ ) most accurately simulate service failures. Examples of the macroscopic features of the failures are shown in Figure 31. Most of the failure times associated with these tests were between 1,000 and 10,000 hours, which are quite longer than those described above in the higher stress tests. 

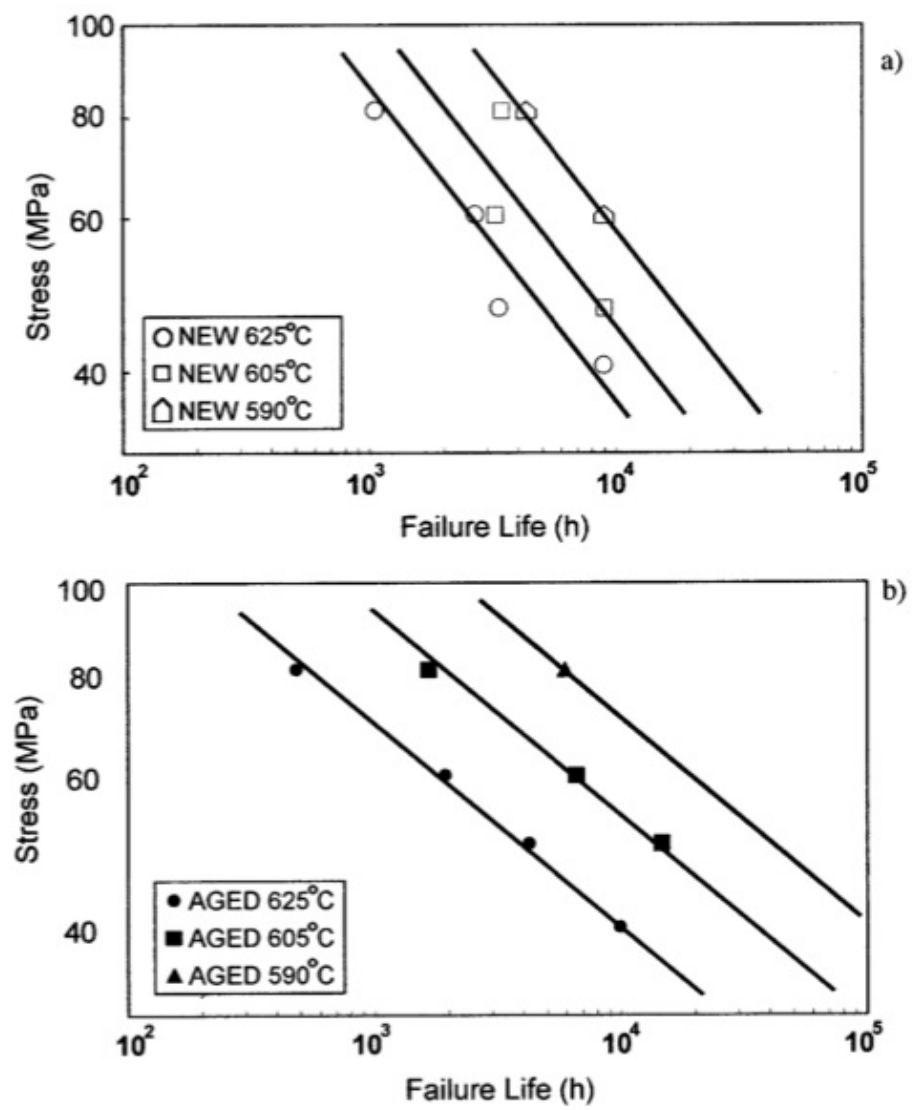

Figure 30. Results from creep tests at temperatures of 590,605 , and $625^{\circ} \mathrm{C}$ for welds between 2.25Cr-1Mo steel and 316 stainless steel made with Inconel 82/182 filler metal. a) "new" condition, b) "aged" condition. ${ }^{35}$

These results demonstrate the need for testing at low stresses and longer times in order to produce failure modes that match those in service. The difference in critical stress level required to replicate service failures was found to depend on the condition of the weld. Stress levels $\leq 50 \mathrm{MPa}$ were needed to simulate service failures in the aged welds, while stress levels $\leq 80 \mathrm{MPa}$ produced service-type failures in the new welds. This difference can be attributed to the tempering effect that the aging treatment had on the $2.25 \mathrm{Cr}-1 \mathrm{Mo}$ steel. Aging at $625^{\circ} \mathrm{C}$ for 3,500 hours decreases the creep strength of the ferritic steel. Thus, the higher stress levels produce considerable creep deformation in the aged ferritic steel, to the point where failure occurs by plastic instability associated with necking (Figure 31a). In the new samples, the creep strength of the $2.25 \mathrm{Cr}-1 \mathrm{Mo}$ steel is higher so that deformation is more localized along the interfacial region and leads to failure along this region (Figure 31b). It is important to note that, although actual service temperatures may be below the $590-625^{\circ} \mathrm{C}$ range considered in this work, the actual service lifetimes will be well beyond the aging and failure times of 3,500 to 10,000 hours, respectively. Thus, considerable softening of the $2.25 \mathrm{Cr}-1 \mathrm{Mo}$ steel in service is expected, and applied stress levels below 50-80 MPa should be included in future creep tests in order to simulate service-type failures. This aspect requires careful consideration when future test programs are developed for the DMWs in the HTGR steam generator. 


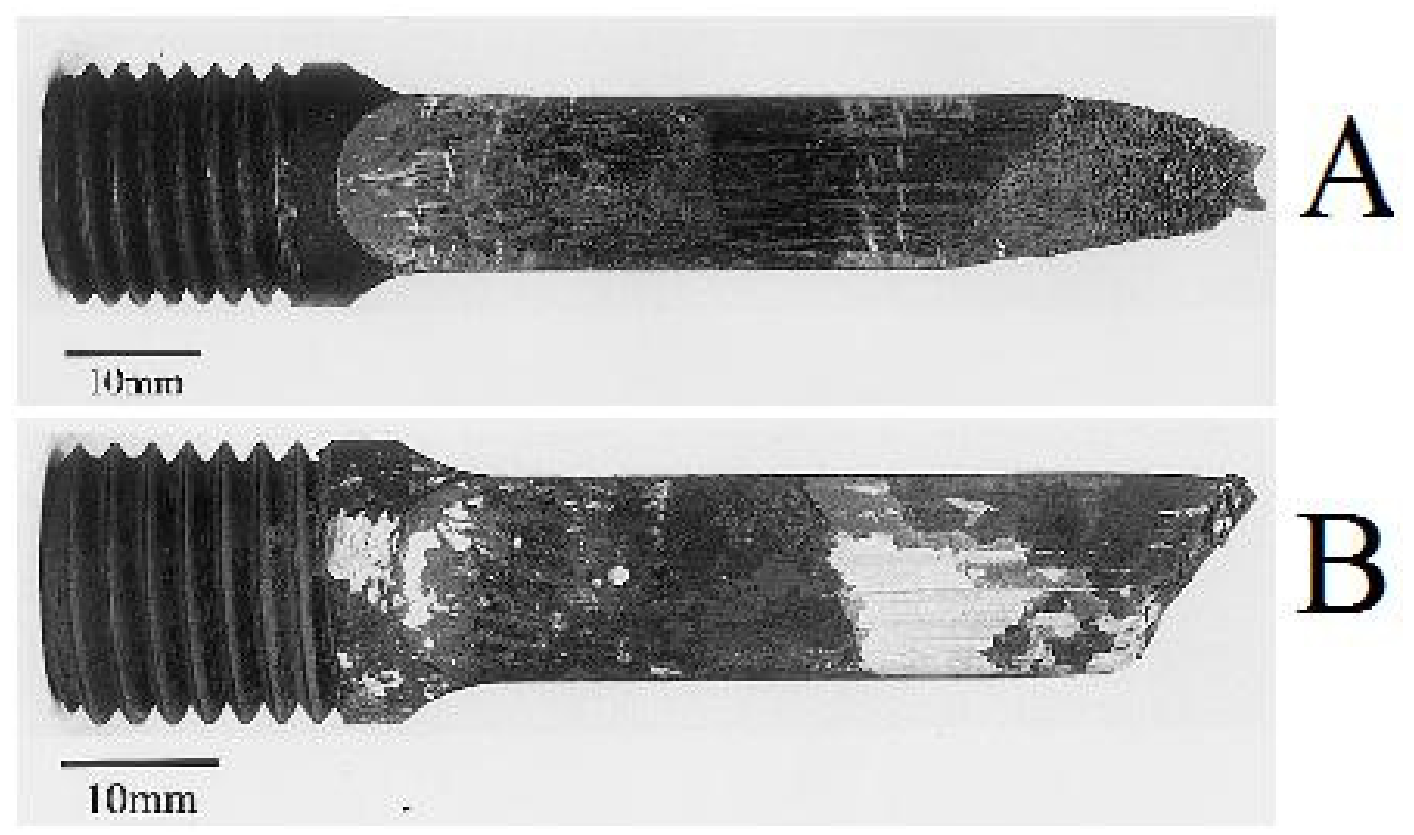

Figure 31. Photographs showing a) sample that exhibited ductile failure in the $2.25 \mathrm{Cr}-1 \mathrm{Mo}$ at elevated stress, and b) sample that failed along the interface with very low ductility via creep cavitation at low stress. $^{35}$

It was also interesting to note that there was relatively little difference in failure lives between the new and aged samples that fractured via creep cavitation. It might be expected that excessive PWHTs and/or thermal aging will accelerate formation of Type I carbides and therefore lead to premature failure times. The similarity in rupture lives between the new and aged welds indicates that pre-existing carbides do not accelerate creep cavitation. This implies that a critical amount of strain is required for creep cavitation to occur, and PWHT is not necessarily detrimental. The deleterious effects of PWHT cited to date $^{42}$ from laboratory tests can actually now be understood. Most of these data were generated for higher stress levels where failure occurred in the $2.25 \mathrm{Cr}$ - 1 Mo steel due to a reduction in creep strength, but this failure mode is not typical of that observed in service. Thus, when tests are conducted under conditions that properly simulate the DMW failure mode, PWHT does not appear to have a deleterious influence on service life.

Figure 32 shows additional creep data for temperatures between $580^{\circ}-625^{\circ} \mathrm{C}$, and Figure 33 shows creep-rupture data in the form of a Larson-Miller plot for DMWs from a wide range of sources ${ }^{16}$. Many of the welds were made using Inconel-type filler metal that is similar to that used for joining $2.25 \mathrm{Cr}-1 \mathrm{Mo}$ to alloy $800 \mathrm{H}$. Thus, the data are useful for the HTGR steam generator design. The low stress/long time data are particularly useful since these samples generally simulate the interfacial failure mechanism observed in the field. Data for the 2.25Cr-1Mo steel base metal and Inconel 182 filler metal are shown in Figure 33 for comparison. Note that the reduction in failure life for the DMWs compared to the $2.25 \mathrm{Cr}-1 \mathrm{Mo}$ steel base metal increases as the stress level is reduced. 


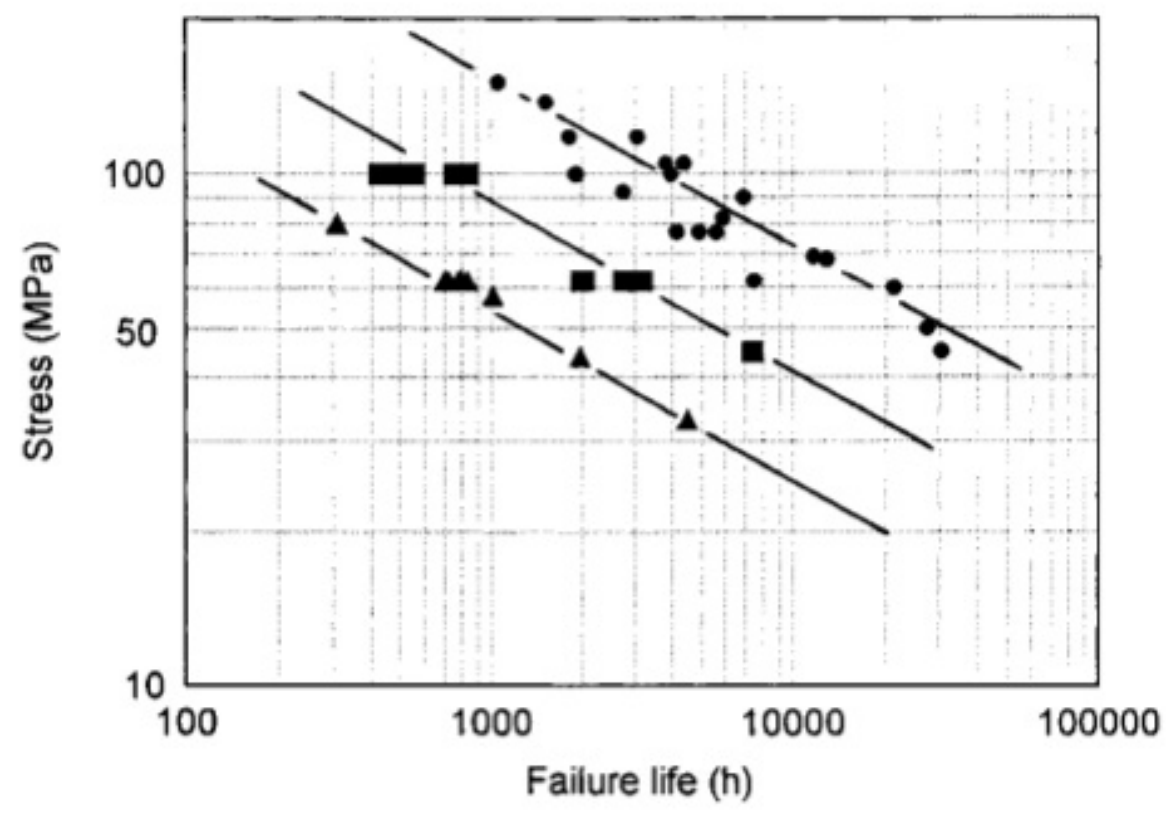

Figure 32. Creep rupture data for dissimilar welds involving ferritic steel and Inconel type filler metals. ${ }^{16}$

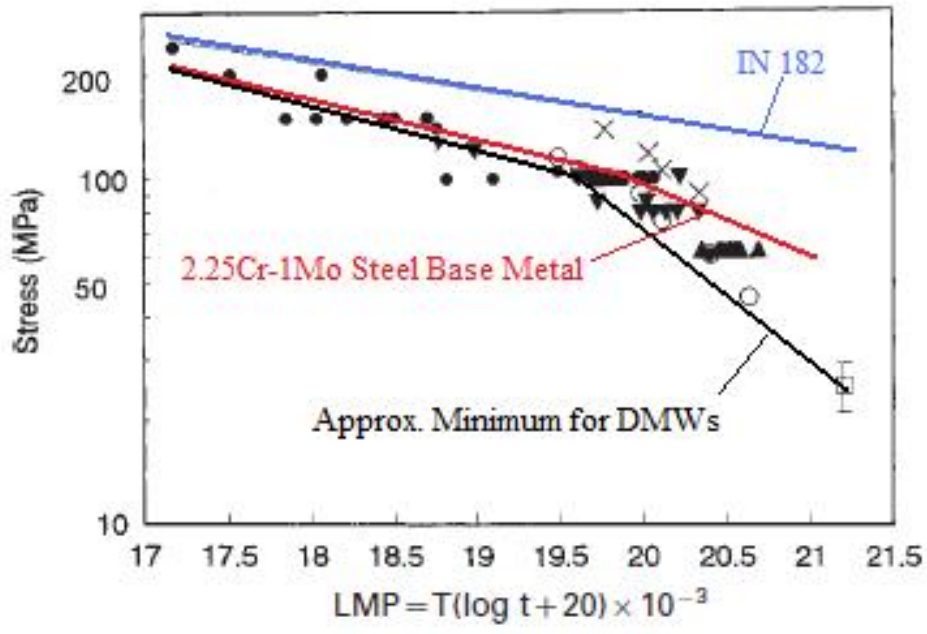

Figure 33. Larson-Miller plot of creep rupture data for a wide range of dissimilar welds involving ferritic steel and Inconel-type filler metals. ${ }^{16}$

The data provided in Figure 32 and Figure 33 require comparison with other well-established creep data for a meaningful interpretation of the results. In view of this, the large database of creep data recently reviewed $^{64}$ for $2.25 \mathrm{Cr}-1 \mathrm{Mo}$ base metal and welds is quite useful. Use of the $2.25 \mathrm{Cr}-1 \mathrm{Mo}$ data set is justified as a basis for comparison for the HTGR steam generator because the DMW between alloy $800 \mathrm{H}$ and $2.25 \mathrm{Cr}-1 \mathrm{Mo}$ steel is expected to be located within a region where the $2.25 \mathrm{Cr}-1 \mathrm{Mo}$ steel will provide adequate service life. Thus, the creep life of the DMW should be compared to that of $2.25 \mathrm{Cr}-1 \mathrm{Mo}$ steel base metal and welds. An example of typical creep rupture data ${ }^{64}$ is shown in Figure 34 and Figure 35 for temperatures of $593^{\circ} \mathrm{C}\left(1100^{\circ} \mathrm{F}\right)$ and $621^{\circ} \mathrm{C}\left(1150^{\circ} \mathrm{F}\right)$. Shown on each Figure is the minimum stress-rupture curve for the base metal according to data from Code Case N-47 of the American Society of Mechanical Engineers (ASME). (It is recognized that Code case N-47 is now replaced by Subsection 
NH. The document is used here only for utilizing the large amount of creep data that is associated with that document.) Also shown on each plot are the reduction-factored values of the minimum stress rupture curve for the weld metal. Figure 36 shows a very large range of data for both base metal and weldments plotted according to the Larson-Miller parameter. The ASTM/ASME minimum curve provided in Figure 36 is the same curve as the minimum stress-rupture curve for the base metal that is shown in Figure 34 and Figure 35 and is also the same curve for the 2.25Cr-1Mo steel shown in Figure 33. The large range of data and minimum values provided in these figures provide a useful basis for comparison to data available for DMWs. These comparisons are provided in Figure 34 and Figure 35, where the trend lines for the various test temperatures from Figure 32 are superimposed on the $2.25 \mathrm{Cr}-1 \mathrm{Mo}$ data.

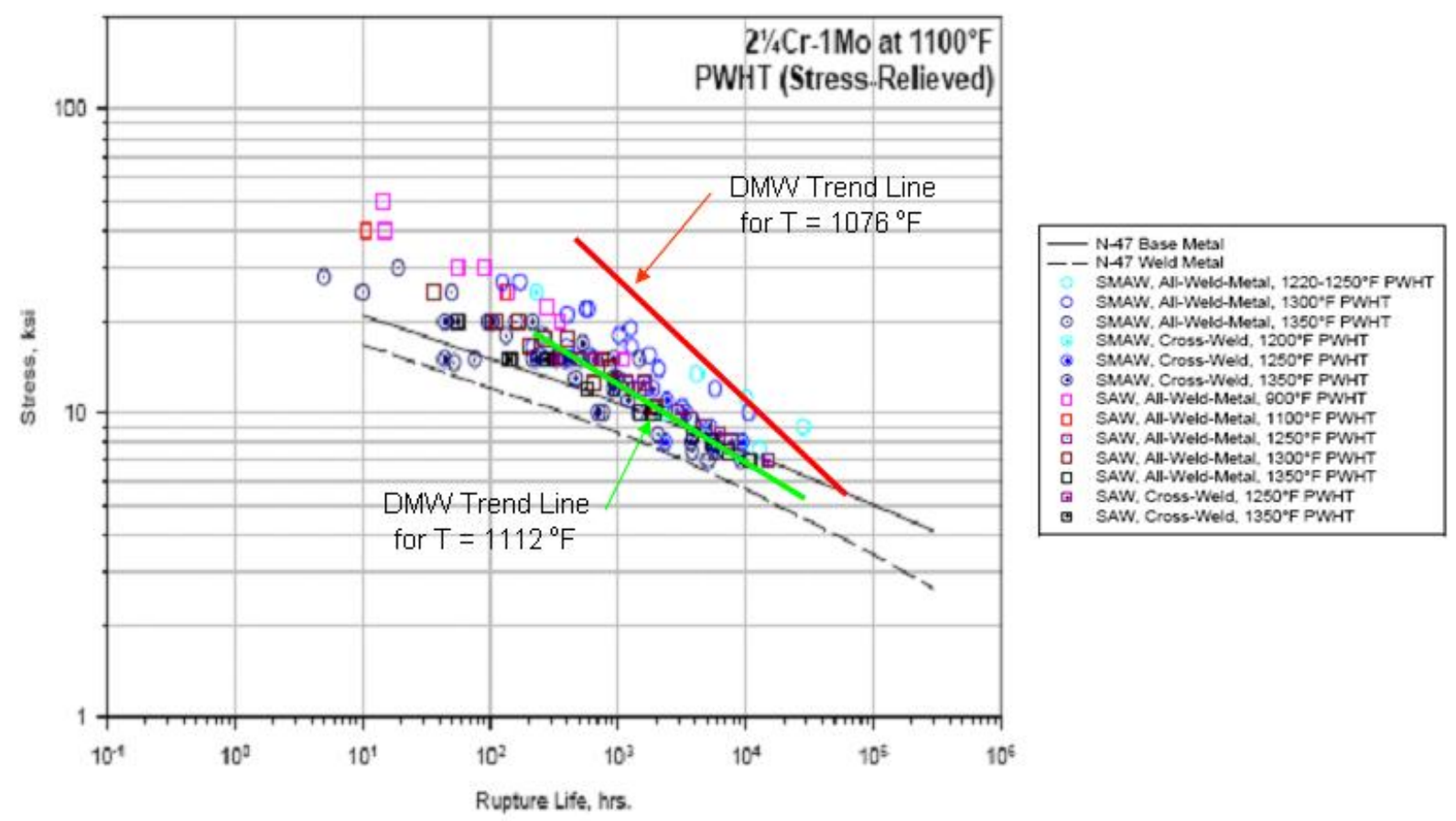

Figure 34. Creep rupture data for $2.25 \mathrm{Cr}-1 \mathrm{Mo}$ base metal and welds at $593^{\circ} \mathrm{C}\left(1100^{\circ} \mathrm{F}\right)$. Also shown is the minimum stress rupture curve for the base metal according to data from Code Case N-47 of the American Society of Mechanical Engineers (now replaced by Subsection NH) along with the reduction-factored values of the minimum stress rupture curve for the weld metal. Trend lines for dissimilar welds from Figure 32 are also shown for comparison. ${ }^{64}$ 


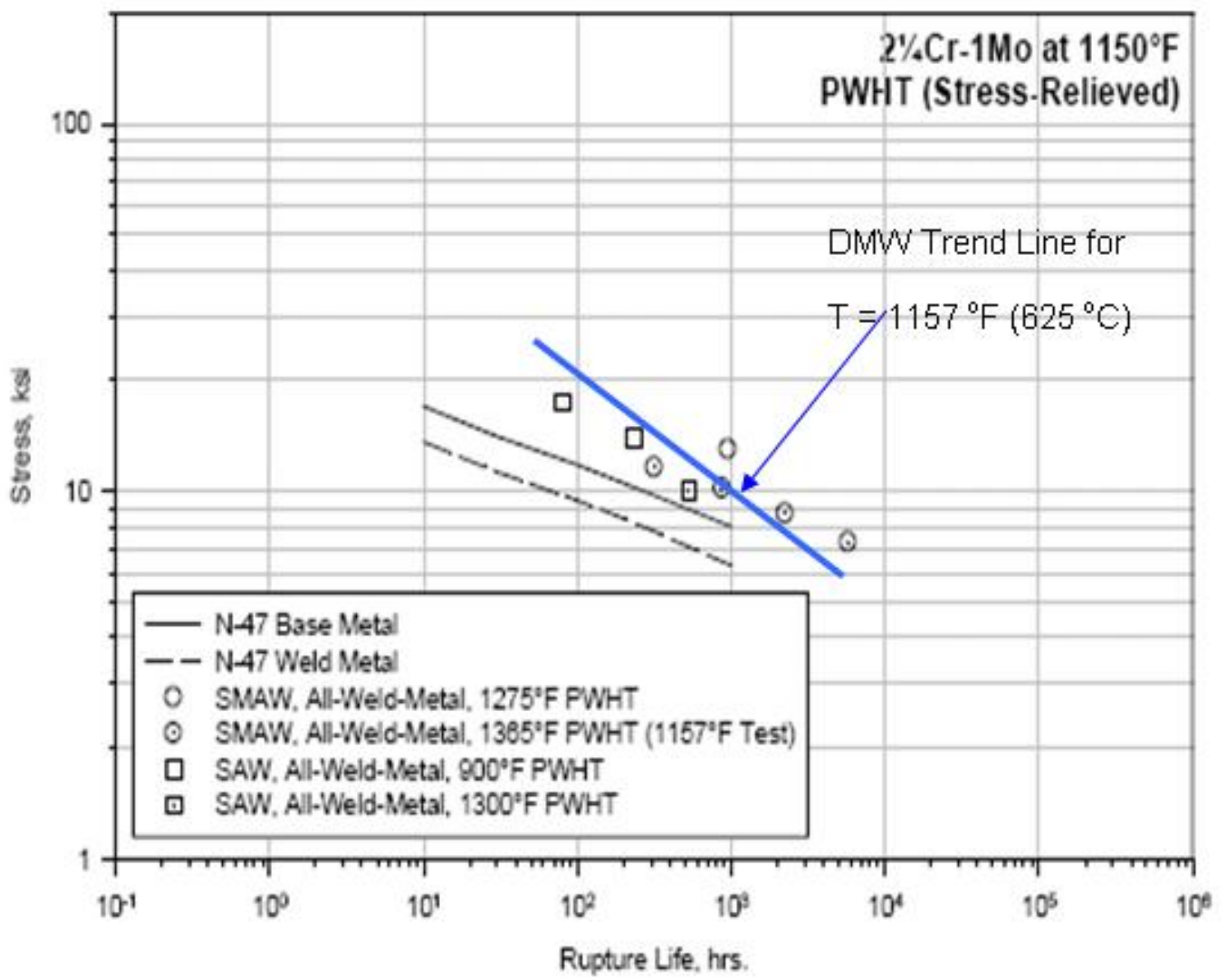

Figure 35. Creep rupture data for $2.25 \mathrm{Cr}-1 \mathrm{Mo}$ base metal and welds at $621^{\circ} \mathrm{C}\left(1150^{\circ} \mathrm{F}\right)$. Also shown is the minimum stress rupture curve for the base metal according to data from Code Case N-47 of the American Society of Mechanical Engineers (now replaced by Subsection NH) along with the reduction-factored values of the minimum stress-rupture curve for the weld metal. Trend line for dissimilar welds from Figure 32 is also shown for comparison. ${ }^{64}$ 


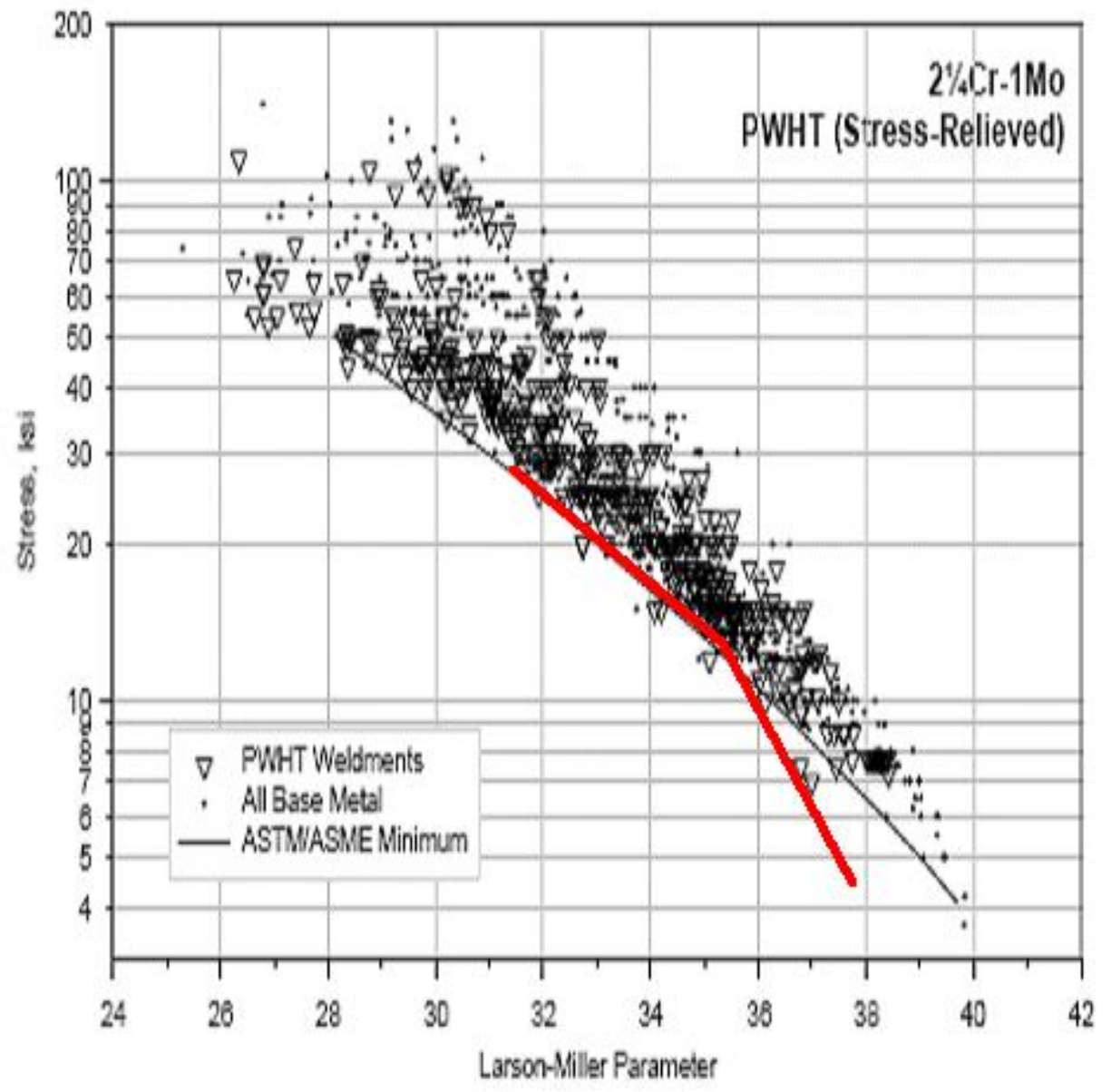

Figure 36. Creep rupture data for 2.25Cr-1Mo base metal and weldments plotted according to the Larson Miller parameter. The ASTM/ASME minimum curve provided is the same curve as the minimum stress-rupture curve for the base metal shown in Figures 34 and 35, and is also the same curve for the 2.25Cr-1Mo steel shown in Figure 33. The minimum trend line for dissimilar welds shown in Figure 33 is also shown for comparison. ${ }^{64}$

Direct comparison of the data in these figures is somewhat complicated since the tests for the 2.25Cr-1Mo steel and DMWs were conducted at slightly different temperatures, but the comparisons are still quite useful. Examination of the data clearly indicates that the failure time of the DMWs becomes increasingly lower than that for the $2.25 \mathrm{Cr}-1 \mathrm{Mo}$ steel as the stress is reduced. It is also significant to note that these lower stresses are most representative of those expected in service. Although two of the three data sets for the DMWs were acquired at slightly higher temperatures than those used for the $2.25 \mathrm{Cr}-1 \mathrm{Mo}$ steels, the small differences in temperature of 7 and $12^{\circ} \mathrm{F}$ are not likely to account for the rather large difference in creep life at the lower stresses. A similar trend is provided with the results shown in Figure 33 and Figure 36. Again, the minimum ASTM/ASME trend line for 2.25Cr-1 Mo steel is provided in each figure. An approximate minimum trend line was also established from the data for DMWs shown in Figure 33, and this line is superimposed on the 2.25Cr-1Mo data in Figure 36. Note that the separation between the minimum trend lines increases as the stress is reduced, indicating that the creep life of the DMWs is expected to be significantly less than that of the $2.25 \mathrm{C} 5-1 \mathrm{Mo}$ steel at stresses typical of service. 
The large scatter in creep data observed for both the 2.25Cr-1Mo steel and DMWs is common and can be attributed to differences in test conditions and sample attributes. In view of this, it is useful to consider additional factors beyond stress and temperature that will influence the creep rupture life of DMWs. This information could be useful for future test programs in order to improve the consistency of results between various laboratories and also establish the relative influence of secondary factors on creep life. This latter point could also be useful for improving the performance of DMWs in service. Some of the important secondary factors that affect the creep life include the test environment (e.g., air vs. inert atmosphere), sample size, groove angle of the weld, and filler metal composition. As previously discussed, the test environment can clearly have a large influence on the creep-rupture time through formation of an oxide notch. The effect can be particularly strong at high temperatures and small sample sizes. High temperatures can induce an artificially high effect from the oxide notch because the oxidation rate increases rapidly with increasing temperature. In addition, the oxide will form a larger stress concentration and produce an overall increase in the applied stress as the sample size is reduced. This influence is observed in field failures, where oxide notching can play a significant role in failures of thin--walled tubes, but becomes less important for heavy wall pipes. This points to the need to develop coatings that could be used to eliminate the oxide notch effect, which would provide two advantages. First, it could lead to improvements in creep life, particularly for thin-walled tubing. Second, it would permit test results conducted in inert environments (or on coated samples) to provide a more accurate representation of the performance expected in service.

The influence of weld-groove angle on creep life appears to warrant further consideration. The results of finite-element modeling by King et al. ${ }^{56}$ suggest that the peak stresses in the weld can be reduced with a reduction in the weld-groove angle. However, as previously discussed, industrial experience suggests that wider groove angles improve service life. It is interesting to note that review of the large database for $2.25 \mathrm{Cr}-1 \mathrm{Mo}$ steels ${ }^{64}$ also did not reveal any systematic influence of weld-groove angle. Future work that combines finite element modeling with experimental verification for the DMWs of interest appears necessary to resolve this issue. The influence of filler metal type is now established in detail and has already been discussed. Ni base filler metals provide a significant increase in life over stainless steel filler metals due to reduced $\mathrm{C}$ migration and improved CTE matching. Currently, DMWs are typically made by joining the 2.25Cr-1Mo steel to alloy $800 \mathrm{H}$ using Inconel 82 (for GTAW) and Inconel 182 (for SMAW). However, much of the data currently available was generated using a wide variety of both stainless steel (for older creep data) and $\mathrm{Ni}$ base filler metals (for newer data). In addition, the exact alloys utilized to fabricate the DMW samples can vary widely among researchers. For example, some welds were made directly between 2.25Cr-1Mo steel and stainless steel using a Ni base filler metal while others were fabricated with an alloy $800 \mathrm{H}$ transition piece. There are also variations in the end-member alloy for samples that include an alloy $800 \mathrm{H}$ transition section. For laboratory samples that properly simulate creep fractures in the field, failure occurs along the fusion line between the $2.25 \mathrm{Cr}-1 \mathrm{Mo}$ and alloy $800 \mathrm{H}$. In view of this, variations in the end-member alloys may not have a significant effect. On the other hand, differences in creep properties along the joint are known to be a contributing factor to failure because they can lead to strain accumulation along the interface. This area also appears to warrant further attention and should be considered when comparing creep data from samples with different end members.

\subsection{Aging Behavior of ERNiCr-3 Filler Metal}

Inconel alloys 82 and 182 (which conform to American Welding Society ERNiCr-3 filler metal specifications) are currently the most commonly used filler metals for DMWs. It is important to note, however, that the ERNiCr-3 weld metal will also undergo microstructural changes during high-temperature aging that have been shown to effect the low-temperature mechanical properties of the weld. This has been investigated by Klueh and King ${ }^{65,66}$ and more recently Sireesha et al. ${ }^{18,67}$. Klueh and King ${ }^{65}$ aged ERNiCr-3 weld metal for temperatures between 510 and $677^{\circ} \mathrm{C}$ for up to 15,000 hours. The influence of aging time and temperature on the yield strength and ductility are shown in Figure 37, where a significant increase in strength and reduction in ductility is observed during aging. Siressha et al. ${ }^{18,67}$ 
observed a similar effect on the toughness of welds made between $9 \mathrm{Cr}-1 \mathrm{Mo}$ steel and alloy $800 \mathrm{H}$ using ERNiCr-3 filler metal that were aged at $625^{\circ} \mathrm{C}$ for up to 5,000 hours. The changes in hardness and impact toughness of the welds are shown in Figure 38, where an increase in hardness and reduction in impact toughness are readily apparent. The notches for the charpy impact tests were placed in the fusion zone, where the weld metal resides. Thus, the results can be compared with the all-weld-metal data in Figure 37.
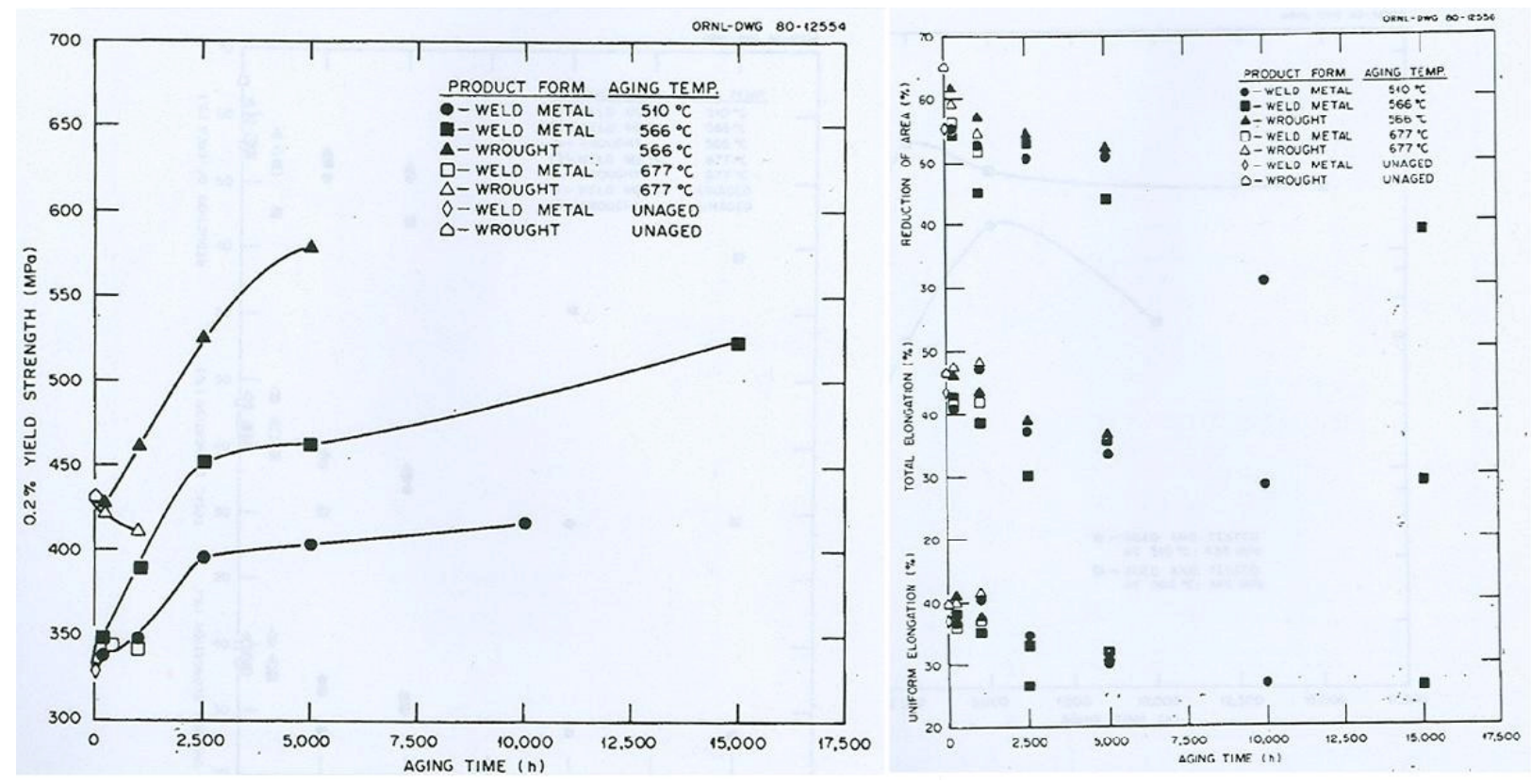

Figure 37. Influence of aging time and temperature on the yield strength and ductility of ERNiCr-3 weld metal. $^{65}$ 


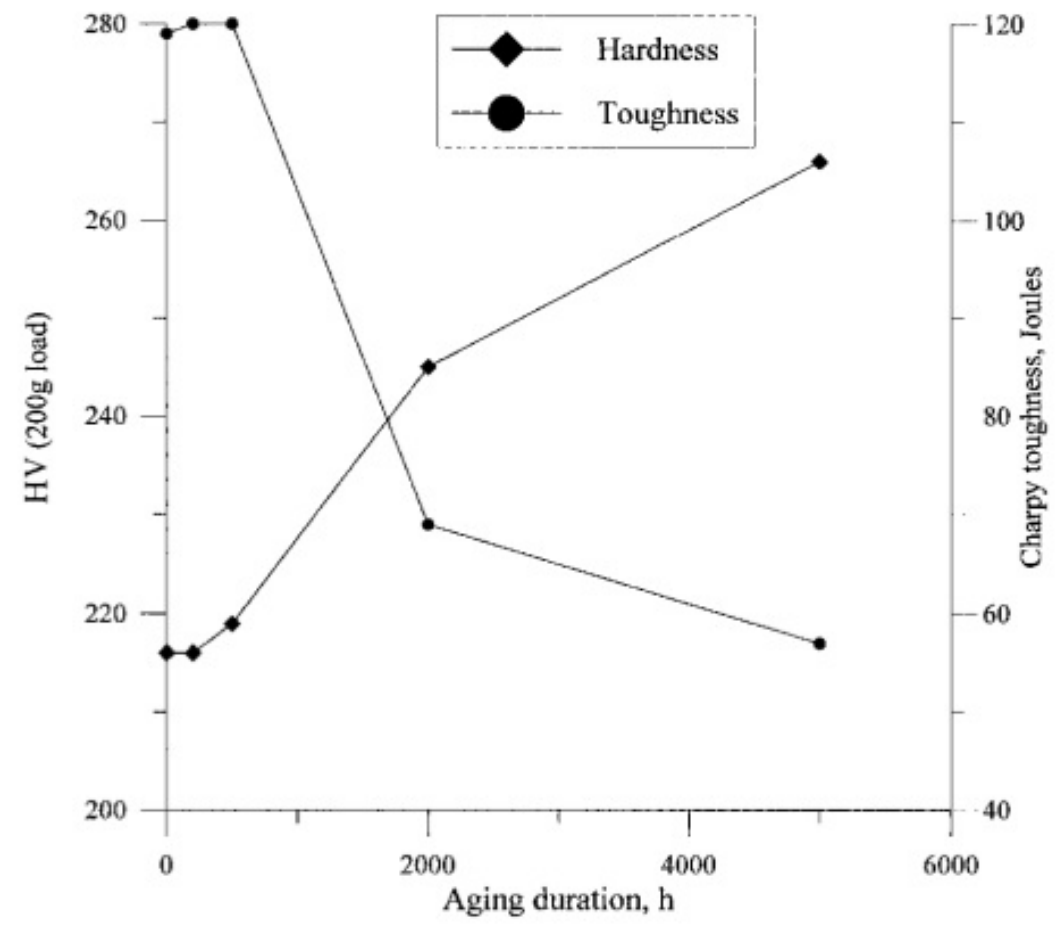

Figure 38. Variation in hardness and impact toughness of the fusion zone for welds between $9 \mathrm{Cr}-1 \mathrm{Mo}$ steel and alloy $800 \mathrm{H}$ (made using ERNiCr-3 filler) that were aged at $625^{\circ} \mathrm{C} .{ }^{67}$

These changes in properties have been attributed to both short range ordering and precipitation that occurs at these temperatures. Klueh and King ${ }^{65}$ observed precipitation within the weld and identified both precipitation and short-range ordering to be responsible for the property changes, but did not identify the precipitates involved. Siressha et al. ${ }^{18}$ identified the precipitates as $\mathrm{M}_{23} \mathrm{C}_{6}, \mathrm{Ni}_{3} \mathrm{Ti}$, and $\mathrm{NbC}$. SEM photomicrographs of the charpy impact-test specimens in the as--welded and aged conditions are shown in Figure 39. The as-welded sample exhibits typical microvoid coalescence and a relatively fine dimple spacing. By contrast, the aged sample exhibits evidence of both microvoid coalescence and cleavage fracture along with evidence of precipitates on the fracture surface. The precipitates and long-range order are expected to contribute to increased strength and decreased ductility. The precipitates can also lead to premature fracture by accelerating the microvoid coalescence process since they provide sites for decohesion between the particles and matrix. Although the ductility and toughness are still relatively high (i.e., total elongation values are above $30 \%$ and impact toughness values are above 50 Joules), the changes are nonetheless significant and should be noted. 


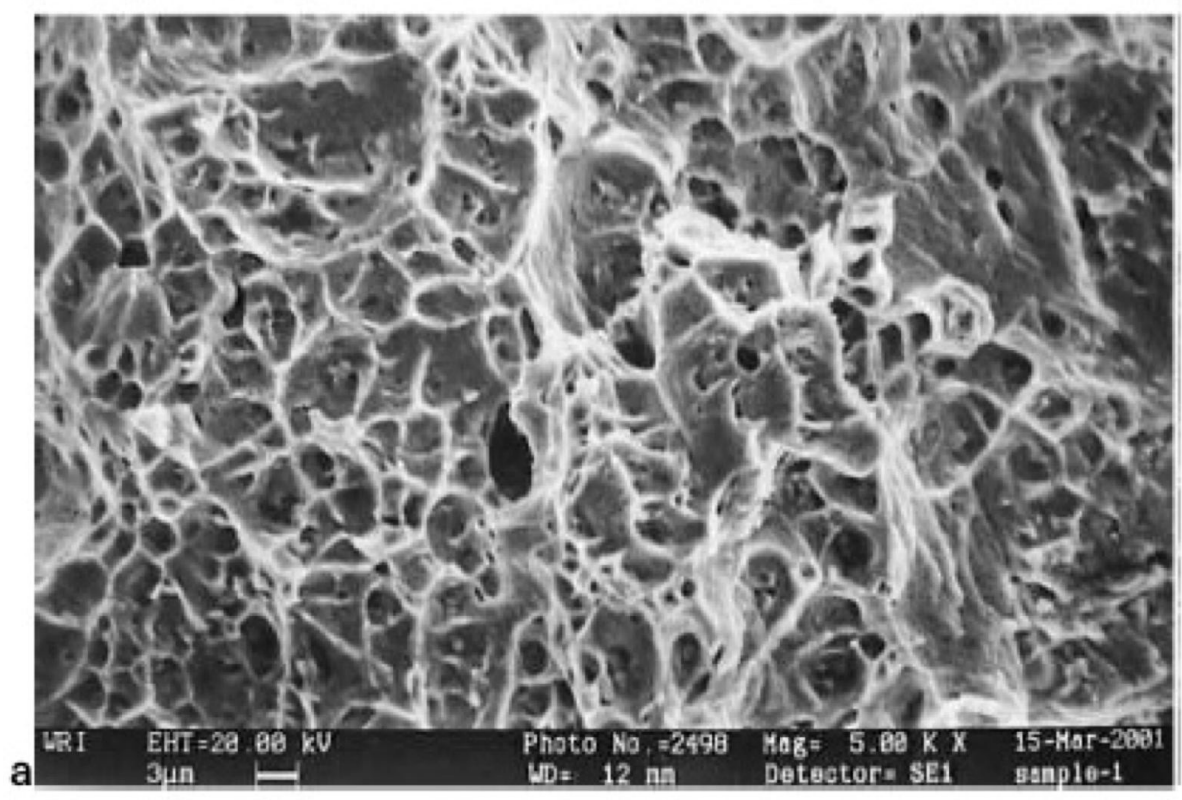

A

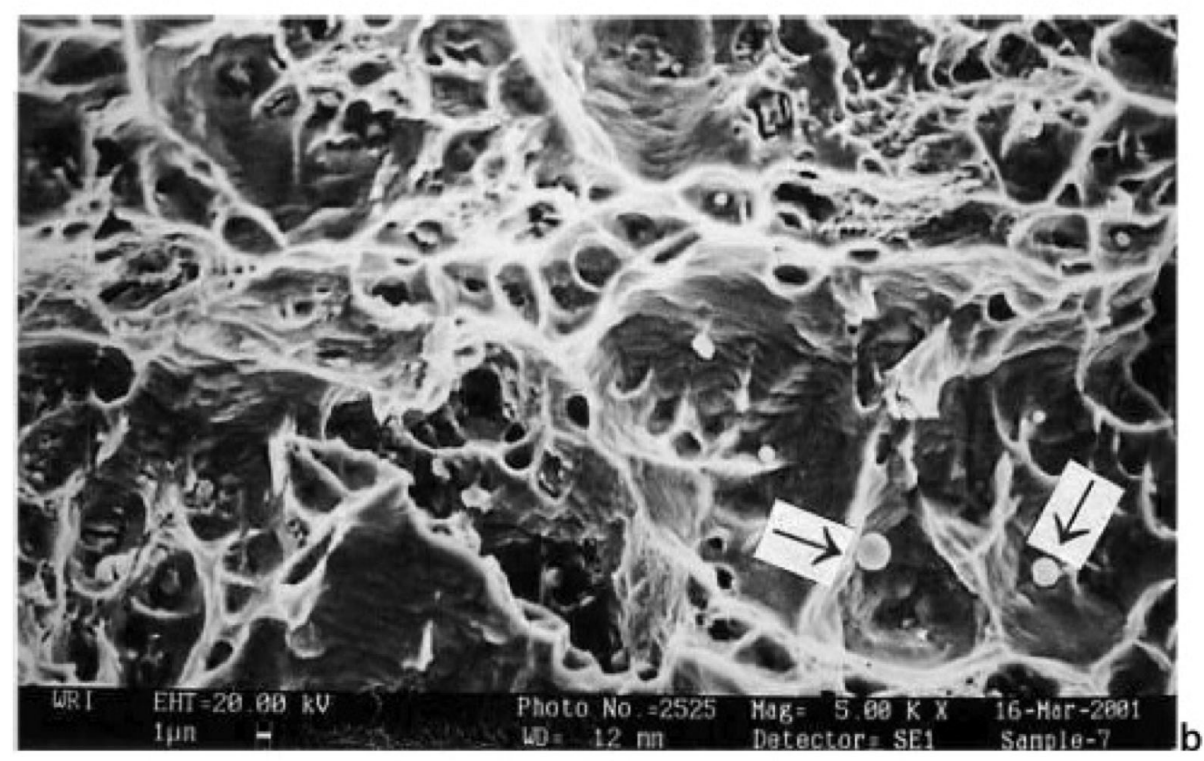

Figure 39. SEM photomicrographs of the charpy impact specimens in the (a) as-welded condition and (b) aged for 5,000 hours at $625^{\circ} \mathrm{C}$. ${ }^{67}$ 


\subsection{Remaining Life Estimation Techniques}

The potential for premature failure of DMWs provides impetus for development of techniques for estimating the remaining life of components in service. Several approaches to this problem have been proposed and are worth noting. In the simplest sense, the condition of DMWs can be qualitatively assessed using metallographic techniques to examine the condition of the weld. Since the microstructural mechanism of failure is known (i.e., creep cavitation at Type I carbides followed by micro- and macro-crack formation), direct examination of metallographic samples and/or replication techniques can be applied to evaluate the extent of damage. The qualitative relation between damage morphology and remaining life for homogenous wrought materials is known and shown schematically in Figure 40, where the microvoid and crack morphology is qualitatively related to remaining life ${ }^{68}$. (This qualitative relation requires modification to account for the unique fracture features of DMWs made with Ni base filler metals in which the creep cavitation is concentrated along the Type I carbides.) With this approach, the inspection frequency is typically increased when isolated creep cavities are first identified, and component replacement would occur prior to the link up of creep cavities. The challenge to this approach is proper identification of critical components and locations within each component that are most vulnerable to creep damage. This can be difficult when one considers that the area utilized for examination is an extremely small fraction of the potential volume of material that may be subjected to damage. Results from finite element thermal and stress modeling should be combined with plant history data in order to guide such an assessment, and all the various sources of stress previously described in Section 2.2 should be considered. An additional concern with the replication technique is that failure may not always be most severe on the component surface where the replication is acquired. In fact, some service inspections ${ }^{36,69}$ indicate that void formation and cracking can initiate within the interior of the wall.

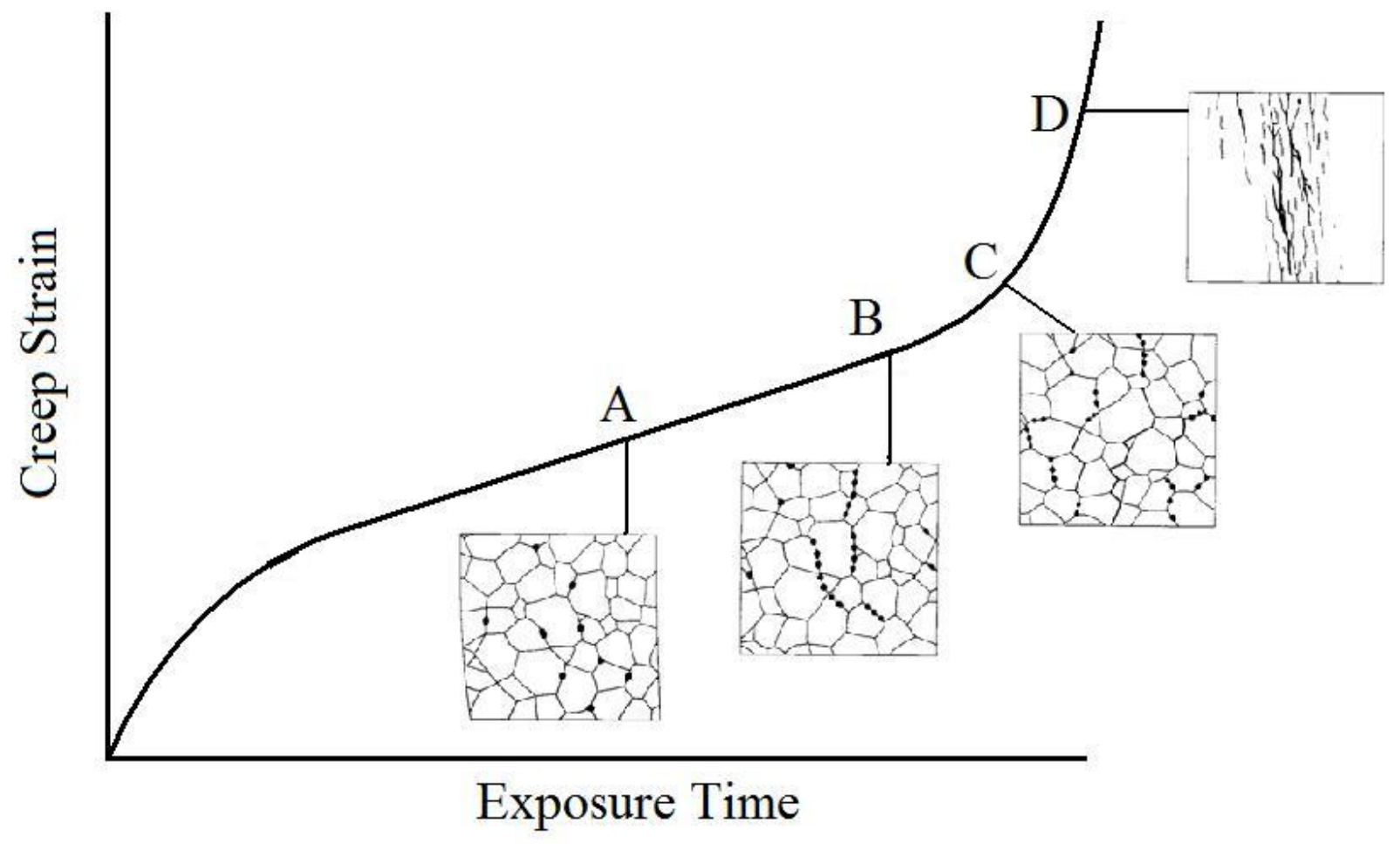

Figure 40. Qualitative relation between damage morphology and remaining life for homogenous wrought materials. $^{68}$ 
Figure 41 shows recent laboratory data that may serve as the basis for potentially providing a more quantitative approach to the relation between cavitation and remaining life fraction ${ }^{34,35}$. These data show the maximum amount of cavities (measured in number of cavities per unit length along the interface) as a function of life fraction for DMWs between 2.25Cr-1Mo steel and 316 stainless steel welded with Inconel 82 and 182 filler metals. Data for all the "new" welds, and for "aged" welds that exhibited low ductility failure, generally lie on a single curve. These samples all fractured by creep cavitation at Type I carbides. The aged samples tested at higher stresses failed in the $2.25 \mathrm{Cr}-1 \mathrm{Mo}$ steel and, thus, do not replicate field conditions. Note that data for these welds generally fall outside of the curve. It was noted that a cavity density of about 400 cavities/mm existed just prior to crack formation, and this corresponded to about $85 \%$ of the creep life. The instantaneous cavity density $(\mathrm{N})$ at any given life fraction $(\mathrm{t})$ can then be related to the cavity density at fracture $\left(\mathrm{N}_{\mathrm{f}}\right)$ associated with the end of life $\left(\mathrm{t}_{\mathrm{f}}\right)$. The authors propose a relationship of the form:

$\frac{t}{t_{f}}=1-\left(1-\frac{N}{N_{f}}\right)^{\lambda}$

where $\lambda$ is the Monkman-Grant constant. Figure $41 \mathrm{~b}$ shows experimental data along with a plot of equation (3) using a value of $\lambda=2.5$, and a reasonable correlation is obtained. Additional data are needed, particularly from well-documented field studies, to provide further experimental verification of this potential technique. It should also be noted that this approach is subject to the same challenges described above for metallographic and/or replication techniques.
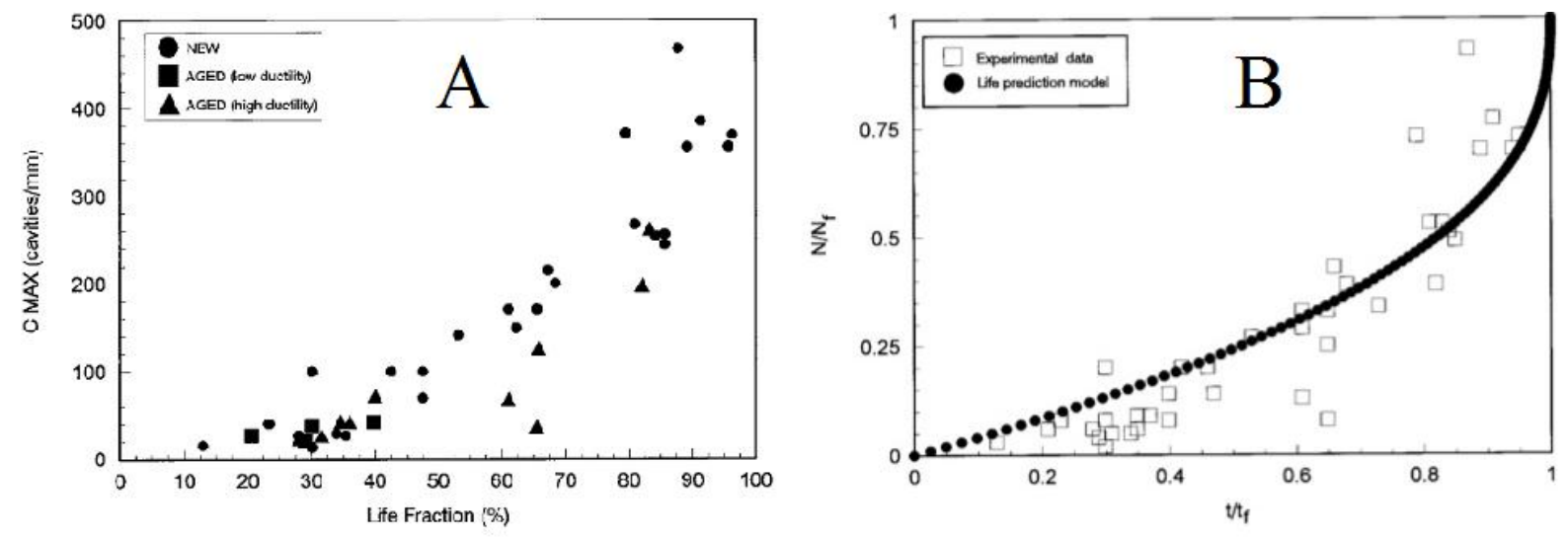

Figure 41. a) Maximum amount of cavities (measured in number of cavities per unit length along the interface) as a function of life fraction for DMWs between 2.25Cr-1Mo steel and 316 stainless steel welded with Inconel 82 and 182 filler metals, b) experimental data along with a plot of equation (3) using a value of $\lambda=2.5{ }^{35}$

A method has also been proposed for direct calculation of the damage fraction from operating parameters $^{36,69}$. The technique, known as Prediction of Damage In Service (PODIS), considers total damage, $\mathrm{D}_{\text {TOT, }}$, to develop from three sources

$D_{T O T}=D_{I}+D_{P}+D_{S} D_{T O T}=D_{I}+D_{P}+D_{S}$

where $D_{I}$ is the intrinsic damage associated with temperature cycling due to changes in power loads, $D_{P}$ is damage associated with primary loads during steady state operation that include both pressure and component weight, and $\mathrm{D}_{\mathrm{S}}$ is damage from secondary bending loads that arise from load cycling and creep-rupture that accumulates during hold periods. Loads associated with the latter factor are considered strain controlled. They will relax at elevated temperature, but will be regenerated during temperature cycling. The value of $\mathrm{D}_{\text {Tот }}$ is specifically defined as the amount of interfacial area that has suffered 
damage due to voiding/cracking and is therefore not capable of sustaining a load. For example, if $\mathrm{A}_{\mathrm{o}}$ is the original interfacial area of the weld prior to service and $A_{i}$ is the amount of remaining interfacial area that has not been damaged after some service time (and therefore capable of carrying the load), then $\mathrm{D}_{\text {TOT }}$ is given by

$D_{T O T}=\frac{A_{O}-A_{i}}{A_{o}}$

The technique is divided into two failure scenarios. Mode I failure is associated with intergranular cracking along PAGBs within the HAZ of the ferritic steel. As described above, this occurs in welds made with stainless steel filler metals. Mode II failure involves creep cavitation and cracking along Type I carbides associated with welds made using $\mathrm{Ni}$ base filler metals. For Mode II failure, the $\mathrm{D}_{\mathrm{I}}$ term is considered negligible due to the small difference in CTE between the weld metal and ferritic steel. The values of $D_{P}$ and $D_{S}$ for this case are then given by

$$
\begin{aligned}
& D_{P}=\sum_{1}^{m} k_{1} t_{m} 10^{f\left(T_{o}\right)}\left[\frac{\sigma_{P}}{1-k_{2}} 10^{g\left(T_{o}\right)} t_{n}^{1 / 3}\right]^{\beta} \\
& D_{S}=\sum_{1}^{m} k_{3} n\left(\varepsilon_{S}\right)^{\gamma}+k_{4} t_{m} 10^{f\left(T_{o}\right)}\left[\frac{\sigma_{S}}{1-k_{5} 10^{g\left(T_{o}\right)} t_{n}^{1 / 3}}\right]^{\beta}
\end{aligned}
$$

where the variables are defined as follows

$$
\begin{array}{ll}
\mathrm{m} & \text { number of loading conditions } \\
\sigma_{\mathrm{P}} & \text { primary axial stress } \\
\sigma_{\mathrm{S}} & \text { secondary axial stress } \\
\mathrm{t}_{\mathrm{m}} & \text { incremental time for a constant } \sigma_{\mathrm{P}} \\
\mathrm{t}_{\mathrm{n}} & \text { cumulative time from } \mathrm{t}=0 \text { up to } \mathrm{t}_{\mathrm{m}} \\
\mathrm{T}_{\mathrm{o}} & \text { average operating temperature at steady state loading conditions, } \mathrm{m} \\
\mathrm{f}\left(\mathrm{T}_{\mathrm{o}}\right) \text { and } \mathrm{g}\left(\mathrm{T}_{\mathrm{O}}\right) & \text { functions of } \mathrm{T}_{\mathrm{o}} \\
\varepsilon_{\mathrm{S}} & \text { strain range } \\
\mathrm{k}^{\mathrm{i}}, \gamma, \beta & \text { onstants }
\end{array}
$$

The report by Ryder and Dahms ${ }^{69}$ contains more details on values of the constants and the calculation procedure. The values for the required constants were determined from both laboratory and field data. Predictions were then compared with additional data obtained from controlled laboratory experiments or well-documented samples removed from actual plants.

Figure 42 shows a comparison of the calculated damage to that observed experimentally, where the dotted lines are for a 95\% confidence interval. Reasonable agreement is obtained between the measured and calculated values. There are, however, a number of instances in which the predictions are non-conservative. It is possible that additional data may be helpful for refining the constants and improving the accuracy of the predictions. 


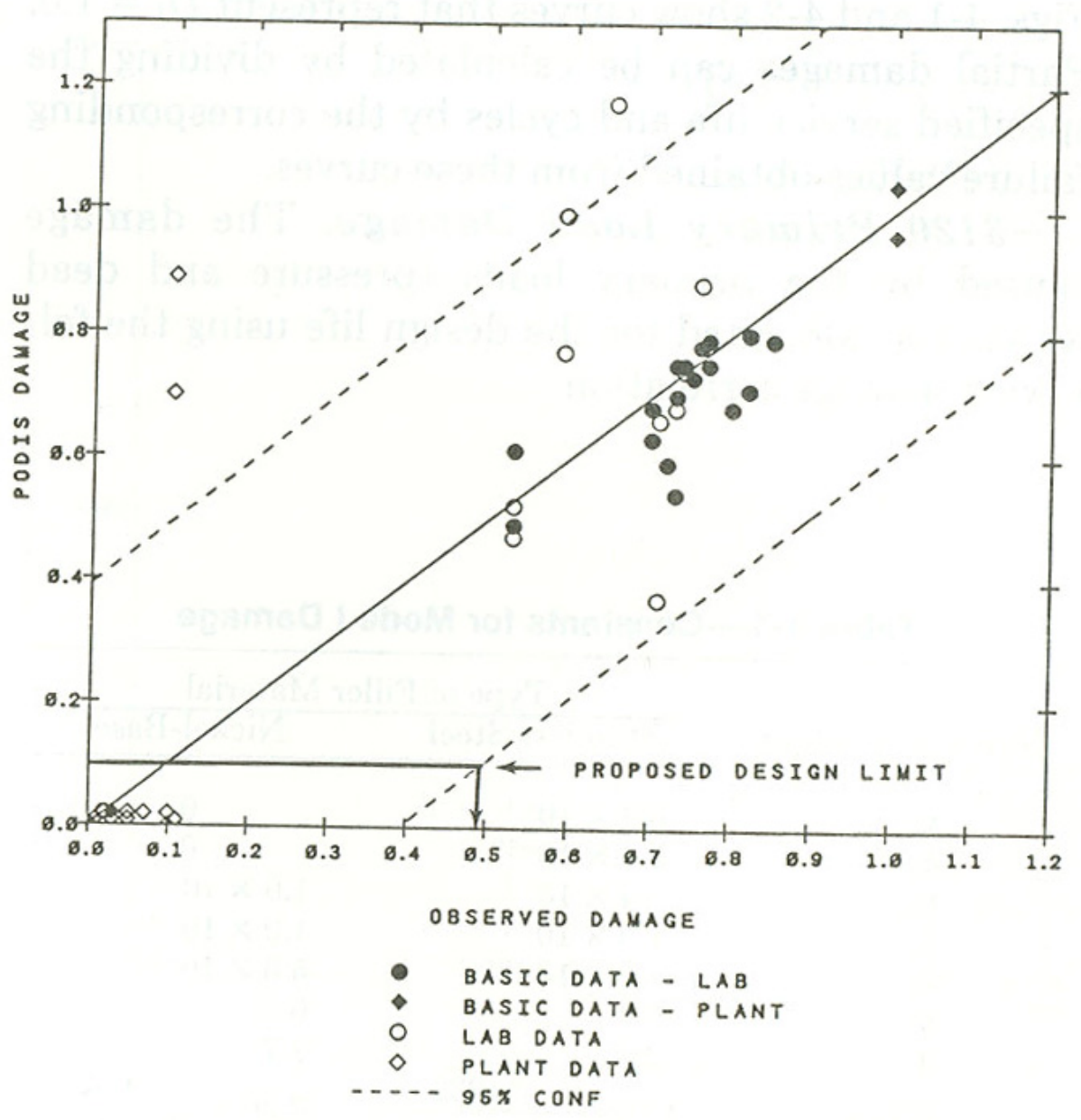

Figure 42. Comparison of calculated damage to that observed experimentally using the PODIS method, where the dotted lines are for a $95 \%$ confidence interval. ${ }^{69}$

Nondestructive examination (NDE) techniques are often useful for detecting cracks in DMWs that may be associated with premature failure. A review of existing techniques for this application is beyond the scope of this review and the expertise of the author. The NDE Center of the Electric Power Research Institute (EPRI) is actively involved in assessing the ability of NDE techniques for detecting flaws in DMWs operating in both coal- and nuclear-powered plants. Shear wave ultrasound is currently being assessed to determine the capability limit of this technique ${ }^{70}$, and information is available on best practices for ultrasonic examinations of DMWs in field conditions ${ }^{71}$.

\subsection{Effect of Environment on Creep Rupture Properties}

As previously mentioned, preferential oxidation of the $2.25 \mathrm{Cr}-1 \mathrm{Mo}$ steel and formation of the concomitant oxide notch is an important factor that contributes to premature failure of DMWs in service. Thus, it is important to consider additional factors associated with the HTGR steam generator environment that could accelerate the corrosion and associated failure rate of DMWs. Although information is available on the corrosion behavior of various base metal alloys in the HTGR environment ${ }^{59,72,73,74,75,76}$ no reports are available in the open literature on the influence of gas impurities on creep-rupture properties of the DMWs. Lai and Wolwowicz ${ }^{59}$ examined the effect of flowing helium on the creep rupture properties of $2.25 \mathrm{Cr}-1 \mathrm{Mo}$ steel and alloy $800 \mathrm{H}$ with the following impurities and concentration levels: $1500 \mu$ atm $\mathrm{H}_{2}, 450 \mu \mathrm{atm} \mathrm{CO}, 50 \mu \mathrm{atm} \mathrm{CH}_{4}, 50 \mu \mathrm{atm} \mathrm{H}_{2} \mathrm{O}$, and $5 \mu \mathrm{atm} \mathrm{CO}_{2}$. This 
environment was chosen to represent the maximum levels of impurities in the steam cycle primary coolant system of the HTGR when operated continuously with a steam and/or water leak. The effect of sample size on the creep-rupture curves was also investigated by using samples with $4.8 \mathrm{~mm}$ and $9.5 \mathrm{~mm}$ diameters.

Figure 43 shows the creep rupture data in the simulated HTGR environment for the $9.5 \mathrm{~mm}$ diameter samples, where the minimum and scatter band lines are taken from the data within ASME Code Case N-47 (which is now replaced with Subsection NH). The scatter in the data can be attributed to various factors. Differences arising from variations in chemical composition associated with different heats of materials are a primary source of scatter. Although the data fall within the scatter band of the N-47 data, significant effects of environment and sample size were observed when comparisons were made within identical heats of data. Figure 44 shows the creep strain as a function of time for samples from identical heats of material tested in air and the simulated HTGR environment. The creep strain rate significantly increases and the failure time decreases for the samples tested in the HTGR environment compared to those tested in air. As shown in Figure 45, the $4.8 \mathrm{~mm}$ diameter samples exhibit accelerated strain rates and reduced failure times relative to the larger $9.5 \mathrm{~mm}$ diameter samples. These effects have been directly attributed to accelerated corrosion that occurs during the test from the presence of impurities. Similar deleterious effects have been observed on the creep properties for both alloy $800 \mathrm{H}^{77,78}$ and $2.25 \mathrm{Cr}-1 \mathrm{Mo}$ steel $^{79}$. 

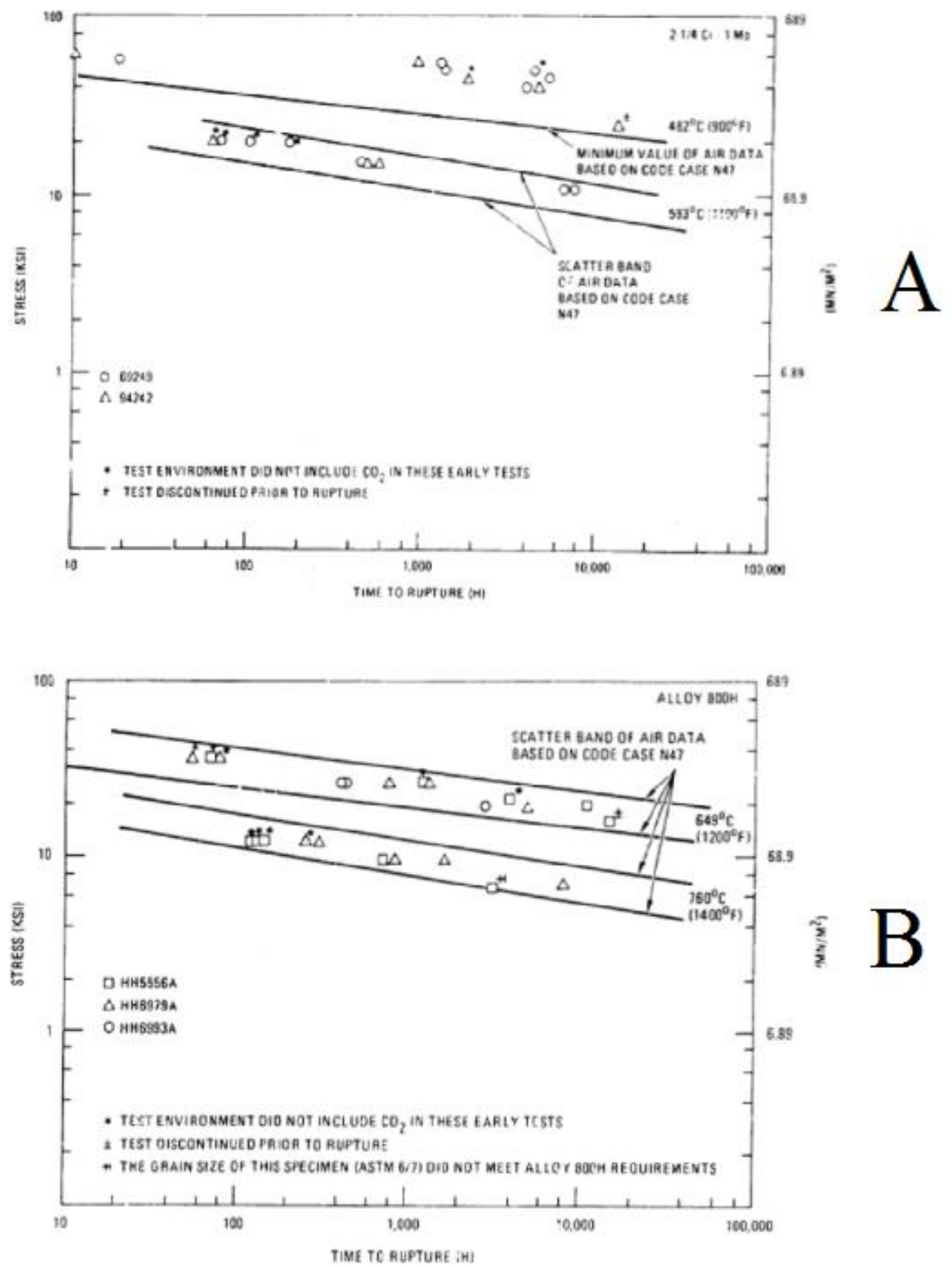

Figure 43. Creep rupture data for $9.5 \mathrm{~mm}$ diameter samples of (a) $2.25 \mathrm{Cr}-1 \mathrm{Mo}$ steel and (b) alloy $800 \mathrm{H}$ in the simulated HTGR helium gas with $1500 \mu \mathrm{atm} \mathrm{H}_{2}, 450 \mu \mathrm{atm} \mathrm{CO}, 50 \mu \mathrm{atm} \mathrm{CH}_{4}, 50 \mu \mathrm{atm} \mathrm{H}_{2} 0$, and 5 $\mu$ atm $\mathrm{CO}_{2}$. Minimum and scatter-band lines are taken from data within ASME Code Case N-47 (now replaced by Subsection $\mathrm{NH}){ }^{59}$ 

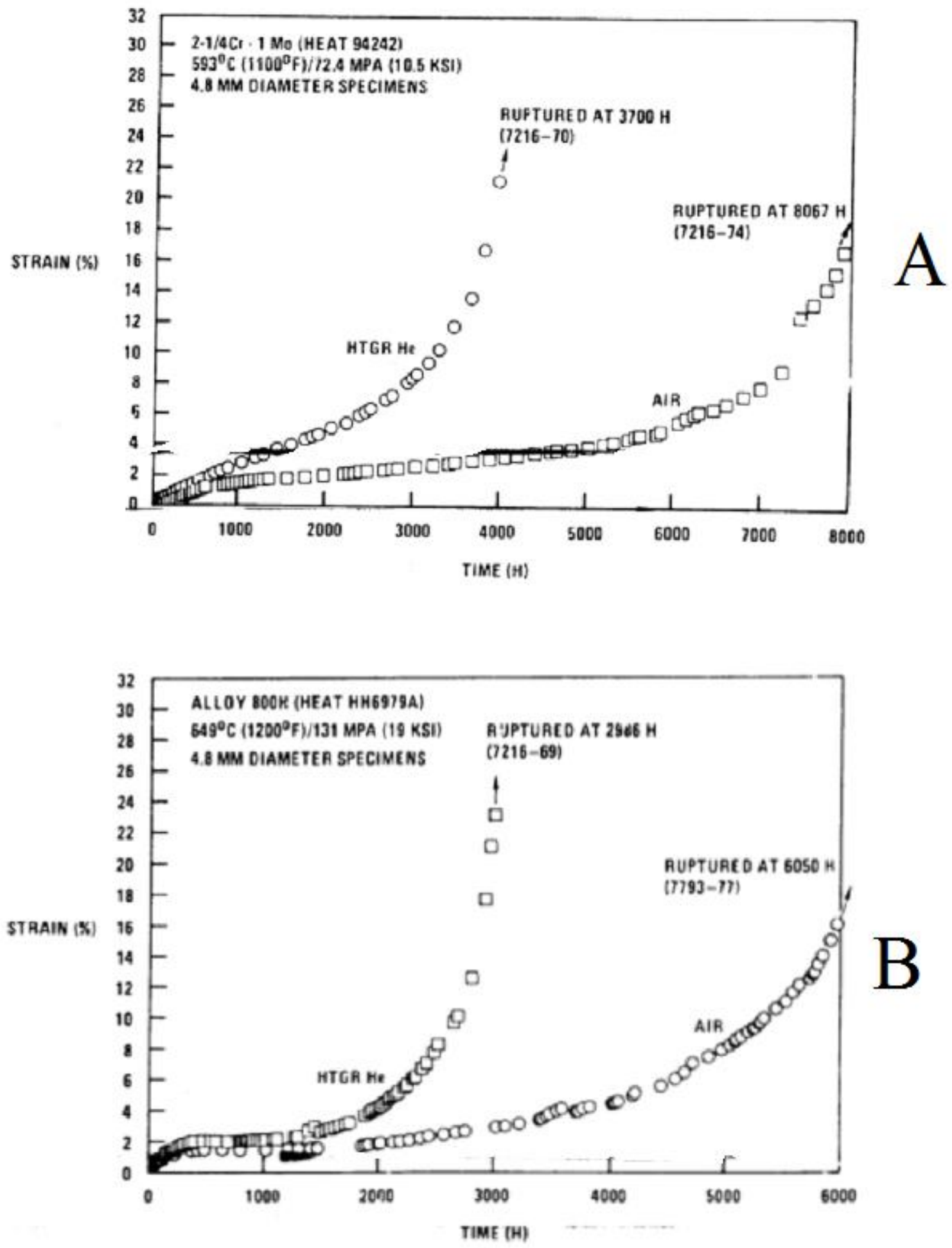

Figure 44. Creep strain as a function of time for (a) $2.25 \mathrm{Cr}-1 \mathrm{Mo}$ steel and (b) alloy $800 \mathrm{H}$ tested in air and the simulated HTGR helium gas (with $1500 \mu \mathrm{atm} \mathrm{H2,} 450 \mu \mathrm{atm} \mathrm{CO}, 50 \mu \mathrm{atm} \mathrm{CH} 4,50 \mu \mathrm{atm} \mathrm{H} 20$, and 5 $\mu$ atm CO2). ${ }^{59}$ 

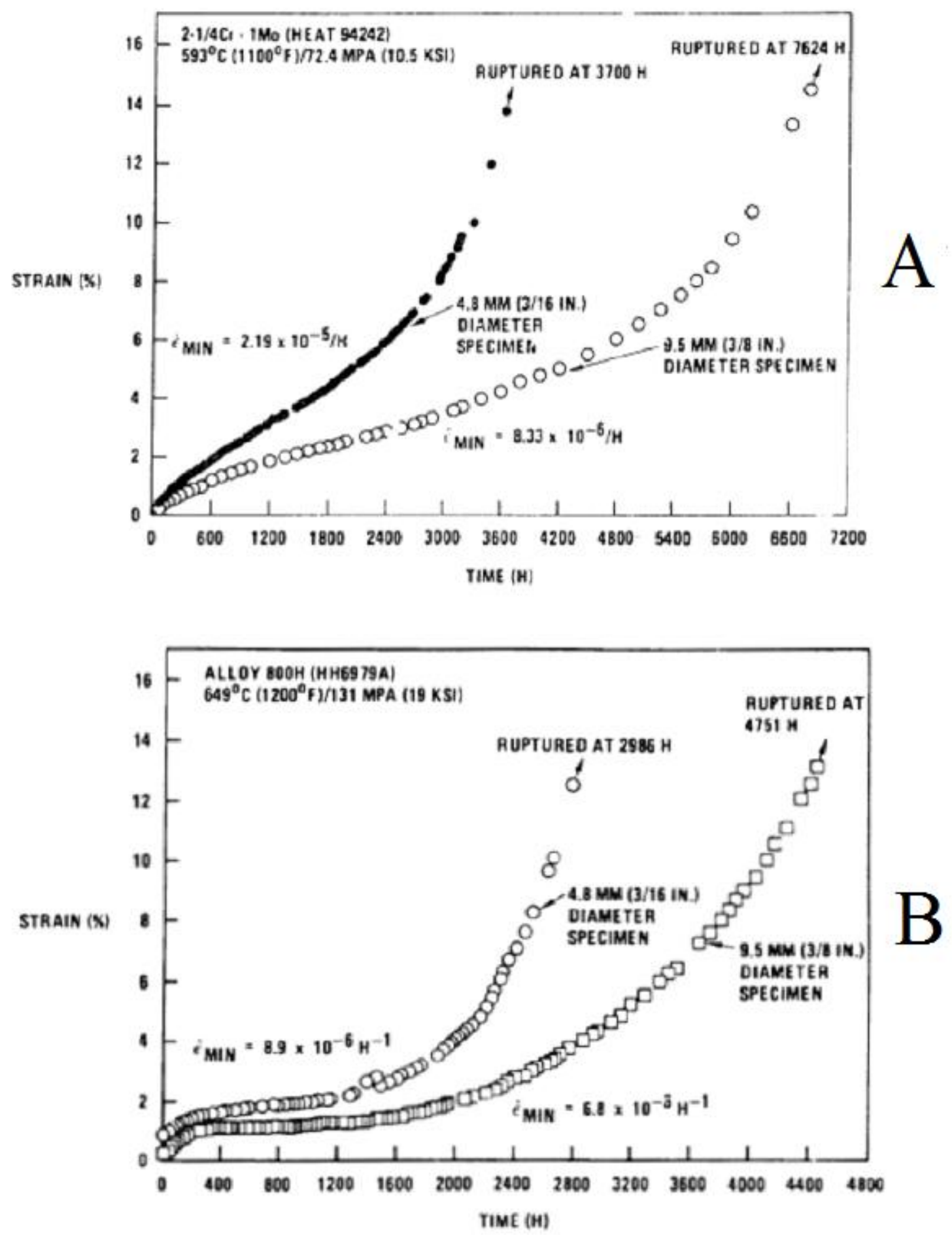

Figure 45. Creep strain as a function of time for $4.8 \mathrm{~mm}$ and $9.5 \mathrm{~mm}$ diameter samples of (a) 2.25Cr-1Mo steel and (b) alloy $800 \mathrm{H}$ tested in simulated HTGR helium gas (with $1500 \mu \mathrm{atm} \mathrm{H}_{2}, 450 \mu \mathrm{atm} \mathrm{CO}, 50$ $\mu$ atm $\mathrm{CH}_{4}, 50 \mu \mathrm{atm} \mathrm{H}_{2}$, and $5 \mu$ atm $\left.\mathrm{CO}_{2}\right) .{ }^{59}$ 
Internal oxidation was observed in the $2.25 \mathrm{Cr}-1 \mathrm{Mo}$ samples tested at $593^{\circ} \mathrm{C}$ in the HTGR environment. No such internal oxidation was observed when testing occurred in air. The authors reported that the $\mathrm{Cr}$ level of the alloy was too low to support formation and maintenance of a uniform and protective $\mathrm{Cr}_{2} \mathrm{O}_{3}$ scale at this test temperature. Testing at $482^{\circ} \mathrm{C}$ for times up to 5,000 hours did not reveal any oxidation when examined by simple light microscopy. It was also noted that carburization or decarburization of the $2.25 \mathrm{Cr}-1 \mathrm{Mo}$ steel could occur in the HTGR environment according to the reaction $\mathrm{C}+\mathrm{H}_{2} \mathrm{O} \leftrightarrow \mathrm{CO}+\mathrm{H}_{2}$, where $\mathrm{C}$ represents the $\mathrm{C}$ in the ferritic steel. Thermodynamic analyses indicated that, for the environment of interest, carburization is expected below $538^{\circ} \mathrm{C}$ and decarburization is expected at temperatures above this. This was partially in line with experimental observations, where samples tested at $593^{\circ} \mathrm{C}$ showed decarburization both directly (i.e., through reduced carbon content at and near the surface) and through a reduction in the carbide content at and near the surface. The samples tested at $482^{\circ} \mathrm{C}$, however, did not reveal any direct evidence of carburization. These results indicate that, as expected, both oxidation and carburization/decarburization degradation mechanisms are very sensitive to temperature. It is possible that degradation of the samples exposed to the lower temperature might be observed at exposure times beyond 5,000 hours. Surface cracking was also observed on the samples tested in the HTGR environment, whereas the samples tested in air did not display such cracking. The authors suggested that surface cracking was induced via the internal oxidation. In any case, the reduced creep strength of the $2.25 \mathrm{Cr}$ - $1 \mathrm{Mo}$ steel in the HTGR environment at $593^{\circ} \mathrm{C}$ was attributed to both decarburization and accelerated oxidation.

Similar effects were observed for alloy $800 \mathrm{H}$, where both surface and internal oxidation occurred in the HTGR environment at each temperature examined $\left(649\right.$ and $\left.760^{\circ} \mathrm{C}\right)$. In this case, the surface oxide scale was noticeably thicker in the reduced section of the gage length where the stress was higher (compared to the larger diameter shoulder section of the sample). This suggests that the surface oxidation rate is enhanced by stress. Although thermodynamic analyses suggested that carburization could occur for alloy $800 \mathrm{H}$ in the HTGR environment, only slight carburization was observed at $760^{\circ} \mathrm{C}$, and little or none was observed at $649^{\circ} \mathrm{C}$. No microstructural changes due to carburization were observed. The samples tested in air exhibited a mixed mode of fracture consisting of intergranular cracking with some areas that fractured by shear. In contrast, the samples tested in the HTGR environment showed predominately intergranular cracking, and the cracking was more extensive relative to samples tested in air. The authors suggested that the reduced creep resistance of the samples tested in the HTGR environment was probably due to enhanced internal oxidation that was observed to occur along the grain boundaries.

Lastly, the effect of sample size on the resultant creep data can be easily understood with reference to Figure 46, which shows the percentage of affected cross section as a function of reaction depth (i.e., depth of corrosion) for sample diameters of $4.8 \mathrm{~mm}$ and $9.5 \mathrm{~mm}$. The sample with the smaller diameter will obviously experience a larger increase in stress due to a loss of the load-bearing area due to corrosion. This effect accounts for the differences in the creep curves shown in Figure 45 and points to the need to carefully consider sample size effects prior to designing creep experiments and placing thin-walled components into service. 


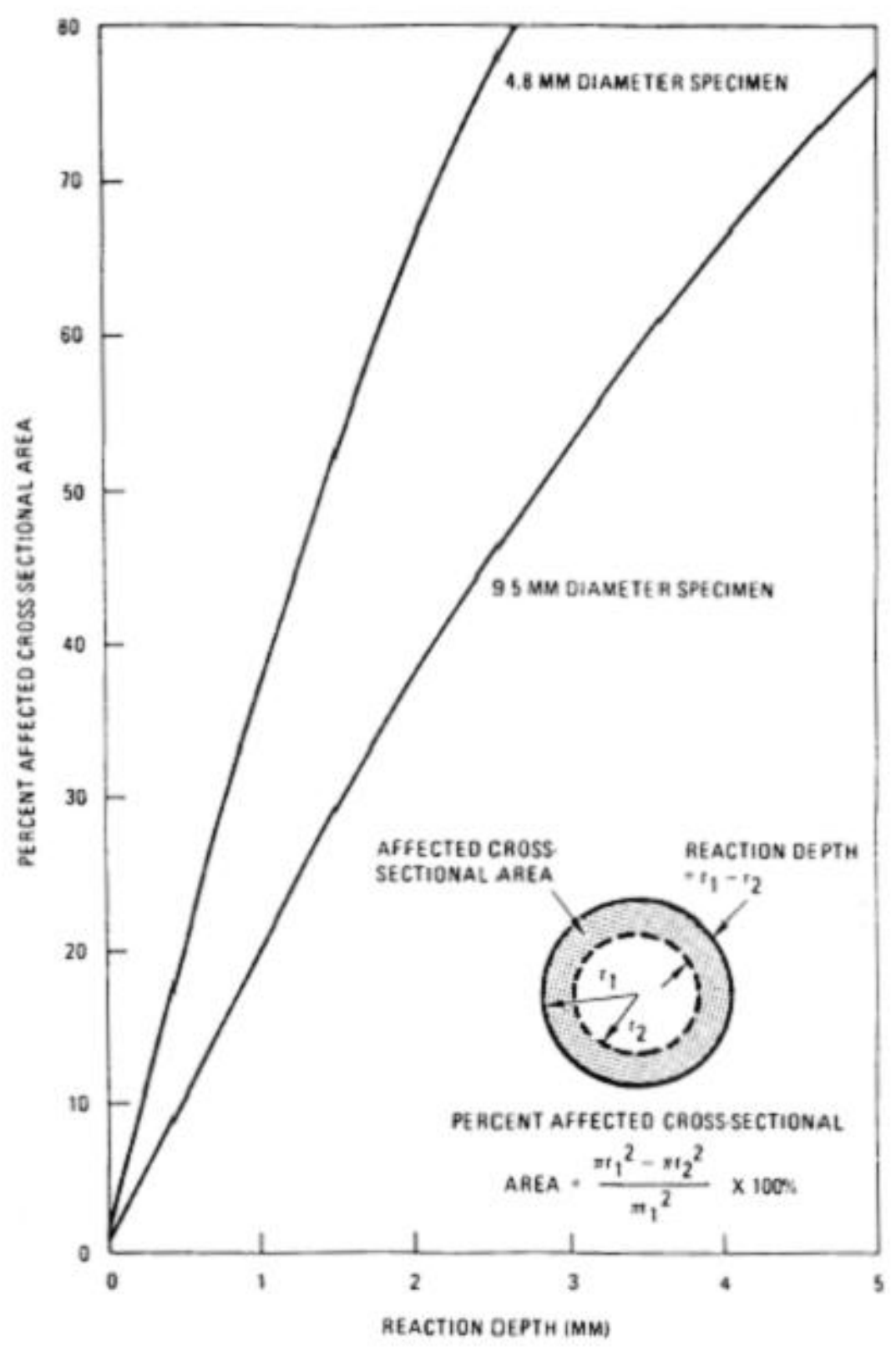

Figure 46. Percentage of affected cross section as a function of reaction depth (i.e., depth of corrosion) for sample diameters of $4.8 \mathrm{~mm}$ and $9.5 \mathrm{~mm}^{59}$

The results of this research have important implications with respect to the corrosion behavior and associated premature failure of DMWs. First, corrosion in the HTGR environment may be accelerated relative to air conditions, and this area requires further attention. No information was found in the open literature that described the influence of service temperature, impurity content, and weld characteristics on the resultant corrosion behavior. The corrosion behavior of welds in high-temperature gaseous environments is known to be significantly different than counterpart wrought alloys due to composition and microstructural gradients, and premature failures of welds in such environments are known to occur ${ }^{80}$. Corrosion data acquired from actual DMW samples under well-controlled conditions are needed to establish the potential effect of service environment. Second, if the effect is observed to be significant, 
then coatings should be evaluated as part of the test program in order to minimize or eliminate the detrimental contribution of environment. The results from the corrosion study will also be useful for assessing the potential impact of environment on future creep tests that are needed as part of the HTGR design.

\subsection{Best Practices}

The practices that are currently utilized to maximize the life of DMWs have been described in the various sections above. They are briefly summarized here due to their importance during construction and operation. The major fabrication variables that must be considered include joint design, filler metal type, and application of PWHT. Operational variables of major importance include operating temperature, temperature cycling, stress, and environment. The optimal design that is currently used for joining ferritic steels to stainless steels is one that consists of a $2.25 \mathrm{Cr}-1 \mathrm{Mo}$ Steel/Alloy $800 \mathrm{H} / \mathrm{Stainless}$ steel trimetallic joint. Inconel 82 and/or 182 filler metals are used for each of the two joints involved with this trimetallic member. These transition sections are typically fabricated in the shop, and then two similar welds are made in the field. As previously mentioned, Alloy $800 \mathrm{H}$ has a CTE intermediate to that of the ferritic and stainless steels, and the Inconel filler metals have a CTE that is intermediate to that of Alloy $800 \mathrm{H}$ and the ferritic steel. Thus, this trimetallic transition approach helps reduce interfacial stresses associated with CTE mismatch. The Ni base filler metal also helps prolong service life by minimizing the extent of carbon migration. The improvement in service life associated with the use of Ni base filler metals has been verified by both laboratory testing ${ }^{81}$ and industry surveys ${ }^{58}$. Based on this, direct welding of $2.25 \mathrm{Cr}-1 \mathrm{Mo}$ steel to alloy $800 \mathrm{H}$ using Inconel filler metals in the HTGR steam generator would be expected to provide similar service life to DMWs made with these best practices. As discussed in the section below, there may be opportunity for further improvement of the $2.25 \mathrm{Cr}-1 \mathrm{Mo}$ steel to alloy $800 \mathrm{H}$ weld via the use of other intermediate alloys and/or graded transition joints.

Early results ${ }^{42}$ suggested that application of a PWHT was detrimental to service life, particularly when conducted at elevated temperatures and long times. This may apply to welds involving stainless steels where $\mathrm{C}$ migration and CTE mismatch is rather extensive. However, more recent results of well-controlled laboratory studies have shown that use of a PWHT does not alter the creep life in any significant way ${ }^{34,35,38,82}$. Nicholson examined the influence of PWHT at $700^{\circ} \mathrm{C}$ on the carbide size and distribution for times up to eight hours ${ }^{38,82}$. He observed that application of a PWHT had a relatively minor effect on the carbides compared to subsequent aging in service. This is supported by available creep data that demonstrates the creep life of DMWs is similar in the as-welded and PWHT conditions $^{34,35,83}$. Use of a PWHT is therefore expected to provide an overall beneficial effect due to relief of residual stress. Verification of this has recently been provided through residual stress measurements.

Joseph et al. ${ }^{84}$ recently measured the residual stresses in DMWs made in the as-welded and PWHT condition. Welds were fabricated between 2.25Cr-1Mo steel and 316 stainless steel using Inconel 82 filler metal with the gas tungsten arc-welding process. The pipe was $19.4 \mathrm{~cm}$ in diameter with a $8 \mathrm{~mm}$ wall thickness. One weld was first prepared with a $6 \mathrm{~mm}$ "butter" layer of Inconel 82 on the $2.25 \mathrm{Cr}-1 \mathrm{Mo}$ steel, exposed to a PWHT at $725^{\circ} \mathrm{C}$ for one hour, and then welded to the 316 stainless steel using the same filler metal. This buttering technique is used to avoid PWHT of the 316 stainless steel that may sensitize that alloy. The residual stress was also measured on a weld made directly between $2.25 \mathrm{Cr}$-1Mo steel and 316 stainless steel (using the same filler metal) without a PWHT. Figure 47 compares the axial residual stresses from each weld. The axial stresses are shown because they are the most important orientation from a creep-damage point of view. The hoop stresses were also measured, and they showed similar trends. As shown in Figure 47a, a maximum tensile axial stress of $350 \mathrm{MPa}$ is observed in the center of the weld metal in the as-welded condition. The interface between the weld metal and $2.25 \mathrm{Cr}-1 \mathrm{Mo}$ steel is the most important location since this is where failure is known to occur. The residual axial stress at this location is $260 \mathrm{MPa}$ in the as-welded condition. As shown in Figure 47b, these values are reduced considerably for the weld exposed to a PWHT, where the maximum stress at the weld centerline is reduced to $300 \mathrm{MPa}$, and the interfacial stress is reduced to $180 \mathrm{MPa}$. Use of longer times may provide 
additional stress relief and warrants further examination. Thus, considering that PWHT provides significant stress relief and no observable reduction in creep-rupture life, use of this heat treatment should be beneficial for extending the life of DMWs. Results from industrial surveys also suggest that large included angles and additional weld reinforcement are beneficial for increasing service life ${ }^{58}$. As mentioned above, additional experimental results and finite-element analysis would be useful for understanding the influence of these factors in more detail.
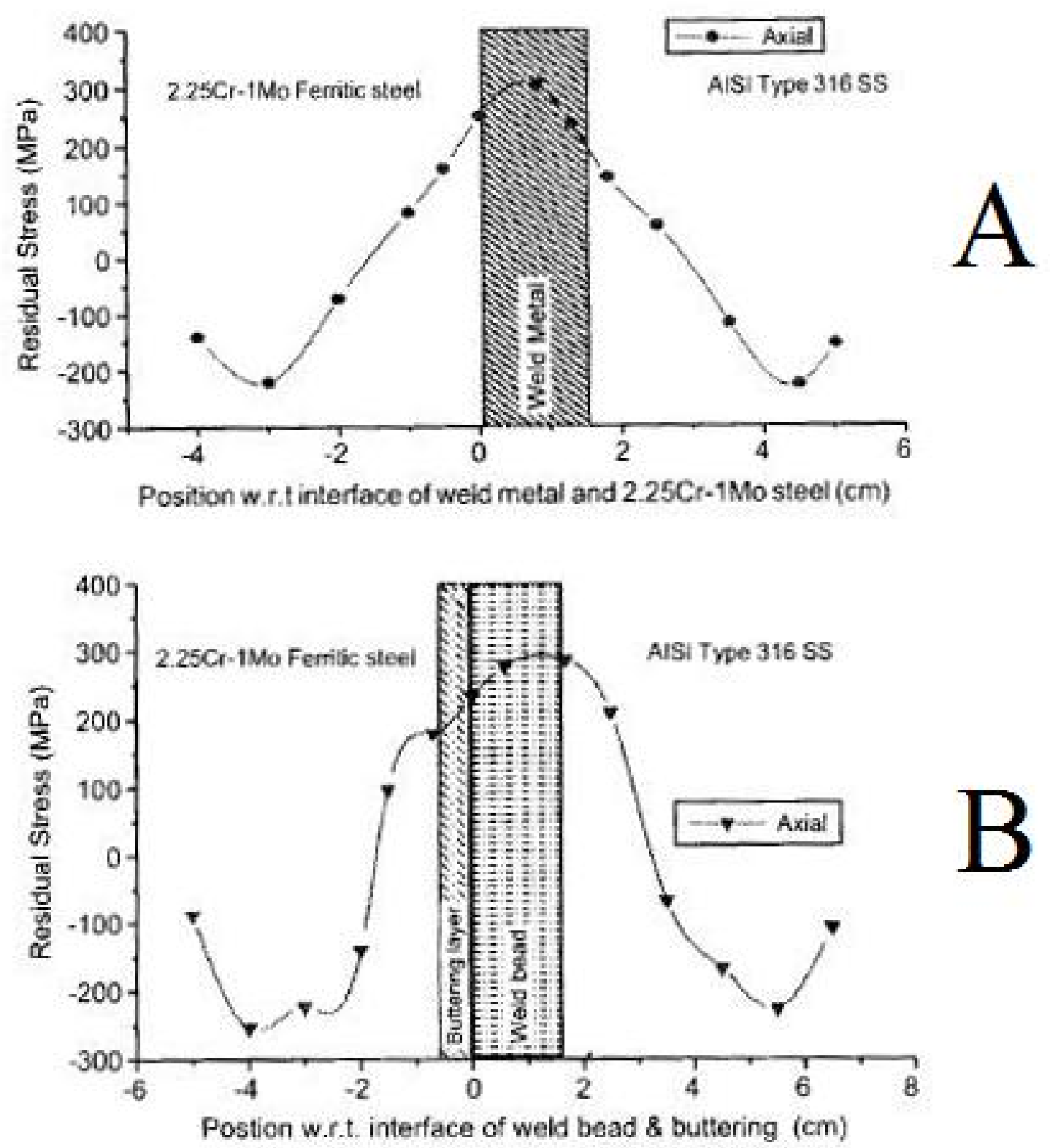

Figure 47. Residual axial stress distribution of welds between 2.25Cr-1Mo steel and 316 stainless made with Inconel 82 filler metal. a) as-welded condition, b) Weld prepared with a $6 \mathrm{~mm}$ "butter" layer of Inconel 82 on the $2.25 \mathrm{Cr}-1 \mathrm{Mo}$ steel, exposed to a PWHT at $725^{\circ} \mathrm{C}$ for one hour, and then welded to the 316 stainless steel using the same filler metal. ${ }^{84}$ 
The microstructural changes and preferential oxidation that occur during aging are generally thermally activated processes and are, therefore, expected to increase significantly with increasing temperature. Similarly, higher temperatures and/or large changes in temperature will exacerbate the stresses generated from CTE mismatch. Thus, DMW life is obviously expected to increase with decreasing operating temperature. This is important from a design perspective as it points to the need to place DMWs in regions where the temperature is as low as feasibly possible. Similar comments can be made with regard to stress, and the various sources of stress need to be minimized beyond those associated with normal operation. Stress sources to consider include those that arise from tube weight and pressure in addition to stresses from through-wall thermal gradients, temperature fluctuations, residual stresses from welding, and mechanical restraint. Abrupt changes in wall thickness between the $2.25 \mathrm{Cr}-1 \mathrm{Mo}$ steel and alloy $800 \mathrm{H}$ should also be avoided in order to minimize stress concentrations associated with changes in geometry. Results from industry surveys ${ }^{58,85}$ have demonstrated that DMWs are significantly more prone to failure when located in high temperature/high stress conditions, and this points to the need for minimizing failures through design strategies that reduce stress and temperature to the fullest extent possible. Lastly, any steps that can be applied to minimize corrosion of the $2.25 \mathrm{Cr}-1 \mathrm{Mo}$ steel near the interface are expected to extend the service life. This would include placing the DMW in locations of reduced temperature and/or less aggressive environments where excessive oxidation or other degradation mechanisms (e.g., carburization/decarburization) will not occur. This is particularly important for thin walled tubing where the localized oxidation can become an important contribution to overall failure. It appears that protective coatings, which could be locally applied to the $2.25 \mathrm{Cr}-1 \mathrm{Mo}$ Steel/Alloy $800 \mathrm{H}$ joint during fabrication in the shop, could offer a means for improved performance. Since the corrosion environments are generally not extremely severe, thermal spray coatings may be adequate for this purpose and warrant further consideration.

\subsection{Research in Progress}

There are currently two research activities being conducted for potential improvement of DMW performance at high temperatures. These include development of a new filler metal (being conducted collaboratively between Babcock and Wilcox and the Electric Power Research Institute) and an NSF-sponsored research program at Lehigh University on the design and fabrication of graded transition joints. The major objective of the B\&W/EPRI study is to develop a Ni base filler metal that can provide an improved CTE match with ferritic steel and reduce $\mathrm{C}$ migration across the fusion line ${ }^{27,28}$. The filler metal has been evaluated in welds made between Grade 91 steels and austenitic alloys. The filler metal contains $\mathrm{C}$ and $\mathrm{Cr}$ levels that closely match those of the Grade 91 steel in order to reduce the driving force associated with $\mathrm{C}$ migration, and the $\mathrm{CTE}$ at $1000^{\circ} \mathrm{F}$ is nearly identical to that of Grade 91 steel. The filler metal is commercially identified as P87. Evaluation of the filler metal is in progress, and preliminary mechanical property measurements have been reported.

Short-term/high-temperature strength data of all-weld-metal and cross-weld samples for DMWs between Grade 91 and $347 \mathrm{H}$ stainless steel are shown in Figure $48^{27}$. The yield strength of the all-weld-metal samples (Figure 48a) is higher than $347 \mathrm{H}$ stainless steel at all temperatures considered and is only slightly below that of Grade 91 steel at $900^{\circ} \mathrm{F}$. The yield strength is above that of Grade 91 steel at higher temperatures. Similar results were observed with the tensile strength for both all-weld-metal and cross-weld samples (Figure 48b). Figure 49 shows creep-rupture results in the form of a Larson-Miller parameter for welds made with various welding processes. The Grade 91 average and minimum values are also shown for reference. These results were generally conducted at elevated stresses and resulted in relatively short failure times. Failure locations for tests conducted at the higher stress levels were in the Grade 91 base metal, while failures at the lower stress levels occurred in the fine-grained region of the HAZ in the Grade 91 material. These results appear promising and have warranted additional testing. Longer duration tests with estimated rupture lives of $\sim 10,000$ hours are in progress ${ }^{27}$ and should provide useful data for comparison to the performance of DMWs currently made with Inconel filler metals. Room temperature tensile test results have demonstrated that the tensile strength of the weld metal made with 
the new filler metal is below that of the base metals of interest. Work is in progress to alleviate this potential problem.
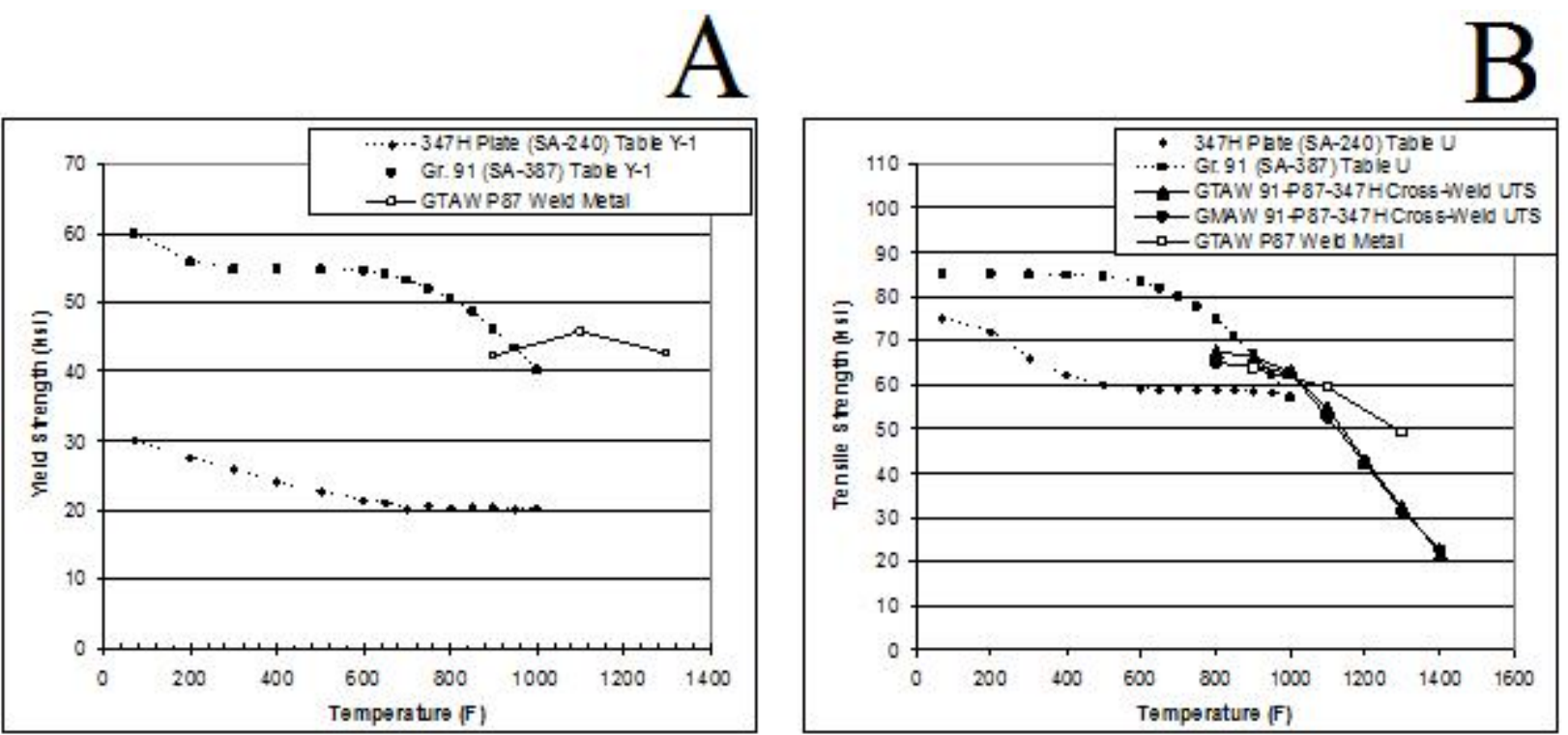

Figure 48. Short-term/high-temperature strength data of all-weld-metal and cross-weld samples for dissimilar welds between Grade 91 and $347 \mathrm{H}$ made with P87 filler metal. a) yield strength, b) tensile strength. $^{27}$

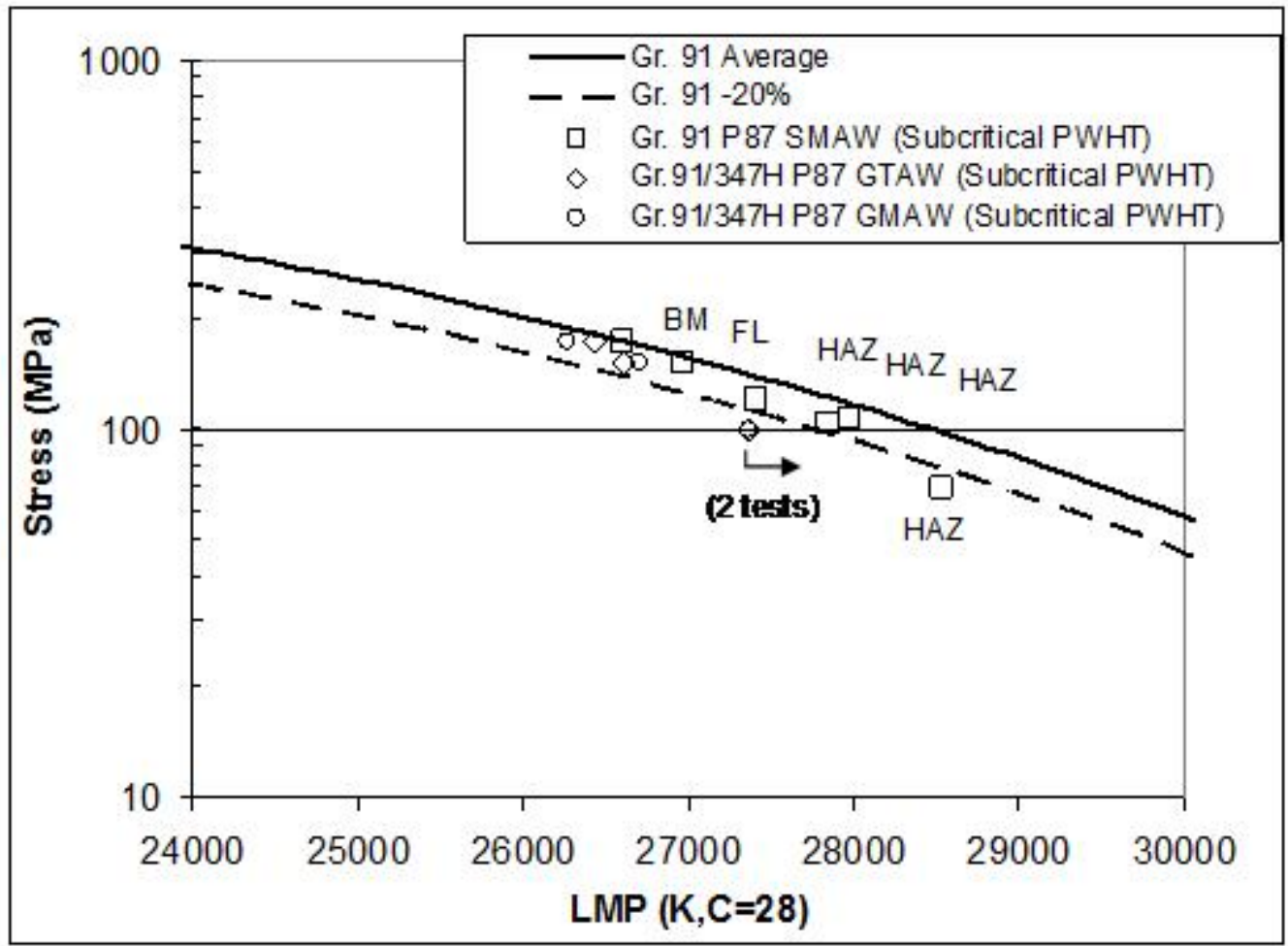

Figure 49. Creep-rupture results in the form of a Larson-Miller parameter for welds made with P87 filler metal using various welding processes. The Grade 91 average and minimum values are also shown for reference. ${ }^{27}$ 
It is important to note that the fundamental cause of premature DMW failure is associated with gradients in both composition and CTE that exist across the fusion line. Thus, any long-term solution to the problem should strive to minimize these gradients to the point at which the adverse microstructural changes and localized stress concentrations are reduced to acceptable levels. Direct metal deposition (DMD) fabrication processes are now available that are capable of producing fully dense complex shapes with localized variations in composition directly from a computer aided design (CAD) drawing. These processes are capable of producing graded alloys that could serve as a long term solution to the DMW problem. Laser Engineered Net Shaping (LENS) is a particular DMD process that uses a computer controlled laser system integrated with dual powder feeders. As shown in Figure 50, the LENS process utilizes a Nd-YAG laser to produce a melt pool on a substrate attached to an X-Y table. Powder from the dual coaxial powder feeders is injected into the melt pool as the table is moved along a pre-designed two dimensional tool path that is "sliced" from the three dimensional CAD drawing. A fully dense part is produced by depositing successive line builds that are built into sequential layers. The dual powder feeders can be controlled independently so that the composition can be changed at various locations within the part for optimized mechanical and/or corrosion performance. In addition, a melt-pool sensor is used to eliminate variations in the melt-pool size that occur due to changes in heat flow associated with variations in part dimensions. The melt-pool sensor forms a closed-loop system with the laser power so that the power is automatically varied in real time to maintain a constant pool size.

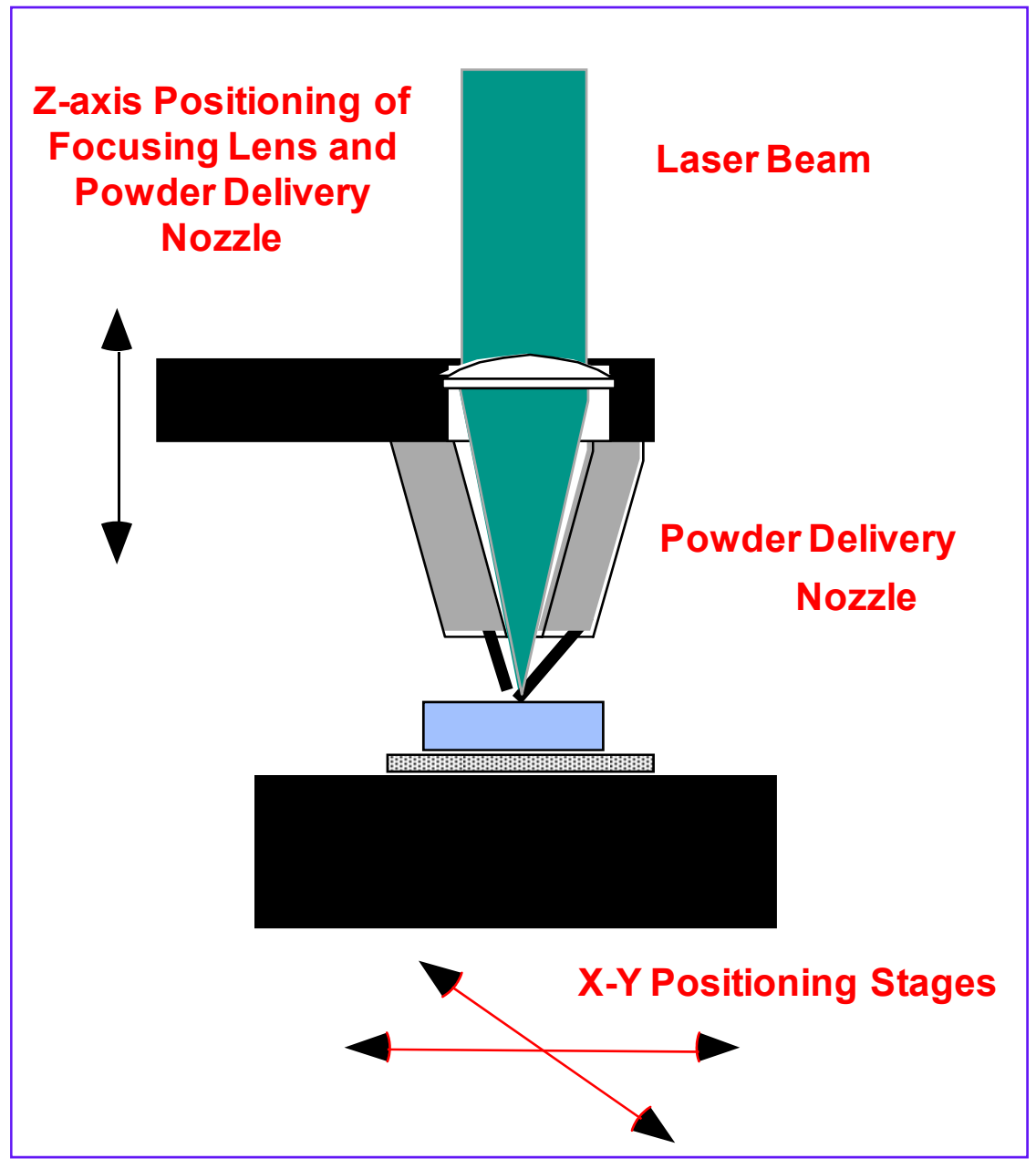

Figure 50. Schematic illustration of Laser Engineered Net Shaping process. ${ }^{86}$ 
The LENS process is currently being used at Lehigh University to design and fabricate graded transition joints that could potentially provide a significant improvement in performance for DMWs. A schematic illustration of this concept is shown in Figure 51. With this approach, the ends of the transition joint have exact composition matches to the ferritic steel and austenitic alloy, and the composition is varied gradually from one end of the joint to the other. With this approach, the graded transition joint can be inserted between the ferritic steel and austenitic alloy tubes to permit the deposition of two similar welds at either end of the joint, replacing the single dissimilar weld that is prone to failure. This would eliminate the sharp changes in composition, microstructure, and concomitant thermal and mechanical properties, thus reducing or eliminating the DMW failure problem.

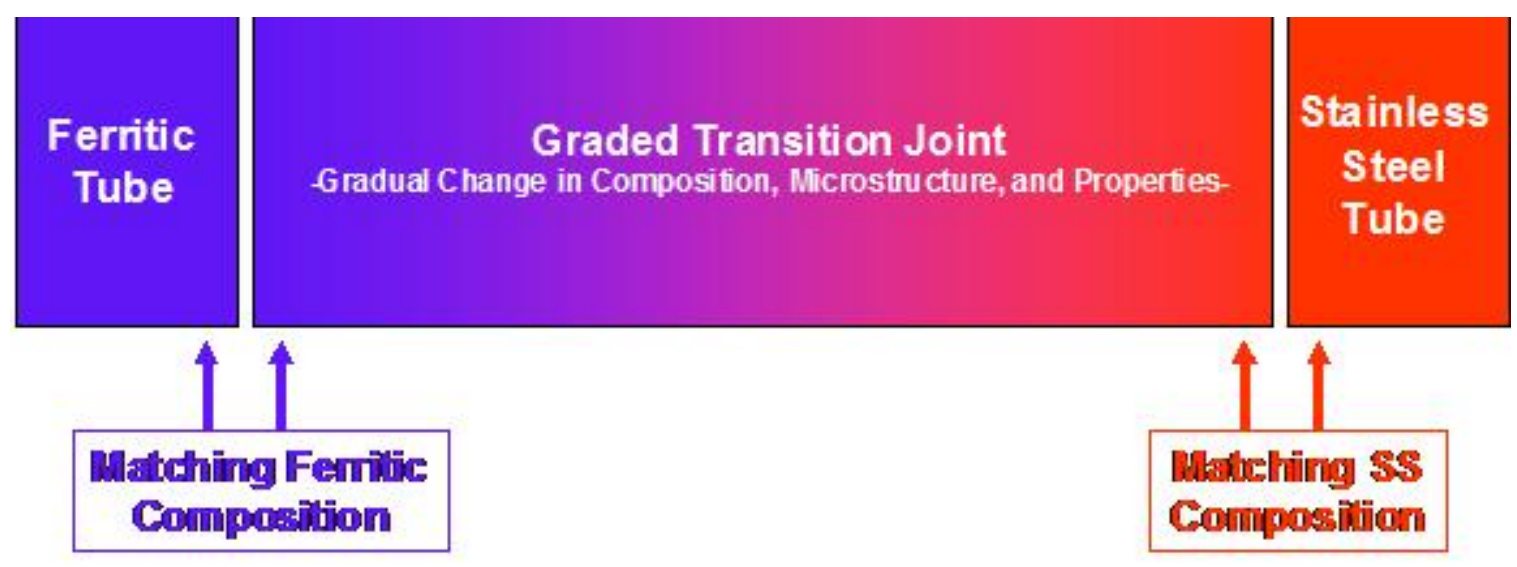

Figure 51. Schematic illustration of graded transition-joint concept. ${ }^{86}$

Research has recently been conducted at Lehigh University to demonstrate the feasibility of this approach $^{86}$. An OPTOMEC Model 750 LENS direct laser deposition unit was used to build a 3-inch long transition joint tube with an outer radius of 0.625 inch and wall thickness of 0.25 inch. The final transition joint is shown in Figure 52. These dimensions were chosen because they represent typical tube dimensions used by the power industry for waterwall panels in fossil-fired boilers. The transition joint was fabricated by first depositing 0.5 inch of SAE 316L stainless steel onto an AISI 1080 steel substrate. Next, two inches of functionally graded material were deposited in which the SAE 316L composition changed gradually to AISI 1080 steel, and concluded with 0.5 inch of AISI 1080 steel. The 1080 steel and 316L stainless steel alloys were chosen because, at the time of fabrication, they were readily available and had the particle size range required for LENS processing. As described below, research is currently underway using industrially relevant alloys such as $2.25 \mathrm{Cr}-1 \mathrm{Mo}$ steel, alloy $800 \mathrm{H}$, and 347 stainless steel. 


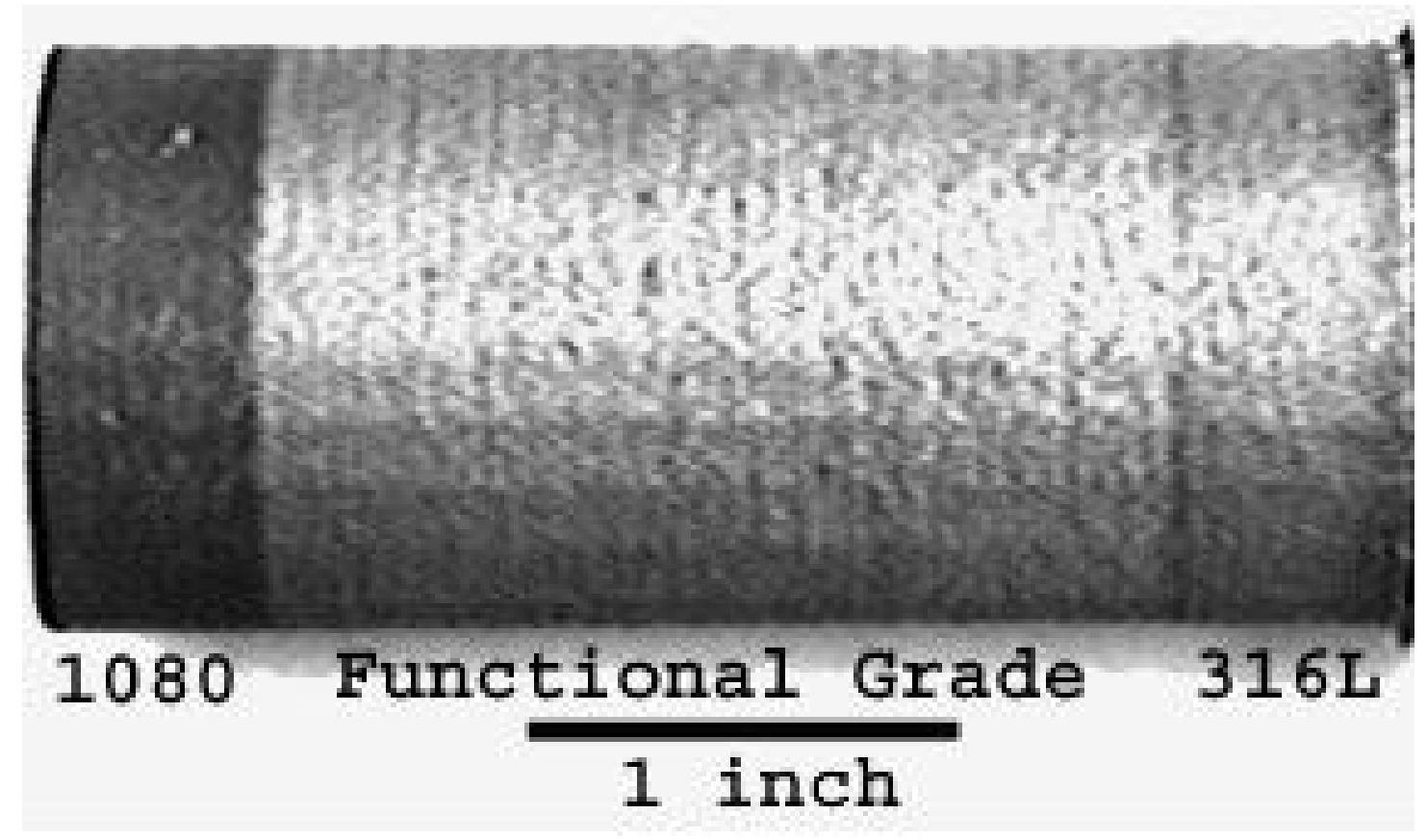

Figure 52. Transition joint between 1080 steel and 316 stainless steel produced with the Laser Engineered Net Shaping process. ${ }^{86}$

The variation in $\mathrm{Ni}$ and $\mathrm{Cr}$ concentration along the transition joint is compared to that of a conventional DMW in Figure 53. In the graded transition joint, the first and final 0.5 inch of the joint have relatively constant compositions. The two-inch length of graded material between the ends varies gradually from $316 \mathrm{~L}$ stainless steel to 1080 carbon steel. The concentration of all other alloying elements across the joint also varied in a smooth manner. Note that the length of the composition gradient of the transition joint is $\sim 50 \mathrm{~mm}$, which is approximately 1,000 times greater than the corresponding concentration gradient shown for the dissimilar metal weld (Figure 53a), which is $\sim 50 \mu \mathrm{m}$ in length. The variation in microhardness across the joint is presented in Figure 54. The extremities of the 316L and 1080 ends of the transition joint are noted in the figure. The hardness changes in a relatively smooth fashion with two notable exceptions. Local increases in hardness occur at the interface between the functionally graded material and the AISI 1080 end and the final layer of the 1080 steel. Microstructural characterization showed that the first local increase in hardness was attributed to a mixed austenite/martensite microstructure. The second region of high hardness is attributed to as-quenched martensite of the last layer of 1080 steel that is not tempered by the heating of subsequent layers. These high hardness regions occur due to the high carbon content of the 1080 powder that was used only for feasibility purposes. These high hardness regions can easily be eliminated by the use of ferritic steel with lower $\mathrm{C}$ content that is more representative of power plant steels. 

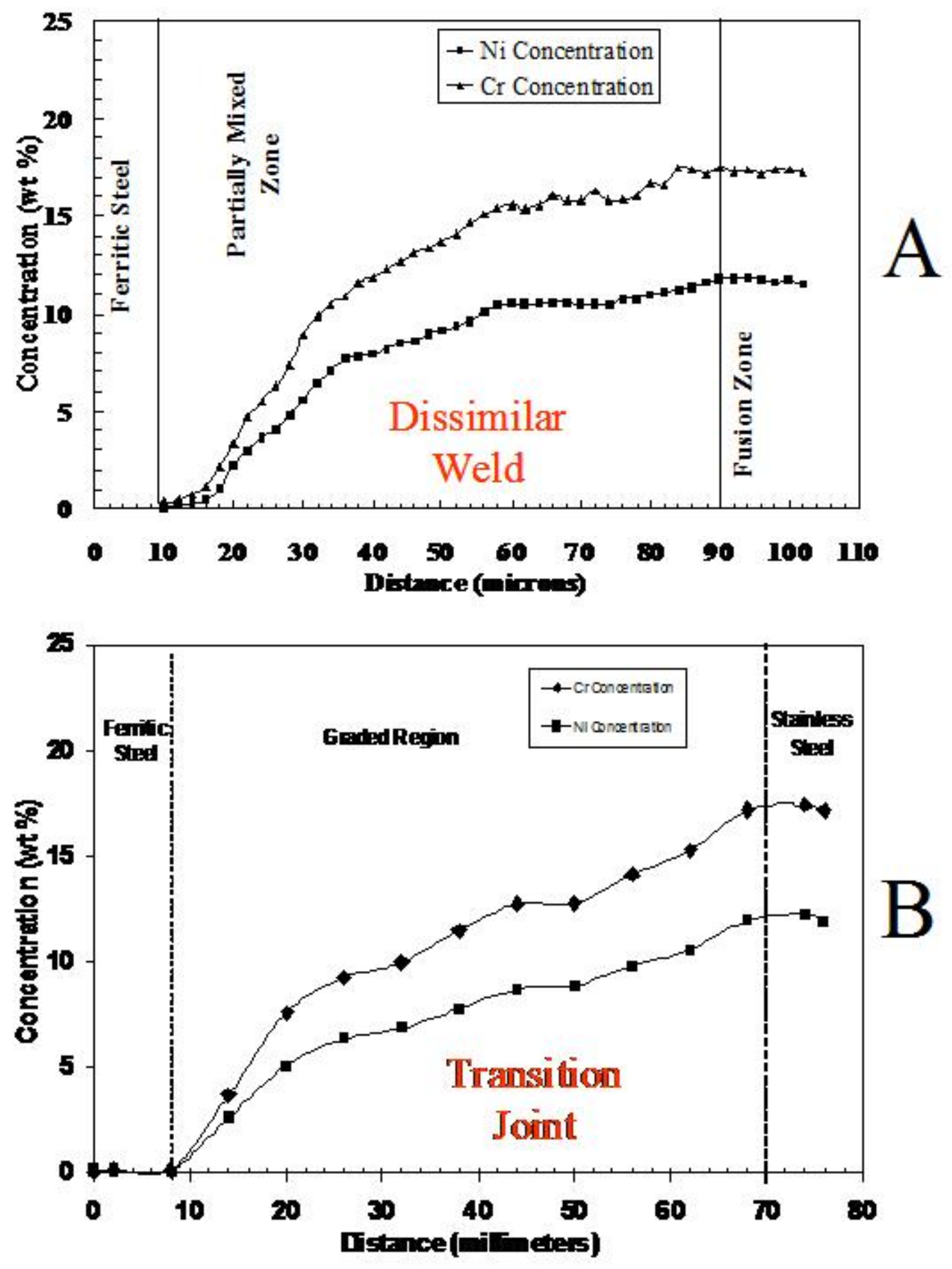

Figure 53. Comparison of $\mathrm{Ni}$ and $\mathrm{Cr}$ concentration gradients along a) dissimilar weld and $\mathrm{b}$ ) transition joint between 1080 steel and 316 stainless steel produced with the Laser Engineered Net Shaping process. ${ }^{86}$ 

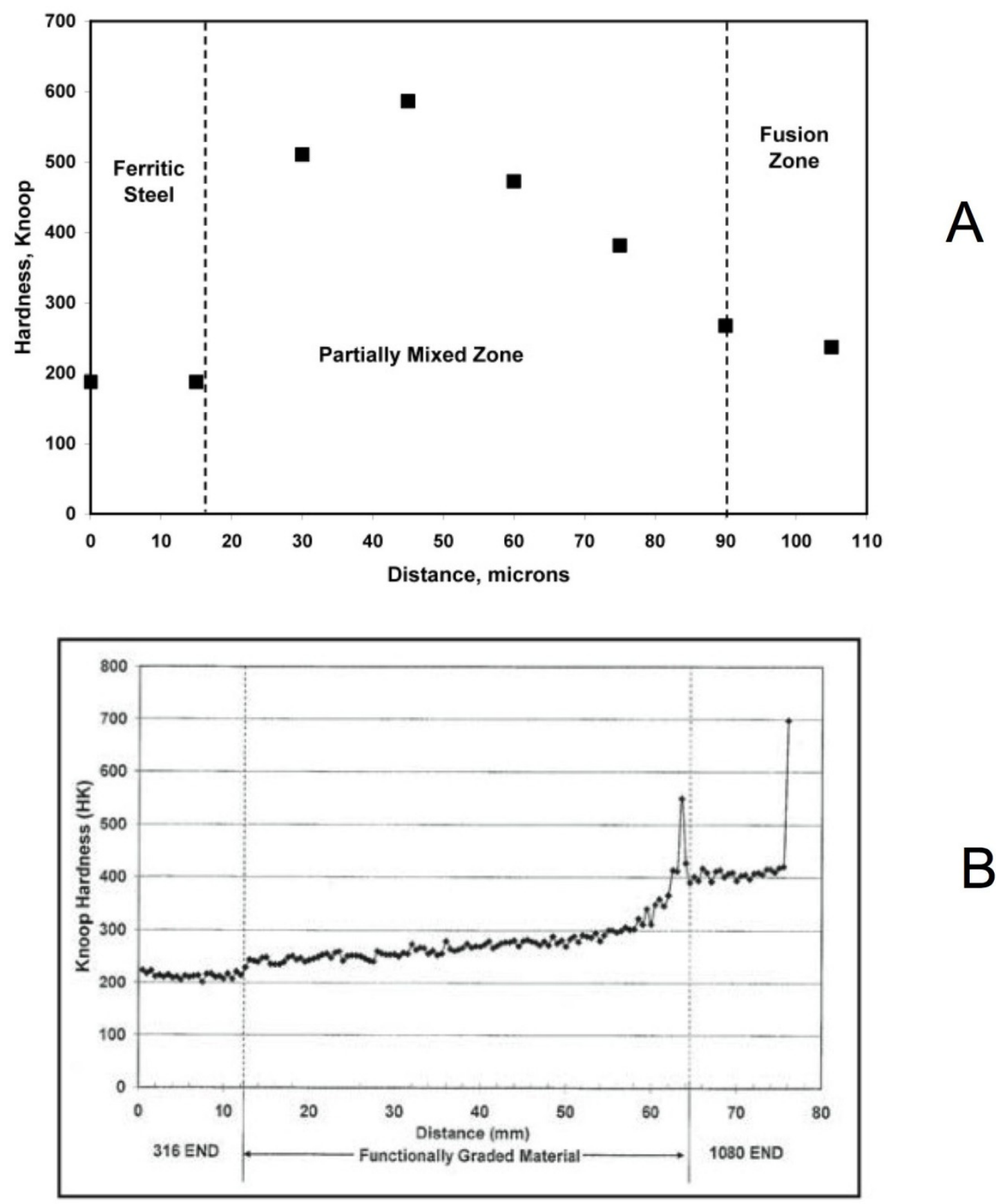

Figure 54. Comparison of hardness gradient along a) dissimilar weld and b) transition joint between 1080 steel and 316 stainless steel produced with the Laser Engineered Net Shaping Process. ${ }^{86}$

Work is currently in progress to develop computational methods for designing graded transition joints for optimal performance ${ }^{87}$. In this work, thermodynamic and kinetic simulations are conducted to identify the required length of the gradient needed to minimize the $\mathrm{C}$ migration problem, and finite-element calculations are used to establish graded transition lengths that minimize stress concentrations due to CTE mismatch. A graded transition from $2.25 \mathrm{Cr}-1 \mathrm{Mo}$ steel to alloy $800 \mathrm{H}$ to $347 \mathrm{H}$ stainless steel is currently being considered due to its importance in coal-fired power plants. For the finite-element calculations, 
high-temperature material-property data for each alloy were found in the literature and implemented into the model. As a first approximation, the mechanical properties of the graded regions were modeled as a linear interpolation between the three known materials. Work is in progress to acquire direct measurements of these properties for different levels of grading. Carbon diffusion was modeled using DICTRA kinetics software ${ }^{22,88}$.

Figure 55 shows typical examples of the finite-element calculations. In these calculations, the transition joints are assumed to be in the stress-free state at room temperature. The temperature is then raised to $650^{\circ} \mathrm{C}$ while a nominal stress of $150 \mathrm{MPa}$ is applied. The stresses due to CTE mismatch and application of the nominal stress are then calculated, and yielding is not yet accounted for in the model. Figure 55a shows the distribution of Von Mises stress for a graded transition length of $5 \mathrm{~mm}$ between the $2.25 \mathrm{Cr}-1 \mathrm{Mo}$ steel and alloy $800 \mathrm{H}$, where the maximum stress is $200 \mathrm{MPa}$. Figure $55 \mathrm{~b}$ shows similar results for a transition length of $25 \mathrm{~mm}$, and the stress is reduced to $168 \mathrm{MPa}$. Transition lengths beyond this value were not observed to provide any further benefit in stress reduction. As a basis for comparison, a direct weld between $2.25 \mathrm{Cr}-1 \mathrm{Mo}$ steel and 316 stainless steel exhibits a maximum stress of $630 \mathrm{MPa}$ for this condition, indicating that yielding would be expected under these conditions. While these initial estimates may not be highly accurate due to the assumptions involved, they do reveal the potential stress reductions associated with the graded approach and use of intermediate alloys. Work is in progress to acquire mechanical and thermal properties of the various graded regions to improve the accuracy of the results. 

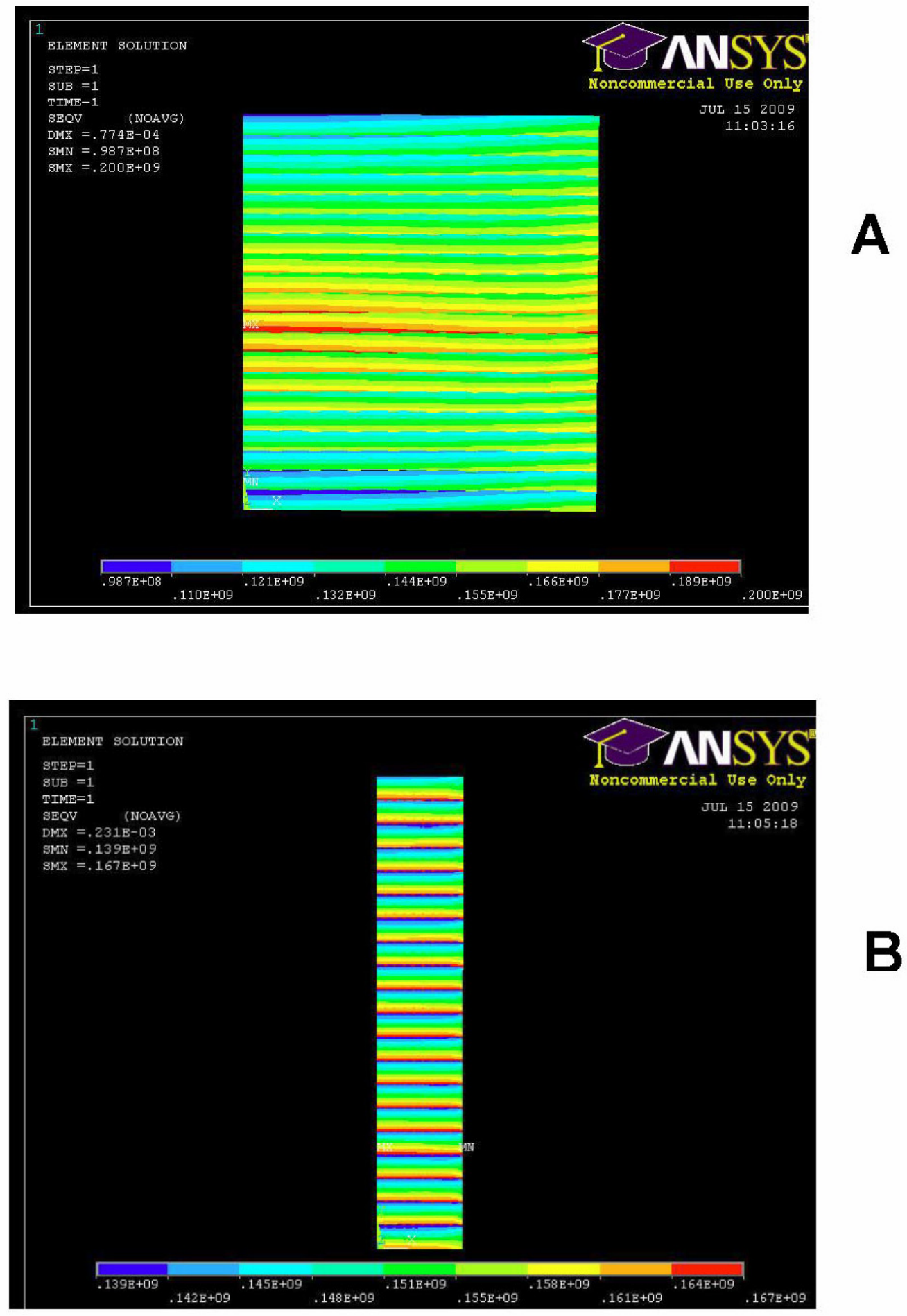

Figure 55. Examples of the finite-element calculations showing Von Mises stress for a) $5 \mathrm{~mm}$ graded transition between the $2.25 \mathrm{Cr}-1 \mathrm{Mo}$ steel and Alloy $800 \mathrm{H}$ where the maximimum stress is $200 \mathrm{MPa}, \mathrm{b}) 25$ mm graded transition between the $2.25 \mathrm{Cr}-1 \mathrm{Mo}$ steel and Alloy $800 \mathrm{H}$ where the maximimum stress is 168 $\mathrm{MPa}^{87}$. 
Figure 56 shows the calculated chemical potential of $\mathrm{C}$ as a function of position in the grade. The chemical potential gradient controls the rate of $\mathrm{C}$ migration. Calculations were made at intervals of $10 \%$ in the linear composition change, with a fixed distance between each position. It is important to note that the stress and chemical potential gradient (i.e., slope of the chemical potential vs. position curve in Figure 56) are each highest on the $2.25 \mathrm{Cr}-1 \mathrm{Mo}$ steel side of the grade near the interface. This is consistent with the established mechanism of DMW failures in which fractures occur in this region due to creep cavitation around Type I carbides (that form due to $\mathrm{C}$ migration) combined with large stresses. Results are also shown for a hypothetical alloy $800 \mathrm{H}$ with a reduced $\mathrm{Cr}$ content of $10 \mathrm{wt} \%$ that leads to a favorable reduction in the chemical potential gradient.

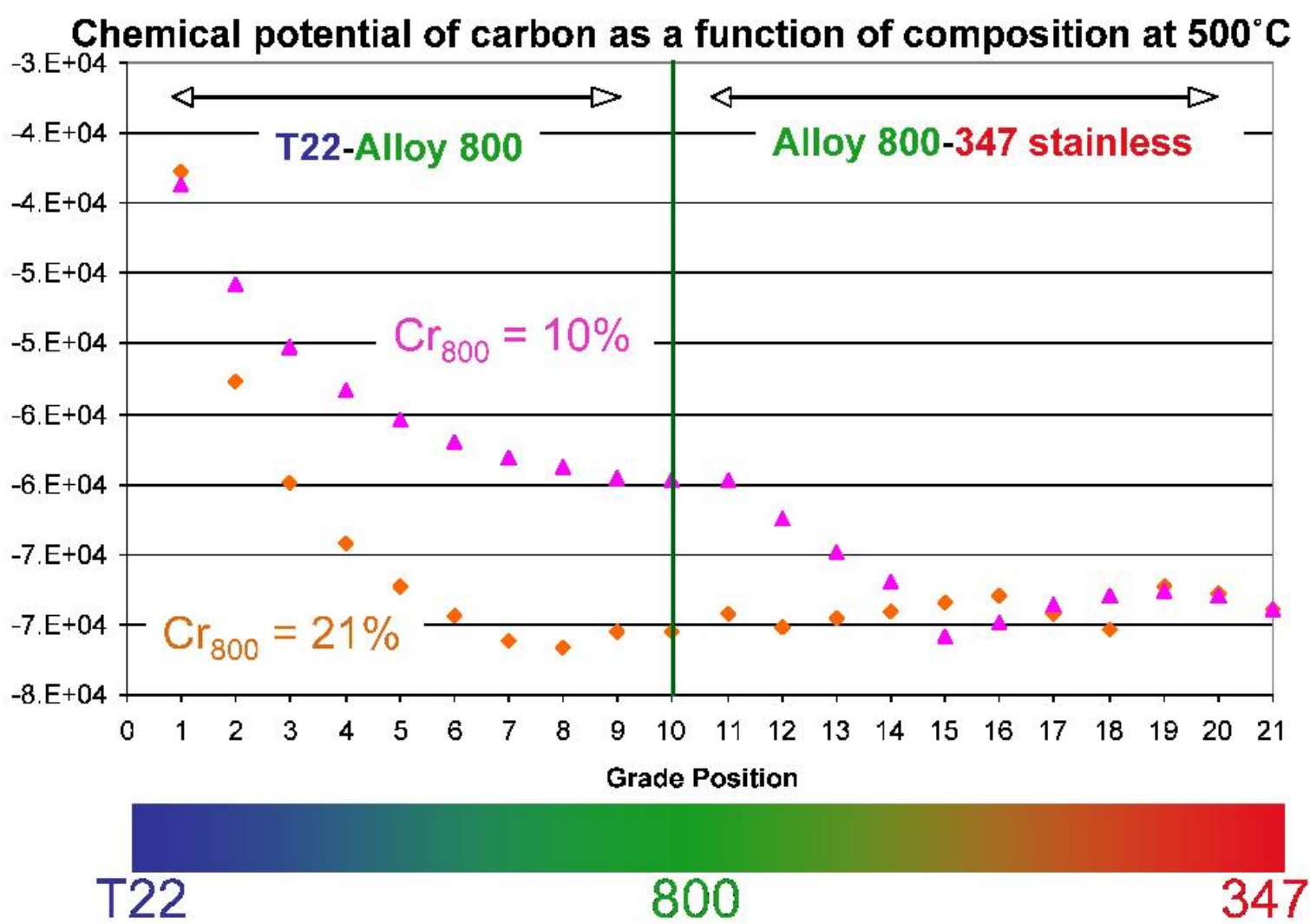

Figure 56. Calculated chemical potential of $\mathrm{C}$ as a function of position for a graded transition joint between $2.25 \mathrm{Cr}-1 \mathrm{Mo}$ steel, alloy $800 \mathrm{H}$, and 347 stainless steel. ${ }^{87}$

The expected change in $\mathrm{C}$ concentration due to the chemical potential gradient was calculated as a function of time and grade length, and example results for transition lengths of $5 \mathrm{~mm}$ and $100 \mathrm{~mm}$ for a temperature of $650^{\circ} \mathrm{C}$ are shown in Figure 57. Results are shown for the initial C concentration profile and that predicted after 20 years of service. Note that, for a relatively short transition length of $5 \mathrm{~mm}$, extensive $\mathrm{C}$ migration is predicted after 20 years. It is also important to note that this $\mathrm{C}$ concentration profile is consistent with that observed in service in which a $\mathrm{C}$-denuded zone forms directly adjacent to a $\mathrm{C}$-enriched zone. Carbide formation would be expected in the $\mathrm{C}$-enriched zone, which is observed experimentally. The graded transition with the length increased to $100 \mathrm{~mm}$ shows a significant reduction in $\mathrm{C}$ migration, even after 20 years of service (note the large differences in the $\mathrm{C}$-concentration scales between Figure 57a and Figure 57b). This difference is attributed to the larger transition length that reduces the chemical potential gradient, which is the driving force for $\mathrm{C}$ migration. These results support the potential approach of using these transition joints for extending the life of DMWs and are currently being used to guide the fabrication of graded transition joints for future creep testing. A process is also 
being developed that provides higher deposition rates along with improved robustness and ease of operation compared to the LENS process.
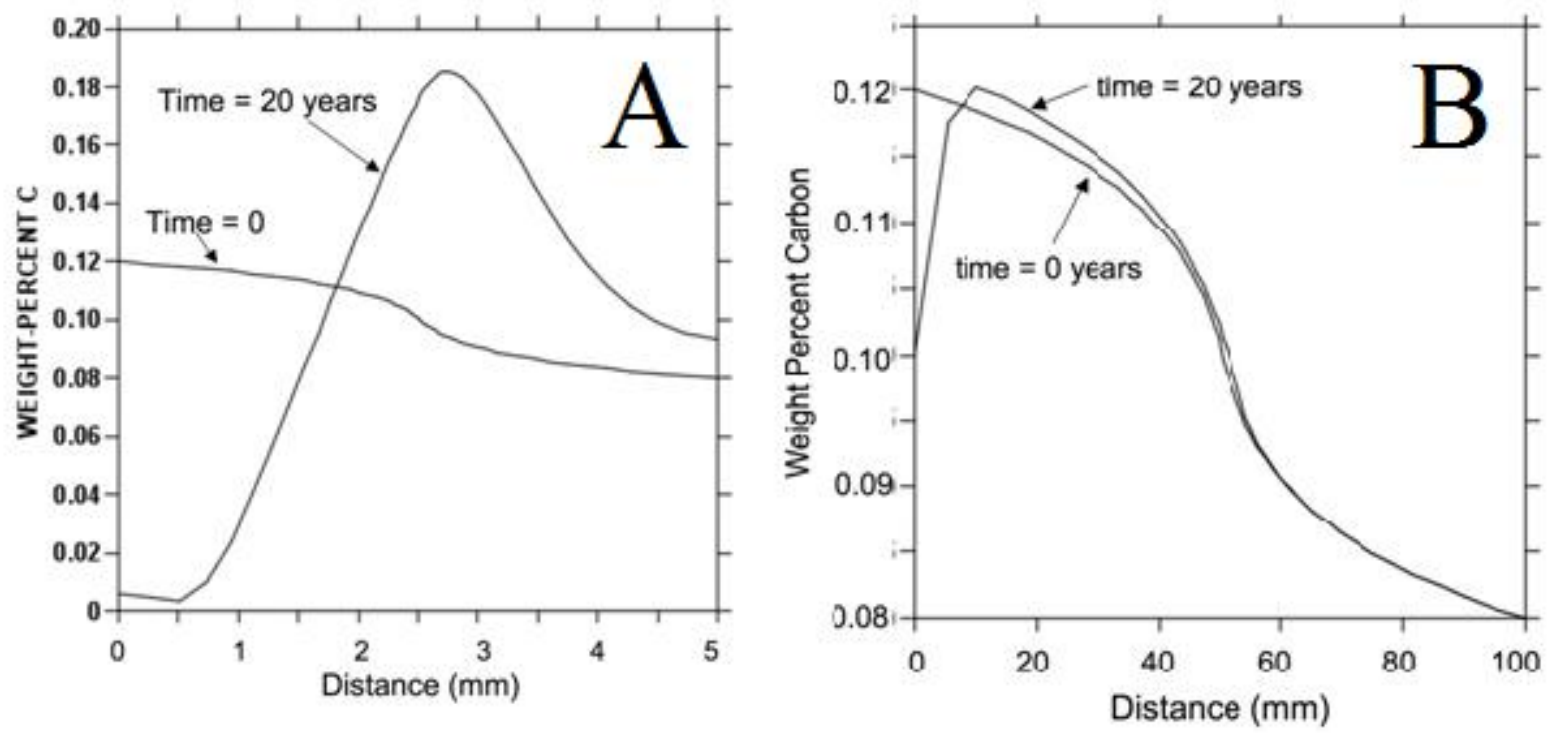

Figure 57. Calculated change in $\mathrm{C}$ concentration between $2.25 \mathrm{Cr}-1 \mathrm{Mo}$ steel and alloy $800 \mathrm{H}$ as a function of time at $650^{\circ} \mathrm{C}$ for transition lengths of a) $5 \mathrm{~mm}$ and b) $100 \mathrm{~mm} .{ }^{87}$

The method described above should also be considered for identifying possible transition alloys for minimizing concentration gradients and sharp changes in CTE for the $2.25 \mathrm{Cr}$ - $1 \mathrm{Mo}$ steel-to-alloy $800 \mathrm{H}$ weld for the HTGR. Alloy $800 \mathrm{H}$ is currently used as a transition alloy between ferritic steels and austenitic stainless steels, and the approach is known to be very effective. In direct welds made between $2.25 \mathrm{Cr}-1 \mathrm{Mo}$ steel and alloy $800 \mathrm{H}$, the opportunity exists for identifying a transition alloy that could potentially reduce the gradients in composition and CTE even further, thus leading to additional improvement in performance. The finite-element calculations and kinetic computations described above should be used for identifying alloys for this purpose. Once promising transition alloys are identified, creep samples should be prepared and tested to verify their expected level of improvement. 


\section{SUMMARY AND RECOMMENDATIONS FOR FUTURE RESEARCH}

The useful service life of DMWs depends on a wide range of factors related to service conditions, welding parameters, and alloys involved in the DMW. Premature failure is generally attributed to sharp changes in microstructure and mechanical properties, large differences in CTE, formation of interfacial carbides, and preferential oxidation of the ferritic steel. The data available to date indicate that a substantial reduction in creep life of DMWs can be expected relative to the minimum creep rupture life of $2.25 \mathrm{Cr}-1 \mathrm{Mo}$ base metal and welds. Impurities in the hot primary helium coolant of the HTGR may reduce the creep life even further. The performance of DMWs can be improved with the use of Ni base filler metals and placement of welds in low temperature/low stress locations. The use of a PWHT should be beneficial for reducing residual stress. The use of wide groove angles and added weld reinforcement may also be helpful, and changes in geometry within the weld joint should be avoided along with operating locations that present corrosive environments.

The following recommendations should be considered with respect to future research needs associated with the $2.25 \mathrm{Cr}-1 \mathrm{Mo}$ steel/alloy $800 \mathrm{H}$ DMW for the HTGR steam generator:

1. The effect of gaseous impurities on the corrosion behavior of DMWs should be established using well-controlled thermogravimetric techniques. This should be done prior to creep testing since the results may help guide selection of environment for the creep tests.

2. Standard creep specimens fabricated for future testing should be prepared with Inconel 82 and 182 filler metals and include application of a PWHT. Applied stress levels should be below approximately $80 \mathrm{MPa}$ in order to properly simulate field failures and provide data representative of service.

Detailed post-test microstructural characterization should be conducted to ensure the failure mode was properly simulated. These samples and conditions will provide creep-rupture data based on current best practices.

3. The effect of sample diameter, gaseous environment, and weld-groove angle should be investigated within the matrix of creep tests. Finite-element analysis should be conducted to help elucidate the role of weld-groove angle.

4. Creep samples should be prepared with the newer P87 filler metal and tested under select conditions to verify any expected level of improvement.

5. The use of transition alloys and graded transition joints between the $2.25 \mathrm{Cr}$ - $1 \mathrm{Mo}$ steel and alloy $800 \mathrm{H}$ warrants further investigation. The selection of candidate transition alloys and graded joints should be guided by kinetic calculations of $\mathrm{C}$ migration and finite-element computations of stress distributions. Creep testing should be conducted of representative samples to verify the expected level of improvement. 


\section{REFERENCES}

1. Shabrokhi, F. et al. NGNP High Temperature Materials White Paper. (Areva NP Inc.: 2009).

2. Crozier, J. Test Plan - Steam Generator for $750^{\circ} \mathrm{C}$ Reactor Outlet Helium Temperature. (General Atomics:).

3. Labar, M., R. Phelps, and J. Saurwein, NGNP Steam Generator Alternatives Study. (General Atomics: 2008).

4. Collins, J., V. Tone, and G. Gibbs, Next Generation Nuclear Power Plant Project Technology Development Roadmaps: The Technical Path Forward for 750-800 ${ }^{\circ} \mathrm{C}$ Reactor Outlet Temperature. (Idaho National Laboratory: Idaho Falls, Idaho, 2009).

5. Potential Heat Transport Small-Scale Testing for Prismatic HTGR. (General Atomics:).

6. Next Generation Nuclear Plant System Requirements Manual. (Idaho National Laboratory: Idaho Falls, Idaho, 2009).

7. Kou, S. Welding Metallurgy. (John Wiley and Sons Ltd.: Hoboken, New Jersey, 2003).

8. Laha, K. et al. An assessment of creep deformation and fracture behavior of 2.25Cr-1Mo similar and dissimilar weld joints. Metallurgical and Materials Transactions A 32, 115-124 (2001).

9. DuPont, J. and C. Kusko, "Martensite Formation in Austenitic/Ferritic Dissimilar Alloy Welds," Welding Journal 54S-57S (2007).

10. Banovic, S., J. DuPont, and A. Marder, "Experimental Evaluation of Fe-Al Claddings in High Temperature Sulfidizing Environments," Welding Journal 80, 62s-70s (2001).

11. DuPont, J. and A. Marder, "Dilution in single pass arc welds," Metallurgical and Materials Transactions B 27, 481-489 (1996).

12. Gittos, M. and T. Gooch, "The Interface below Stainless Steel and Nickel-Alloy Claddings," Welding Journal 461s-472s (1992).

13. Omar, A. "Effects of Welding Parameters on Hard Zone Formation at Dissimilar Metal Welds," Welding Journal 86s-93s (1998).

14. Lundin, C.D. "Dissimilar Metal Welds- Transition Joints Literature Review," Welding Journal 61, 58s-63s (1982).

15. Campbell, G., J. Elmer and W. Gibbs, "Evaluation of Factors Controlling High Temperature Service Life of 2-1/4 Cr - 1 Mo Steel to Austenitic Stainless Steel Weldments," Trends in Welding Research in the United States 443-470 (1981).

16. Parker, J. and G. Stratford, "Review of factors affecting condition assessment of nickel based transition joints" Science and Technology of Welding \& Joining 4, 29-39 (1999).

17. Parker, J.D. G.C. Stratford, Characterization of microstructures in nickel based transition joints" Journal of Materials Science 35, 4099-4107 (2000).

18. Sireesha, M., S.K. Albert, and S Sundaresan, "Influence of high-temperature exposure on the microstructure and mechanical properties of dissimilar metal welds between modified 9Cr-1Mo steel and Alloy 800," Metallurgical and Materials Transactions A 36A, 1495-1506 (2005).

19. Albert, S.K. et al. "Soft zone formation in dissimilar welds between two Cr-Mo steels," Welding Journal 76, 135s-142s (1997). 
20. R. Ryder et al. "Dissimilar Metal Weld Failures in Power Plants - Causes and Remedies," Trends in Electric Utility Research (1984).

21. Christoffel, R. and R. Curran, "Carbon Migration in Welded Joints at Elevated Temperatures," Welding Journal 35, 457s-468s (1956).

22. Helander, T., J. Agren and J. Nilsson, "An Experimental and Theoretical Investigation of Diffusion across a Joint of Two Multicomponent Steels," ISIJ International 37, 1139-1145 (1997).

23. Race, J.M. and H. Bhadeshia, "Carbon Migration Across Dissimilar Steel Welds," International Trends in Welding Science and Technology 1-5 (1993).

24. Kim, B., H. An, and J. Song, "Analysis of Carbon Migration With Post-Weld Heat Treatment in Dissimilar Metal Weld," International Trends in Welding Science and Technology 1-5 (1993).

25. You, Y. et al. "The study of carbon migration in dissimilar welding of the modified 9Cr-1Mo steel" Journal of Materials Science Letters 20, 1429-1432 (2001).

26. Eckel, J.F. "Diffusion Across Dissimilar Metal Joints," Welding Journal 43, 170s-178s (1964).

27. Siefert, J. et al. "Development of EPRI P87 Solid Wire," 2-20 (2009).

28. Coleman, K. and D. Gandy, "Alternative Filler Materials for DMWs Involving P91 Materials," Advances in Materials Technology for Fossil Power Plants 940-967 (2008).

29. Yasuda, K. "Cracking of Overlay Weldment for Pressure Vessel," Welding Research Committee of Japan Welding Society (1982).

30. Li, C., R. Viswanathan, and R. Ryder, Advances in Life Prediction Methods. (ASME: New York, NY, 1983).

31. David-Thomas, R., R. Diletto, and J. DeLong, Proceedings of 1994 Pressure Vessels and Piping Conference 288, 201 (1994).

32. Nath, B. "Creep Behaviour of Dissimilar Metal Welds on Stress Relieving," Welding in Nuclear Engineering: Lectures of the 4th International Conference in Aachen 52-56 (1982).

33. Nath, B." Creep rupture and creep crack growth behavior of transition joints," International Conference on Welding Technology for Energy Applications 597-621 (1982).

34. Parker, J.D. and G.C. Stratford, "The high-temperature performance of nickel-based transition joints: I. Deformation behaviour," Materials Science and Engineering A 299, 164-173 (2001).

35. Parker, J.D. and G.C. Stratford, "The high-temperature performance of nickel-based transition joints: II. Fracture behaviour," Materials Science and Engineering A 299, 174-184 (2001).

36. Roberts, D., R. Ryder, and R. Viswanathan, "Performance of Dissimilar Welds in Service," Journal of Pressure Vessel Technology 107, 247-254 (1985).

37. Nicholson, R. "Creep-rupture properties of austenitic and nickel-based transition joints," Metals Technology 9, 305-311 (1982).

38. Nicholson, R. "Effect of aging on interfacial structures of nickel-based transition joints," Metals Technology 11, 115-124 (1984).

39. Viswanathan, R. Conference Proceedings of Boiler Tube Failures in Fossil Power Plants, EPRI (1987).

40. Wagner, C. "Theory of Precipitate Aging via Dissolution/Reprecipitation; Ostwald Ripening," $Z$. Electrochem. 65, 581(1961). 
41. Lifshitz, I. and V.V. Slyozov, "The kinetics of precipitation from supersaturated solid solutions," Journal of Physics and Chemistry of Solids 19, 35 (1961).

42. Klueh, R.L. and J.F. King, Elevated-Temperature Tensile and Creep-Rupture Behavior of Alloy 800H/ERNiCr-3 Weld Metal/2.25Cr-1Mo Steel Dissimilar-Metal Weldments. (Oak Ridge National Laboratory: Oak Ridge, TN, USA, 1982).

43. Nicholson, R. and J. Williams, "Failure and Deformation Modes in Heavy Section Dissimilar Welds Subjected to Accelerated Thermal Cycle: Creep Loading," International Journal of Pressure Vessels and Piping 20, 239-274 (1985).

44. Klueh, R.L. and J.F. King, “Austenitic Stainless Steel-Ferritic Steel Welded Joint Failures,” Welding Journal 302-s-311-s (1982).

45. Slaughter, G.M. and T. Housley, "The Welding of Ferritic Steels to Austenitic Stainless Steels," Welding Journal 43, 454s-460s (1964).

46. Bhaduri, A.K. et al. "Performance of a trimetallic transition joint," Materials at High Temperatures 10, 45-50 (1992).

47. Budden, P.J. and I. Curbishley, "Assessment of creep crack growth in dissimilar metal welds," Nuclear Engineering and Design 197, 13-23(2000).

48. Williams, J.A. and J.D. Parker, "Effect of thermal cycling on creep behavior of 2.25Cr-1Mo/type 316 steel dissimilar metal welds," Materials Science and Technology 10, 915923 (1994).

49. Gauzzi, F. and S. Missori, "Microstructural transformations in austenitic-ferritic transition joints," Journal of Materials Science 23, $782-789$ (1988).

50. Browne, R.J. et al. "Creep Failure Analysis of Butt Welded Tubes," Int. Conf $>$ on Creep and Fracture of Engineering Materials and Components Swansea (1981) 645-659.

51. Ainsworth, R.A. "Characterization of creep fracture at interfaces in weldments," Recent advances in analytical fracture mechanics and fatigue 143-153 (1997).

52. Tucker, J. and F. Eberle, "Development of a Ferritic-Austenitic Weld Joint for Steam Plant Application," Welding Journal 35, 529S-540S (1956).

53. Emerson, R.W., R. W. Jackson, and C.A. Dauber, "Transition Joints Between Austenitic and Ferritic Steel Piping for High Temperature Steam Service," Welding Journal 41, (1962).

54. Parker, J.D. "High temperature failure of thick-section, low alloy steel to stainless steel transition weld," Materials at High Temperatures 12, 25-33 (1994).

55. Roberts, B. “Combustion Engineering Experience with Dissimilar Welds," Seminar on Dissimilar Welds in Fossil-Fired Boilers I73-I88 (1985).

56. King, J.F., M.D. Sullivan, and G.M. Slaughter, "Development of an Improved Stainless Steel to Ferritic Steel Transition Joint," Welding Journal 56, (1977).

57. W. Sartory Revised Analysis of the Transition Joint Test. (Oak Ridge National Laboratory: Oak Ridge, TN, USA, 1984).

58. Roberts, D. et al. Volume 8: Design and Procedure Guide for Improved Welds. (EPRI: New York, NY, 1989).

59. Lai, G. and R. Wolwowicz, Creep Rupture Behavior of 2.25Cr-1Mo Steel, Alloy 800H, and Hastelloy Alloy X in a Simulated HTGR Helium Environment. (General Atomics: 1979). 
60. Smith, E., B. Blanchard, and R. Apps, Welding of Creep Resistant Steel. $79-89$ (The Welding Institute: Cambridge, United Kingdom, 1970).

61. Roy, P. and T. Lauritzen, "The Relative Strength of Base Metal and Heat-Affected Zone in 2.25Cr-1Mo Weldments- A Microstructural Evaluation," Welding Journal 45S-47S (1986).

62. Chilton, I., A. Price, and B. Wilshire, "Creep deformation and local strain distributions in dissimilar metal welds between AISI type 316 and $2.25 \mathrm{Cr}-1 \mathrm{Mo}$ steels made with $17 \mathrm{Cr}-8 \mathrm{Ni}-2 \mathrm{Mo}$ weld metal," Metals Technology 11, 383-391 (1984).

63. Laha, K. et al. "Creep deformation and rupture behavior of 2.25Cr-1Mo steel weldments and its constituents (base metal, weld metal and simulated heat affected zones)," Heat Resistant Materials II 399-404 (1995).

64. Viswanathan, R. and D. Gandy, A Review of High Temperature Performance Trends and Design Rules for Cr-Mo Steel Weldments. (EPRI: Palo Alto, CA, USA, 1998).

65. Klueh, R.L. and J.F. King, Thermal Aging Behavior of ERNiCr-3 Alloy (Weld and Base Metal). (Oak Ridge National Laboratory: Oak Ridge, TN, USA, 1981).

66. Klueh, R. and J. King, "Short-range order effects on the tensile behavior of a nickel-base alloy," Metallurgical and Materials Transactions A 10, 1543-1548 (1979).

67. Sireesha, M., S.K. Albert, and S. Sundaresan, "Metallurgical changes and mechanical behaviour during high temperature aging of welds between Alloy 800 and 316LN austenitic stainless steel," Materials Science and Technology 19, 1411-1417 (2003).

68. Viswanathan, R. "Dissimilar Metal Weld and Boiler Creep Damage Evaluation for Plant Life Extension," Journal of Pressure Vessel Technology 107, 218-225(1985).

69. Ryder, R. and C. Dahms, Design Criteria for Dissimilar Metal Welds. (Welding Research Council: New York, NY, 1990).

70. Walker, S. Personal Communication. (2010).

71. Lindberg, J. et al. Nondestructive Evaluation: Guideline for Conducting Ultrasonic Examinations of Dissimilar Metal Welds. (EPRI: Palo Alto, CA, USA, 2009).

72. Quadakkers, W. and H. Schuster, "Thermodynamic and Kinetic Aspects of the Corrosion of High-Temperature Alloys in High-Temperature Gas-Cooled Reactor Helium," Nuclear Technology 66, 383-391 (1984).

73. Inouye, $\mathrm{H}$., "Relationship of $\mathrm{H}_{2} \mathrm{O}$ and $\mathrm{CH}_{4}$ Supply Rates in HTGR Helium to the Carburization of Hastelloy-X and Alloy 800H," Nuclear Technology 66, 392-403 (1984).

74. Bates, H. "The Corrosion Behavior of High-Temperature Alloys During Exposure for Times up to 10000h in Prototype Nuclear Process Helium at 700 to $900^{\circ}$ C," Nuclear Technology 66, 415-428 (1984).

75. Li, C., W. Johnson, and L. Thompson, "The Effects of Controlled Impurity Helium on the Mechanical Behavior of Hastelloy Alloy X.” Nuclear Technology 66, 439-464 (1984).

76. Cappeleare, M., M. Perrot, M. and J. Sannier, "Behavior of Metallic Materials Between 550 and 870C in High-Tempera-ture Gas-Cooled Reactor Helium Under Pressures of 2 and 50 bar," Nuclear Technology 66, 465 (1984).

77. Wood, D. "A Preliminary Study of the Effect of Helium Environment on the Creep and Rupture Behavior of Type 316SS and Incoloy 800," Proceedings of the International Conference on the Effects of Environment on Material Properties in Nuclear Systems 179 (1971). 
78. Wood, D. "Creep-Rupture Properties of Some High-Temperature Reactor Circuit Materials in He," Proceedings of the International Conference on Creep and Fatigue in Elevated Temperature Applications 158 (1974).

79. McCoy, H. Creep Behavior of Hastelloy X, 2.25Cr-1Mo steel, and other Alloys in Simulated HTGR Helium. (Oak Ridge National Laboratory: Oak Ridge, TN, USA, 1979).

80. Luer, K. et al. "Corrosion Fatigue of Alloy 625 Weld Claddings Exposed to Combustion Environments," Materials at High Temperatures 18, 11-19 (2001).

81. Parker, J.D., T. Byrne, and R. Dooley, “Ontario Hydro's Experience with Dissimilar Metal Welds in Boiler Tubing," Seminar on Dissimilar Welds in Fossil-Fired Boilers 3-73 - 3-109 (1984).

82. Nicholson, R. "Effect of post-weld heat treatment on development of interfacial structures in nickel-based transition joints," Materials Science and Technology 1, 227-233 (1985).

83. Jones, W. "Heat Treatment Effect on 2CrMo Joints Welded with a Nickel-Base Electrode," Welding Journal 225s-231s (1974).

84. Joseph, A. et al. "Evaluation of residual stresses in dissimilar weld joints," International Journal of Pressure Vessels and Piping 82, 700-705 (2005).

85. Proceedings: Seminar on Dissimilar Welds in Fossil-Fired Boilers. (EPRI: Palo Alto, CA, USA, 1985).

86. Farren, J.D., J.N. DuPont, and F. Noecker, "Fabrication of a carbon steel-to-stainless steel transition joint using direct laser deposition -- A feasibility study." Welding Journal 55S-61S (2007).

87. Brentrup, G. et al. "Preventing Dissimilar Metal Weld Failures: Application of New Functionally Graded Transition Joints," Proceedings of Materials Science and Technology 2009 2554-2562 (2009).

88. Engström, A., L. Höglund, and J. Ågren, "Computer simulation of diffusion in multiphase systems," Metallurgical and Materials Transactions A 25, 1127-1134 (1994). 